UNIVERSIDADE DE SÃO PAULO

ESCOLA DE ENFERMAGEM

GRASIELLE CAMISÃO RIBEIRO

DIAGNÓSTICO SITUACIONAL DA SISTEMATIZAÇÃO DA ASSISTÊNCIA DE ENFERMAGEM EM UMA UNIDADE BÁSICA DE SAÚDE DE CAMPINAS- SP

SÃO PAULO 


\title{
DIAGNÓSTICO SITUACIONAL DA SISTEMATIZAÇÃO DA ASSISTÊNCIA DE ENFERMAGEM EM UMA UNIDADE BÁSICA DE SAÚDE DE CAMPINAS- SP
}

\author{
Dissertação apresentada ao Programa de Pós- Graduação: \\ Mestrado profissional em enfermagem em atenção primária no \\ Sistema Único de Saúde (SUS), da Escola de Enfermagem de \\ São Paulo, para obtenção do título de Mestre em Ciências \\ Área de concentração: Cuidados em Atenção Primária a Saúde \\ Orientadora: Prof. Dra. Maria Clara Padoveze
}

São Paulo 
AUTORIZO A REPRODUÇÃO E DIVULGAÇÃO TOTAL OU PARCIAL DESTE TRABALHO, POR QUALQUER MEIO CONVENCIONAL OU ELETRÔNICO, PARA FINS DE ESTUDO E PESQUISA, DESDE QUE CITADA A FONTE.

Assinatura:

Data:

Catalogação na Publicação (CIP)

Biblioteca "Wanda de Aguiar Horta"

Escola de Enfermagem da Universidade de São Paulo

Ribeiro, Grasielle Camisão

Diagnóstico situacional da sistematização da assistência de enfermagem em uma unidade básica de saúde de Campinas-SP / Grasielle Camisão Ribeiro. São Paulo, 2015.

$140 \mathrm{p}$.

Dissertação (Mestrado) - Escola de Enfermagem da Universidade de São Paulo.

Orientadora: Prof. $\stackrel{\text { a }}{\text { Dr. }}$. Maria Clara Padoveze

Área de concentração: Cuidados em Atenção Primária à Saúde

1. Assistência de enfermagem. 2. Equipe de enfermagem. 3. Enfermagem - avaliação. I. Título. 
Nome: Grasielle Camisão Ribeiro

Titulo: Diagnóstico situacional da Sistematização da Assistência de Enfermagem em uma unidade básica de saúde de Campinas- SP

Dissertação apresentada ao Programa de Pós-Graduação: Mestrado profissional em enfermagem em atenção primária no Sistema Único de Saúde (SUS), da Escola de Enfermagem de São Paulo, para obtenção do título de mestre em ciências.

Aprovado em:

\section{Banca Examinadora}

Prof. Dr.

Julgamento:

Prof. Dr.

Julgamento:

Prof. Dr.

Julgamento:
Instituição:

Assinatura:

Instituição:

Assinatura:

Instituição:

Assinatura 


\section{AGRADECIMENTOS}

À orientadora, $\operatorname{Prof}^{\mathrm{a}} \mathrm{Dr}^{\mathrm{a}}$ Maria Clara Padoveze pela competência, paciência e dedicação que conduziu este processo.

À minha família, que mesmo de longe, me apoiou nessa trajetória.

À equipe de enfermagem do C.S Integração que colaborou prontamente com minha pesquisa. 
Ribeiro, G.C. Diagnóstico situacional da Sistematização da Assistência de Enfermagem em uma unidade básica de saúde de Campinas-SP. 2015. Dissertação (Mestrado profissional em atenção primária no SUS) - Escola de Enfermagem da Universidade de São Paulo, São Paulo, 2015.

\section{RESUMO}

Introdução: A Sistematização da Assistência de Enfermagem (SAE) é uma ferramenta que fornece embasamento para a organização da assistência de enfermagem e a gerência do cuidado, aumentando a qualidade da assistência. $O$ processo de enfermagem (PE) é o método utilizado para realizar a SAE no Brasil. Considerando que o diagnóstico situacional é essencial para fundamentar o planejamento de uma intervenção, o objetivo deste estudo é descrever como é realizada a SAE no uma Unidade Básica de Saúde (UBS) e identificar a percepção da equipe de enfermagem sobre a realização da mesma. Método: Trata-se de um estudo descritivo-exploratório de abordagem quantitativa realizado em uma UBS de Campinas, São Paulo. Para a coleta dos dados foi utilizada a técnica de questionário estruturado com escala tipo likert que foi validado por especialistas e aplicado aos profissionais de enfermagem da unidade. Os dados foram avaliados por meio de análise descritiva, utilizando tabelas e gráficos. Resultados: Os resultados possibilitaram a construção e validação de um questionário para diagnóstico situacional da SAE por meio da percepção da equipe de enfermagem. A aplicação do questionário mostrou que a implantação da SAE e PE é incipiente na unidade. A equipe possui entendimento razoável sobre o tema e aponta que a formação profissional não prepara para a realização da SAE e PE na atenção primária, mostrando necessidade de educação permanente para sua efetivação. As principais dificuldades para aplicação dessa metodologia estão relacionadas à falta de estrutura institucional. Foram apontados como facilitadores para implantação da SAE/PE na unidade: a adoção de protocolos, capacitação para equipe, envolvimento com o trabalho, elaboração de impressos e a adoção de uma nomenclatura padronizada. Conclusão: É necessário interesse institucional pela proposta da SAE/PE para sua viabilidade prática a fim de proporcionar melhorias na assistência ao paciente. O presente estudo pode contribuir para a implantação da SAE nesta unidade, pois oferece subsídios para reflexão dos enfermeiros e gestão, a fim de 
buscar um caminho para efetivar o cuidado de forma sistematizada, atendendo a legislação vigente.

Palavras chave: Assistência de Enfermagem; Equipe de Enfermagem; Avaliação; Enfermagem. 
Ribeiro , G.C. Situational diagnosis of systematization of nursing care in a primary care unit of Campinas -SP. 2015. Dissertation ( Professional Master in primary care in the SUS ) - School of Nursing, University of São Paulo, São Paulo, 2015.

\begin{abstract}
Introduction: The Systematization of Nursing Assistance is a tool that provides basis for the organization of nursing care and care management, increasing the quality of care. The nursing process is a method, used in Brazil, to perform the Systematization of Nursing Assistance. Considering the situational diagnosis as an essential step to support the planning of an intervention, the objective of this study is to describe how the Systematization of Nursing Assistance is performed at a Basic Health Unit and to identify the perception of the health team on dealing with this tool. Method: This is a descriptive-exploratory study with a quantitative approach carried out at a basic health unit in Campinas, São Paulo. For data collection, it was used a structured questionnaire with a Likert type scale that has been validated by experts and applied to the unit nursing professionals. The data was analyzed through descriptive analysis using charts and graphs. Results: The results enabled the construction and validation of a questionnaire for situational diagnosis of the Systematization of Nursing Assistance through the perception of the nursing team. The questionnaire showed that the implementation of the Systematization of Nursing Assistance and nursing process is incipient in the Basic Health Unit. The team has a reasonable understanding of the subject and points out that generation nursing formation does not prepare for the realization of Systematization of Nursing Assistance and nursing process in primary care, showing the need for continuing education for their enforcement. The principal difficulties for the application of this methodology are related to the lack of institutional structure. The adoption of protocols, training for staff, job involvement, printed guidelines and the adoption of a standardized nomenclature were appointed as facilitators to implement the Systematization of Nursing Assistance / nursing process in the drive. Conclusion: Institutional engagement in the proposal of Systematization of Nursing Assistance is necessary to promote practical viability in order to provide improvements in patient care. This study may contribute to the implementation of the Systematization of Nursing Assistance in this unit since it offers subsidies for reflection of nurses and managers in order to seek a way to perform patient care in a systematic manner, in accordance with the current legislation.
\end{abstract}

Keywords: Nursing Care; Nursing staff; evaluation Nursing. 


\section{LISTA DE ILUSTRAÇÕES}

Figura 1 - Distribuição percentual dos itens validados, segundo o Índice de Validade de Conteúdo (IVC) obtido a partir da avaliação de juízes com relação a da pertinência de cada item do questionário sobre Diagnóstico Situacional da Sistematização da Assistência de Enfermagem. Campinas, 2015.

Figura 2 - Distribuição percentual dos itens validados, segundo o Índice de Validade de Conteúdo (IVC) obtido a partir da avaliação de juízes com relação ao critério clareza das questões do questionário sobre Diagnóstico Situacional da Sistematização da Assistência de Enfermagem. Campinas, 2015.

Figura 3 - Distribuição percentual dos membros da equipe de 64 enfermagem participantes da pesquisa sobre Diagnóstico Situacional da Sistematização da Assistência de Enfermagem em uma Unidade Básica de Saúde, segundo faixa etária. Campinas, 2015.

Figura 4 - Distribuição percentual dos membros da equipe de 65 enfermagem participantes da pesquisa sobre Diagnóstico Situacional da Sistematização da Assistência de Enfermagem em uma Unidade Básica de Saúde, segundo escolaridade. Campinas, 2015.

Figura 5 - Distribuição percentual dos membros da equipe de 66 enfermagem participantes da pesquisa sobre Diagnóstico Situacional da Sistematização da Assistência de Enfermagem, em uma Unidade Básica de Saúde segundo tempo de formação profissional. Campinas, 2015. 
Figura 6 - Distribuição percentual dos membros da equipe de 66 enfermagem participantes da pesquisa sobre Diagnóstico Situacional da Sistematização da Assistência de Enfermagem, em uma Unidade Básica de Saúde segundo categoria profissional Campinas, 2015.

Figura 7 - Distribuição percentual dos membros da equipe de 67 enfermagem participantes da pesquisa sobre Diagnóstico Situacional da Sistematização da Assistência de Enfermagem em uma Unidade Básica de Saúde, segundo tempo de atuação na instituição. Campinas, 2015.

Figura 8 - Percentual de concordância (respostas concordo totalmente e 75 concordo parcialmente) da equipe de enfermagem em relação aos dificultadores para implementação da SAE e realização do PE. Campinas. 2015.

Figura 9 - Percentual de concordância (respostas concordo totalmente e concordo parcialmente) da equipe de enfermagem em relação aos benefícios que a SAE e PE podem trazer. Campinas. 2015.

Figura 10- Percentual de concordância (respostas concordo totalmente e 78 concordo parcialmente) dos fatores que podem facilitar a implantação da SAE PE, segundo a percepção da equipe de enfermagem. Campinas, 2015.

Figura 11- Distribuição das respostas das questões sobre como é 80 realizado a SAE e PE na unidade, segundo a percepção da equipe de enfermagem. Campinas, 2015. 
Figura 12- Percepção dos enfermeiros quanto sua atuação profissional 82 individual em relação ao PE . Campinas, 2015.

Figura 13- Percepção dos auxiliares e técnicos de enfermagem quanto 84 sua atuação profissional individual em relação ao $\mathrm{PE}$. Campinas, 2015. 


\section{LISTA DE QUADROS}

Quadro 1 - Quadro comparativo de conceitos Sistematização a As 25 Enfermagem (SAE) e Processo de Enfermagemmagem ( $F$ diferentes autores.

Quadro 2 - Índice de Validade de Conteúdo (IVC) obtido a partir da 52 avaliação de juízes com relação a abrangência dos domínios do questionário sobre Diagnóstico Situacional da Sistematização da Assistência de Enfermagem. Campinas, 2015.

Quadro 3 - $\quad$ Quadro 3 - Índice de Validade de Conteúdo (IVC) obtido a 52 partir da avaliação de juízes com relação a pertinência de cada item do questionário sobre Diagnóstico Situacional da Sistematização da Assistência de Enfermagem. Campinas, 2015.

Quadro 4 - Sugestão dos especialistas, comentários e decisão da 53 pesquisadora para as questões que obtiveram com Índice de Validade de Conteúdo (IVC) $<0,8$, quanto ao critério pertinência avaliado por juízes, referente ao questionário sobre Diagnóstico Situacional da Sistematização da Assistência de Enfermagem. Campinas, 2015. 


\section{LISTA DE TABELAS}

Tabela 1- Distribuição das respostas da equipe de enfermagem do em 69 uma Unidade Básica de Saúde de acordo com a Percepção sobre Sistematização da Assistência de Enfermagem e Processo de Enfermagem. Campinas, 2015.

Tabela 2- Distribuição das respostas das questões sobre Percepção 73 sobre capacitação sobre Sistematização da Assistência de Enfermagem e Processo de Enfermagem. Campinas, 2015. 


\section{LISTA DE SIGLAS}

AB- Atenção básica

ABEn- Associação Brasileira de Enfermagem

ACS - Agentes Comunitários de Saúde

CEP- Comitê de ética e Pesquisa

CIPE®- Classificação internacional para prática de enfermagem

CIPESC $^{\oplus}$ - Classificação Internacional das Práticas de Enfermagem em Saúde

Coletiva

COREN- SP- Conselho Regional de Enfermagem do estado de São

Paulo

CETS- Centro de Educação dos trabalhadores de Saúde

C.S- Centro de Saúde

ESF- Estratégia de Saúde da Família

IVC- Índice de Validação de Conteúdo

NANDA (North American Nursing Association International)

NIC (Nursing Interventions Classification)

NOC (Nursing Outcomes Classification)

PE- Processo de enfermagem

PSF- Programa de Saúde da Família

PUC- Pontifica Universidade Católica

SAE- Sistematização da assistência de enfermagem

SMS- Secretaria Municipal da Saúde

SUS- Sistema Único de Saúde

UBS- Unidade Básica de Saúde

UNICAMP- Universidade de Campinas

USP- Universidade de São Paulo 


\section{SUMÁRIO}

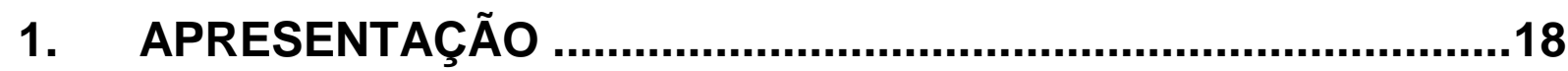

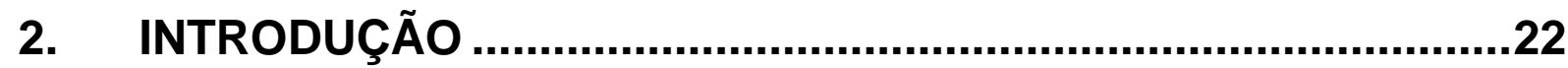

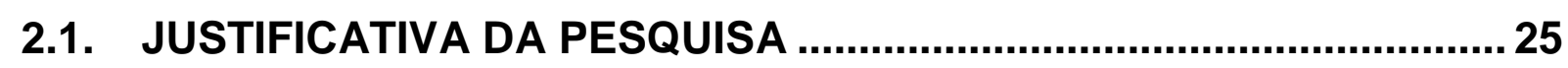

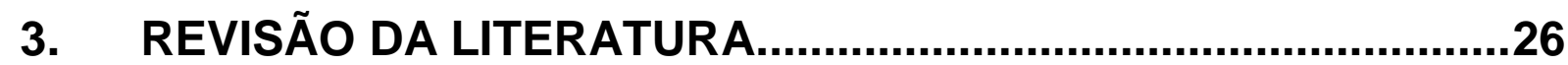

3.1 SISTEMATIZAÇÃO DA ASSISTÊNCIA DA ENFERMAGEM (SAE) E PROCESSO DE ENFERMAGEM (PE) ........................................................ 27

3.2. SISTEMATIZAÇÃO DA ASSISTÊNCIA DE ENFERMAGEM, PROCESSO DE ENFERMAGEM E A ATENÇÃO BÁSICA...........................30

3.1. SISTEMAS CLASSIFICATÓRIOS OU TERMINOLOGIA EM

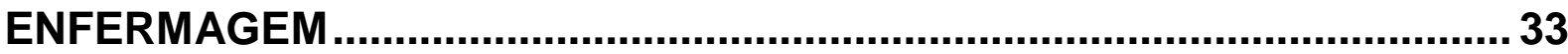

4. OBJETIVOS

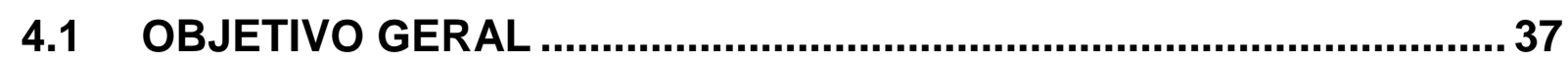

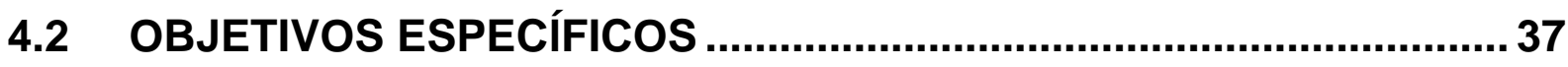

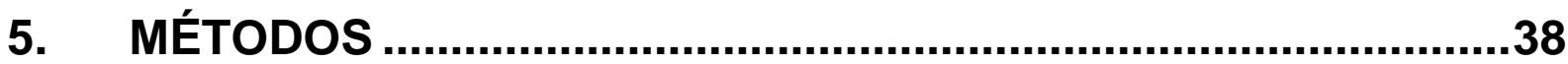

5.1 CENÁRIO DA PESQUISA.............................................................. 39

5.1.1. Cidade de Campinas …………………………………………………..... 39

5.1.2. Atenção Básica em Campinas: estrutura da rede............................................39

5.1.3. Modelo de atenção à saúde: atenção básica no município de Campinas ......40

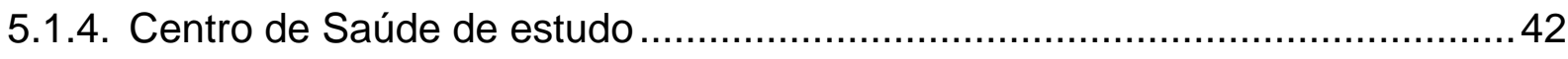

5.1.5. Processo de trabalho na unidade de estudo................................................ 43

5.1.6. Processo do trabalho de enfermagem na unidade ........................................4 45

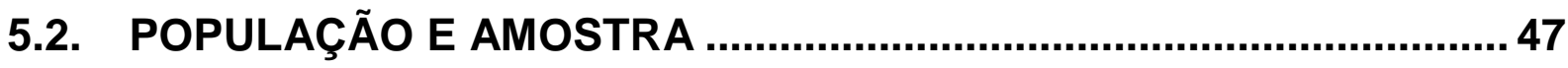

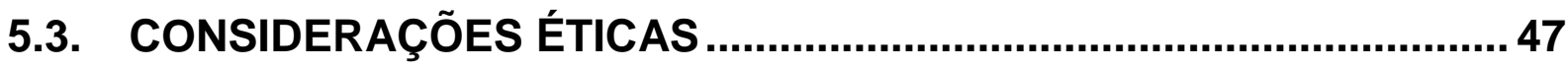

5.4. PERCURSO DO MÉTODO ……...................................................... 47

5.5. ETAPA 1- ELABORAÇÃO E VALIDAÇÃO DO INSTRUMENTO DE COLETA DE DADOS (QUESTIONÁRIO)..................................................48

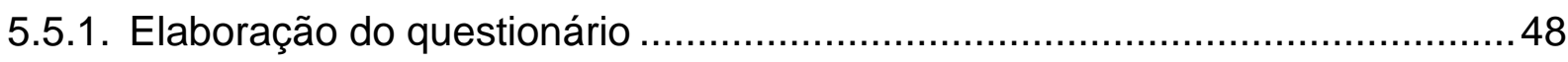

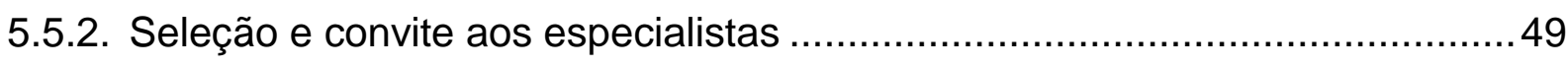


5.6. ETAPA 2- COLETA E ANÁLISE DE DADOS …..................................51

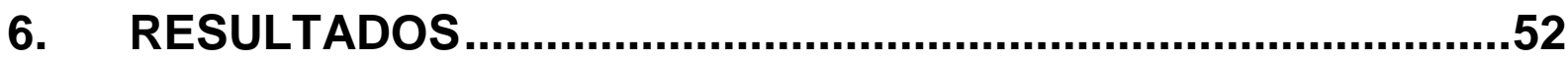

6.1. RESULTADOS DA ETAPA 1- VALIDAÇÃO DO INSTRUMENTO DE COLETA DE DADOS (QUESTIONÁRIO).....................................................53

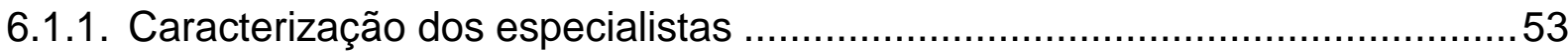

6.1.2. Validação de conteúdo quanto à abrangência dos domínios...........................53

6.1.3. Validação de conteúdo das questões quanto ao critério pertinência ...............55

6.1.4. Validação de conteúdo das questões quanto ao critério clareza....................62

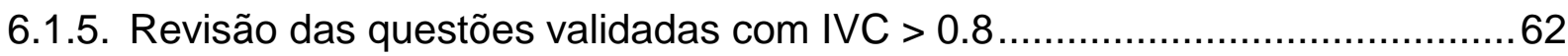

6.1.6. Síntese dos resultados de validação do questionário ......................................64

6.2. RESULTADOS DA ETAPA 2- APLICAÇÃO DO QUESTIONÁRIO E REALIZAÇÃO DO DIAGNÓSTICO SITUACIONAL EM UMA UNIDADE BÁSICA DE SAÚDE DE CAMPINAS-SP ....................................................64

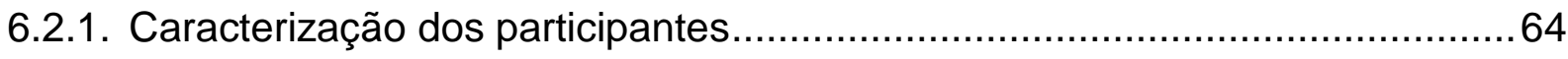

6.2.2. Domínio 1 - Percepção sobre Sistematização da Assistência de enfermagem

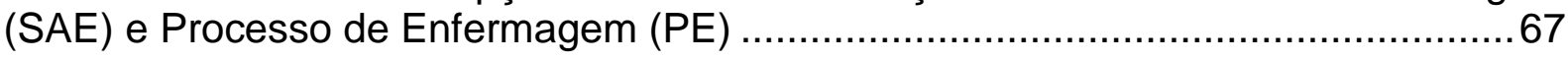

6.2.3. Domínio 2 - Percepção sobre capacitação sobre SAE e PE..........................71

6.2.4. Domínio 3 - Percepção sobre as dificuldades na implementação da SAE e realização do PE na sua unidade......................................................................

6.2.5. Domínio 4 - Sua percepção sobre os benefícios que a SAE e PE podem trazer. 74

6.2.6. Domínio 5 - Sua percepção sobre o que poderia facilitar a implementação da

SAE e realização do PE na sua unidade............................................................... 75

6.2.7. Domínio 6 - Sua percepção sobre o que ocorre na sua unidade....................77

6.2.8. Domínio 7 - Sua percepção quanto a sua atuação profissional individual em

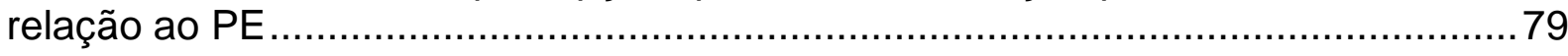

7. DISCUSSÃO ............................................................................83

7.1. ETAPA 1- VALIDAÇÃO DO INSTRUMENTO DE COLETA DE DADOS

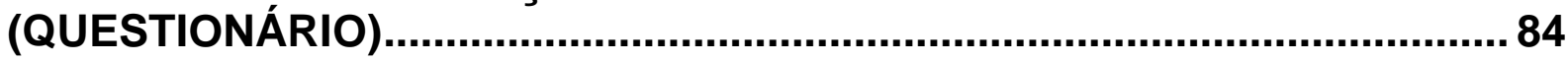




\subsection{ETAPA 2- DIAGNÓSTICO SITUACIONAL DA SAE DE UMA UNIDADE

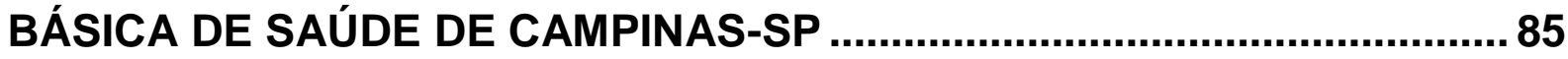

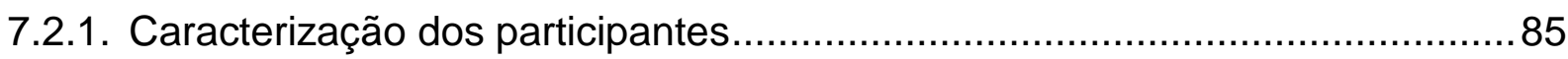

7.2.2. Domínio 1 - Percepção sobre Sistematização da Assistência de enfermagem

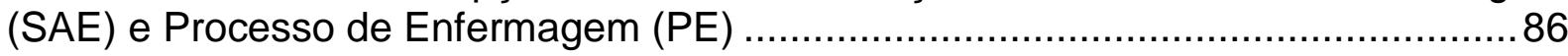

7.2.3. Domínio 2 - Percepção sobre capacitação sobre SAE e PE .......................... 89

7.2.4. Domínio 3- Percepção sobre as dificuldades na implementação da SAE e

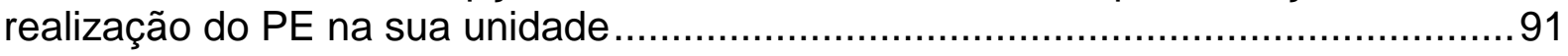

7.2.5. Domínio 4 - Percepção sobre os benefícios que o uso da SAE e PE podem trazer 94

7.2.6. Domínio 5 - Sua percepção sobre o que poderia facilitar a implementação da

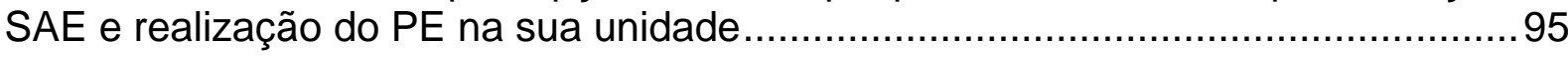

7.2.7. Domínio 6 - Sua percepção sobre o que ocorre na sua unidade .....................96

7.2.8. Domínio 7 - Sua percepção quanto a sua atuação profissional individual em

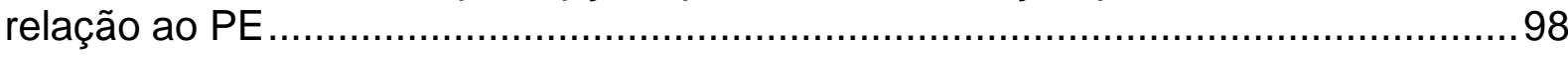

7.2.9. Possíveis desdobramentos do mestrado profissional .....................................99

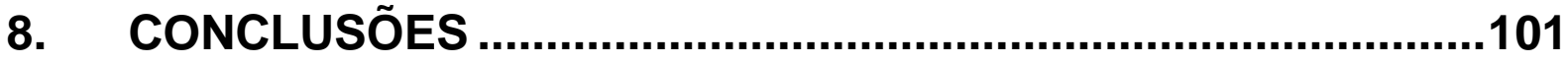

9. REFERÊNCIAS .................................................................104

10. APÊNDICES ...................................................................114

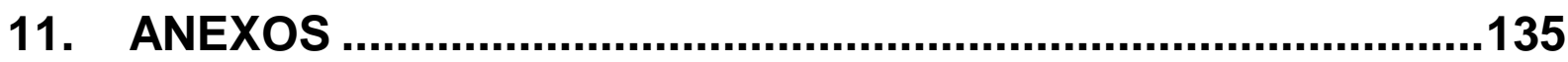




\section{APRESENTAÇÃO}

O objeto desta pesquisa surgiu após o ingresso da pesquisadora no Mestrado profissional em Atenção Primária na Escola de Enfermagem da Universidade de São Paulo (USP).

Tendo em vista que uma das propostas do mestrado profissional é contribuir para a melhoria da prática assistencial, eu e minha orientadora Profa. Dra. Maria Clara Padoveze optamos por realizar uma pesquisa que pudesse contribuir para a resolução de um problema de relevância na assistência de enfermagem em saúde coletiva.

Em minha prática profissional como Enfermeira de Saúde da Família no município de Campinas, durante mais de sete anos, me deparei com a dificuldade de executar a Sistematização da assistência de Enfermagem (SAE) e Processo de Enfermagem (PE) na prática da saúde coletiva. Atribuo essa dificuldade à minha formação acadêmica, onde as aulas e discussões sobre SAE eram totalmente hospitalares e focavam o campo biológico.

Percebi que essa limitação não era um problema individual, pois os meus colegas enfermeiros, em sua maioria, não tinham familiaridade com nenhuma ferramenta de sistematização que se adequasse à realidade vivenciada na Atenção Básica (AB).

Ao que parece essa realidade não é apenas na minha prática profissional, pois segundo Hermida (2004) há fatores que interferem na não aplicação do PE que se iniciam desde o preparo inadequado na graduação até a falta de estrutura das organizações de saúde, sendo que muitas vezes as dificuldades tornam inviável a implantação da SAE.

Acreditamos que a falta de definição de uma teoria de enfermagem e a ausência de adoção de nomenclatura padronizada e única para os diagnósticos de enfermagem na cidade de Campinas-SP favorece a heterogeneidade das ações, dificultando a realização da SAE e PE de forma correta.

No momento, percebemos que cada profissional sistematiza a consulta de uma forma, muitas vezes diferente do que é estipulado pela Resolução COFEN Nº $358 / 2009$. 
Apesar da maioria dos enfermeiros demonstrarem vontade de realizar a SAE e PE, muitas vezes não a realizam adequadamente por falta de capacitação ou familiaridade com um instrumento adequado. Isso faz com que o diagnóstico de enfermagem não seja feito, ou que seja feito sem reflexão.

Quando estamos inseridos na prática da saúde coletiva no paradigma da Estratégia de Saúde da Família (ESF), em que o cuidado é longitudinal e as intervenções são em longo prazo, fica difícil realizar o aprazamento das ações e as prescrições de enfermagem. É preciso criar linhas de cuidados que contemplem o sujeito em sua face individual e coletiva, deixando o foco biológico-tecnicista. Então surge a necessidade de encontrar uma ferramenta adequada para realizar o processo de enfermagem.

Levando-se em consideração minha necessidade como profissional de melhorar a minha prática assistencial, a urgência da adequação legal exigida pelo órgão fiscalizador da profissão e a demanda do serviço de efetivação do processo de enfermagem, nasceu meu interesse por esse objeto de pesquisa.

Sendo assim, a Sistematização da Assistência de Enfermagem em saúde coletiva tornou-se o foco da pesquisa. Entre muitas leituras, discussões e estudos, surgiu a ideia de implementar uma ferramenta diagnóstica em uma unidade de saúde. Entretanto, o tempo do mestrado profissional é insuficiente para viabilizar uma implementação da SAE por completo e realizar a avaliação da mesma, levando a necessidade de realizar recortes para focar mais apropriadamente o objeto de pesquisa.

Considera-se que o diagnóstico situacional é essencial para fundamentar o planejamento e desenvolver ações efetivas para sua implementação. Além disto, há o fato de que os pressupostos levantados acima são subjetivos, advindos da prática profissional da pesquisadora. Surge assim a necessidade de um diagnóstico real, com objetivo de verificar como está sendo a realização da SAE na unidade de saúde e a percepção dos trabalhadores da saúde sobre este processo.

Sendo assim, optamos por realizar o diagnóstico situacional da SAE e elaboramos as perguntas de pesquisa: "Como está sendo realizada a SAE e PE em um Centro de Saúde de Campinas e qual a percepção dos trabalhadores de enfermagem dessa unidade sobre a SAE e PE?" 
A intenção da pesquisa foi a realização de um diagnóstico situacional da SAE em uma unidade básica de saúde de Campinas-SP, visando identificar a percepção dos enfermeiros e da equipe de enfermagem sobre o uso dessa ferramenta, dentro da realidade do Sistema Único de Saúde em Campinas. Subsidiando uma possível implementação da SAE e propondo soluções que contribuam para a sua viabilização, com o propósito de aprimorar esta ferramenta de trabalho. 
2. INTRODUÇÃO 


\section{INTRODUÇÃO}

A sistematização da assistência de enfermagem (SAE) é uma ferramenta de gerência do cuidado que fornece subsídios para a organização da assistência de enfermagem (OLIVEIRA et al, 2012).

Entre as diversas vantagens da SAE destaca-se a elevação da qualidade da assistência de enfermagem, que beneficia tanto o paciente, por meio de um atendimento individualizado, quanto o enfermeiro, demonstrando a importância das ações de enfermagem (CUNHA; BARROS, 2005).

O processo de enfermagem (PE) é o método utilizado para realizar a SAE no Brasil. Este é um método utilizado para tomada de decisões apoiado em passos científicos. É imprescindível que os profissionais de enfermagem conheçam a SAE e apliquem as normas regulamentadoras. (DE BARROS; LOPES, 2010).

As etapas devem ser registradas no prontuário do paciente com objetivo de permitir a transparência do que está sendo planejado e possibilitar a continuidade do cuidado (WITTMANN-VIEIRA, 2011). Além disso, a anotação adequada garante respaldo e retrata a qualidade da assistência sendo essencial para efetivação da SAE (NEVES; SHIMIZU, 2010).

A documentação do $P E$ é um requisito legal indispensável à prática, porém o registro no prontuário não é sinônimo de sistematização e sim do cumprimento de uma etapa importante para a SAE (CRUZ, 2008).

A realização do cuidado ao cliente nas diferentes especificidades pode ser efetivada por meio da consulta de enfermagem. Esse instrumento é composto por etapas que se articulam com a finalidade de identificar os problemas e planejar as ações de cuidado, objetivando melhorar o estado de saúde do usuário. A partir do delineamento das necessidades, o enfermeiro denomina os diagnósticos de enfermagem, e suas correspondentes intervenções, as quais propõem ações a serem efetivadas pelo usuário, família ou pelo próprio profissional (ALBUQUERQUE, 2006).

Hermida e Araújo (2006) relatam que a SAE e o PE vem sendo implantado desde a década de 70 no Brasil, quando foi introduzido por Wanda de Aguiar Horta. Entretanto, somente com a legalização em 2002, é que passou a ser exigida sua implementação dentro das instituições de saúde. Apesar disso, atualmente as 
resoluções não garantem sua implantação, pois muitos fatores desencadeiam dificuldades práticas no processo de implantação dessa metodologia.

Os estudos de Neves e Shimuzi (2010), Foschiera e Vieira (2004) e Abrantes (2010) demonstram que a implantação da SAE e PE ocorre ainda de forma bastante fragmentada e incipiente.

Diante do exposto, fica clara a necessidade de se efetivar a SAE nos serviços de saúde; sendo assim é necessário uma implementação que pode ser iniciada a partir de um diagnóstico situacional que favoreça identificar as melhores estratégias a serem adotadas.

Um estudo constatou diversas fases do planejamento para implantação da SAE, sendo necessário primeiramente reconhecer a estrutura institucional, suas demandas e facilidades. As autoras referem que a implantação dessa prática se revela um processo bastante complexo e trabalhoso, mas que pode contribuir na melhoria da qualidade da assistência (HERMIDA; ARAÚJO, 2006).

O diagnóstico administrativo de Enfermagem é definido como um método para identificar e analisar uma realidade e suas necessidades, com vista à elaboração de propostas de organização ou reorganização. Deve ser, portanto, a fase inicial do processo de planejamento. O mesmo tem por objetivo fazer com que se tomem medidas para a organização e correção das inadequações do serviço. Ou seja, é um instrumento para pensar o cotidiano do serviço (COREN-MG, 2010).

As fases do diagnostico situacional são: levantamento de dados; análise dos dados obtidos; estabelecimento de prioridades; propostas de organização e/ou reorganização com justificativas; elaboração do Planejamento Estratégico (CORENMG, 2010).

Hermida e Araújo (2006) propõem os seguintes passos para subsidiar a implantação da SAE: 1) Reconhecimento da realidade institucional; 2) Sensibilização da equipe; 3) Definição do referencial teórico; 4) Elaboração de instrumentos para a realização do PE; 5) Preparo prático para implantação da SAE.

Tendo em vista as potencialidades da SAE e a necessidade de conhecer a realidade institucional, pretendemos avaliar como está sendo realizada a SAE na atenção básica $(A B)$ na cidade de Campinas-SP, tendo como referência uma unidade básica de saúde para esse diagnóstico. Para viabilizar o estudo, optamos por um recorte deste diagnóstico na perspectiva do trabalhador de enfermagem. 


\subsection{JUSTIFICATIVA DA PESQUISA}

Tendo em vista todas as potencialidades expostas sobre a adoção da $\mathrm{SAE} / \mathrm{PE}$ e a necessidade de adequação às normas vigentes, torna-se extremamente importante a implementação da mesma nas unidades de saúde.

O estudo justifica-se, pois para um planejamento eficiente de intervenção é necessário o diagnóstico situacional, visando identificar a realidade atual, servindo de ponto de partida para a adequação da SAE/PE na unidade.

O estudo visa contribuir para uma futura implementação da SAE/PE no Centro de Saúde de estudo e subsidiar um instrumento de avaliação para outras unidades. 
3. REVISÃO DA LITERATURA 


\section{REVISÃO DA LITERATURA}

\subsection{SISTEMATIZAÇÃO DA ASSISTÊNCIA DA ENFERMAGEM (SAE) E PROCESSO DE ENFERMAGEM (PE)}

A Sistematização da Assistência de Enfermagem é uma expressão amplamente utilizada no Brasil, entretanto em outros países ela não é utilizada. Sistematização é utilizada no sentido de organização das ações de enfermagem, de acordo com um planejamento lógico. Compreende a execução, supervisão, gerenciamento das ações, avaliação dos resultados, com registro de todas essas ações (BACHION, RAMOS e ANTUNES, 2010, p. 331).

O PE vem sendo implantado no Brasil desde a década de 70, a partir dos referenciais teóricos propostos por Wanda Horta, mas até hoje há dificuldades para sua efetivação na prática de enfermagem.

Na revisão da literatura percebemos que existem alguns conceitos associados ao tema SAE que têm sido empregados de forma conflituosa. Processo de enfermagem, metodologia da assistência e a própria sistematização da assistência algumas vezes apresentam-se como sinônimos e outras se apresentam com diferentes definições. Acreditamos que o emprego equivocado desses termos gera conflito e dificuldade de entendimento, consequentemente dificultando a sua efetivação na prática profissional da enfermagem.

Fuly, Leite e Lima (2008) analisaram a produção bibliográfica sobre SAE a fim de discutir conceitos associados ao tema. Foram analisados livros e artigos nacionais publicados na base de dados da Biblioteca Virtual em Saúde, Medline, Lilacs e Scielo, no período de janeiro de 2000 a janeiro de 2008. Naquele estudo foram analisados 11 artigos, nos quais as autoras puderam identificar três correntes que divergem no emprego desses termos nas publicações atuais: a primeira corrente trata os termos SAE, PE e Metodologia da Assistência de Enfermagem (MAE) como termos distintos. A segunda corrente trata Metodologia da Assistência de Enfermagem e Processo de Enfermagem como sendo termos equivalentes. $\mathrm{E}$ existe ainda uma terceira corrente afirmando que os três termos são sinônimos. Esse estudo concluiu que esse fato gera dificuldade de articulação, teórico-prática, evidenciada pelos conflitos existentes na própria literatura. 
Levando-se em consideração esses resultados, adotaremos para o presente estudo a linha expressa pela primeira corrente, pois entendemos SAE e PE como termos distintos. Optamos por seguir a Resolução COFEN 358/2009 que considera que: "Sistematização da Assistência de Enfermagem organiza o trabalho profissional quanto ao método, pessoal e instrumentos, tornando possível a operacionalização do PE". Já o processo de enfermagem (PE) é conceituado como "um instrumento metodológico que orienta o cuidado profissional de enfermagem e a documentação da prática profissional, aumentando a visibilidade e o reconhecimento profissional". Quando realizado em instituições prestadoras de serviços ambulatoriais de saúde, o PE corresponde ao usualmente denominado nesses ambientes como Consulta de Enfermagem. (COFEN, 2009). Essa escolha deve-se ao fato de que a intenção dessa pesquisa é buscar a efetivação da SAE na prática profissional, cumprindo as normas regulamentadoras.

Bachion, Ramos e Antunes (2010, p.332) afirmam que SAE envolve tanto a concepção consciente do trabalho de atendimento ao usuário, quanto a ações de cuidado direto e indireto, organizadas por meio de diferentes metodologias, entre as quais pode-se citar a elaboração de normas, protocolos, planos de cuidados e o processo de enfermagem. A SAE precisa ser dinâmica, flexível e ser revisada constante.

Atualmente a implementação da SAE não é apenas uma opção para a organização do trabalho do enfermeiro, apresenta-se como uma questão legal para a enfermagem, estabelecida pela Resolução COFEN 358/2009 a qual determina que: "O PE deve ser realizado, de modo deliberado e sistemático, em todos os ambientes, públicos ou privados, em que ocorre o cuidado profissional de Enfermagem" (COFEN, 2009).

O PE ou consulta de enfermagem é um instrumento composto de etapas que se articulam com a finalidade de obter informações precisas para identificar e planejar as ações de cuidado, com vistas à melhoria e manutenção do estado de saúde do usuário (ALBUQUERQUE, 2006).

O número de fases do $\mathrm{PE}$ varia de acordo com alguns autores, podendo ser de quatro a seis etapas. A divisão em etapas é útil para fins didáticos, sendo que na prática o PE deve ser integrado, com etapas inter-relacionadas (ANDRADE; VIEIRA, 2005). 
No presente estudo consideramos o referencial proposto pelo COFEN que afirma que o PE deve estar baseado num suporte teórico e organiza-se em cinco etapas inter-relacionadas, interdependentes e recorrentes: coleta de dados (ou histórico), diagnóstico, planejamento, implementação e avaliação. Sua execução do deve ser registrada formalmente, envolvendo: um resumo dos dados coletados; diagnósticos de enfermagem; as ações ou intervenções de enfermagem realizadas e os resultados alcançados (COFEN, 2009).

Sendo assim a SAE organiza as condições de realização do PE. Enquanto o $\mathrm{PE}$, sistemático e deliberado, define as necessidades. Além de orientar e documentar o cuidado, contribuindo para a visibilidade e reconhecimento profissional (GARCIA; NÓBREGA, 2009).

O Quadro 1 ilustra os principais referenciais que usaremos para conceituar SAE e PE nessa pesquisa.

Quadro 1 - Quadro comparativo de conceitos Sistematização da Assistência de Enfermagem (SAE) e Processo de Enfermagem (PE), segundo diferentes autores.

\begin{tabular}{|c|c|c|}
\hline Autor & SAE & PE \\
\hline Leopard (2006) & $\begin{array}{l}\text { É a organização do trabalho e das } \\
\text { condições necessárias para a } \\
\text { realização do PE tais como: método, } \\
\text { pessoal e instrumentos. }\end{array}$ & $\begin{array}{l}\text { Exige uma metodologia adequada } \\
\text { à produção do cuidado, visando } \\
\text { uma sistematização consciente do } \\
\text { trabalho. }\end{array}$ \\
\hline $\begin{array}{l}\text { Garcia, Nóbrega } \\
(2009)\end{array}$ & $\begin{array}{l}\text { Sistematização da assistência de } \\
\text { enfermagem organiza as condições } \\
\text { necessárias para realização do PE. }\end{array}$ & $\begin{array}{l}\text { É realizado de forma sistemático e } \\
\text { deliberado. Define necessidades, } \\
\text { orienta e documenta o cuidado, } \\
\text { contribuindo para o } \\
\text { reconhecimento profissional. }\end{array}$ \\
\hline COFEN (2009) & $\begin{array}{l}\text { "Sistematização da Assistência de } \\
\text { Enfermagem organiza o trabalho } \\
\text { profissional quanto ao método, pessoal } \\
\text { e instrumentos, tornando possível a } \\
\text { operacionalização do PE" }\end{array}$ & $\begin{array}{l}\text { PE é um instrumento } \\
\text { metodológico que orienta o } \\
\text { cuidado profissional de } \\
\text { enfermagem e a documentação da } \\
\text { prática profissional, aumentando a } \\
\text { visibilidade e o reconhecimento } \\
\text { profissional. Quando realizado em } \\
\text { instituições prestadoras de } \\
\text { serviços ambulatoriais de saúde, O } \\
\text { PE corresponde ao usualmente } \\
\text { denominado nesses ambientes } \\
\text { como Consulta de Enfermagem. }\end{array}$ \\
\hline
\end{tabular}

Fonte: elaborado pela autora. Campinas, 2015. 


\subsection{SISTEMATIZAÇÃO DA ASSISTÊNCIA DE ENFERMAGEM, PROCESSO DE ENFERMAGEM E A ATENÇÃO BÁSICA}

Segundo o Ministério da Saúde a Atenção Básica é caracterizada por um conjunto de ações que abrangem a promoção e a proteção da saúde, a prevenção de agravos, o diagnóstico, o tratamento, a reabilitação e a manutenção da saúde. É desenvolvida com alto grau de descentralização e capilaridade, utilizando tecnologias de elevada complexidade e baixa densidade (BRASIL, 2011). Utilizaremos atenção primária e atenção básica como sinônimos.

Durante revisão bibliográfica percebemos que há poucos artigos associando SAE ou PE e a atenção básica. Isso converge com um estudo que analisou dissertações e teses que abordam SAE/PE e atenção primária, em que se verificou que de uma população de 120 dissertações e teses que abarcavam reflexões acerca da $\mathrm{SAE}$ e do $\mathrm{PE}$, um quantitativo de apenas $5,0 \%$ relacionados à atenção primária. Sendo assim a incipiência de estudos é preocupante (SALVADOR; SANTOS; DANTAS, 2014).

Outra pesquisa realizada em 2009, que analisou a bibliografia nacional (dissertações, teses e artigos brasileiros publicados entre os anos de 1980 e 2005) sobre a SAE, já demonstrava tal problemática, revelando que as pesquisas realizadas são predominantemente em ambiente hospitalar (VENTURINI; MATSUDA; WAIDMAN, 2009). Cavalcante et al (2011) endossam isso demonstrando em seu estudo de revisão bibliográfica que $92 \%$ das experiências de SAE descritas na literatura são em âmbito hospitalar.

Segundo Barros e Chiesa (2007), diante das mudanças na organização da atenção básica, torna-se necessário rever o seu processo de sistematização das práticas. Os autores entendem Sistematização da Assistência de Enfermagem como o processo de identificação de problemas, interpretação e organização de condutas no âmbito do exercício profissional. Diante do o surgimento de novas práticas como: cadastramento da população; as visitas domiciliárias e dos programas de prevenção e promoção à saúde, a SAE precisa ser moldada de acordo com o novo paradigma de atenção à saúde levando-se em conta a autonomia do profissional, autonomia do paciente, necessidades biológicas e necessidades sociais da população assistida. 
Antunes e Guedes (2010 p.25) afirmam que para alcançar a integralidade do SUS, é necessário um modelo de sistematização da assistência na atenção básica que inclua acolhimento, vínculo, promoção, vigilância, clínica ampliada, entre outros. As autoras enfatizam a importância do uso do PE e SAE para substituir o fazer empírico e realizar os cuidados de forma holística.

Sobre o despreparo para a SAE na atenção primária, percebemos que o enfermeiro possui muitas vezes uma formação que não o prepara para atuar em saúde coletiva. Um estudo que aborda as dificuldades de formação do enfermeiro em atendimento primário à saúde mostrou que o perfil profissional é construído por processos educacionais generalistas e que enfatizam especialidades. Entretanto, independente da instituição de formação (pública ou privada) não há um preparo adequado para atuação na atenção básica. Os resultados mostram que as instituições públicas parecem estar em processo de adequação do processo ensinoaprendizagem, visando preparar o enfermeiro para trabalhar na atenção primária utilizando estratégias diferenciadas, dentre elas, os estágios rurais, a inclusão em grupos de pesquisas e as atividades de extensão (MONTENEGRO; BRITO, 2011).

Argenta (2011) verificou em seu estudo que a não utilização da SAE e PE pelos enfermeiros nas redes públicas, onde os alunos realizam os estágios de saúde coletiva, causa dissociação entre ensino e prática da enfermagem. Esse fato dificulta o ensino e consolidação do significado da SAE e PE, sendo que o aluno que não vivenciou a utilização do método durante a graduação, pode não realizar a SAE e PE quando for profissional.

Encontramos poucos relatos de experiência de SAE na atenção básica. Destaca-se a experiência Curitibana para a efetivação da SAE na atenção básica que teve início desde 1980 com elaboração de protocolos institucionais e manuais. Em 2000 com a informatização dos serviços públicos, a SMS incorporou no prontuário eletrônico do paciente o registro para ações de enfermagem. Nesse período foi solicitada a inclusão do campo consulta de enfermagem e criado um grupo de sistematização das práticas de enfermagem em saúde coletiva, que em parceria com a Associação Brasileira de Enfermagem (ABEn), iniciou um processo de implantação de uma classificação de enfermagem que pudesse ser aderente às bases conceituais do SUS. Em 2001, foram iniciadas atualizações profissionais visando à implantação do inventário vocabular resultante do projeto Classificação 
Internacional da Prática de Enfermagem em Saúde Coletiva (CIPESC®) o mesmo foi incluído no sistema informatizado contemplando os diagnósticos e intervenções de enfermagem, elaborados pelo grupo de trabalho. Essa experiência mostrou que é possível aplicar um sistema de classificação adaptado à realidade local, aumentando a visibilidade das ações de enfermagem (CUBAS et al, 2010). 
Outro relato de experiência, no Rio Grande do Norte, sobre a construção de roteiros para consultas de Enfermagem utilizando Diagnósticos de Enfermagem na perspectiva da CIPESC ${ }^{\circledR}$ articulada à Sistematização da Assistência de Enfermagem, identificou deficiência da formação dos profissionais para realização da SAE no contexto da Atenção Primária à Saúde. Segundo os autores, os profissionais de enfermagem possuem uma concepção sobre a Atenção básica associada a serviços precários e desorganização, sendo que essa realidade dificulta a articulação entre SAE e CIPESC ${ }^{\circledR}$ que é uma alternativa de grande potencial de transformação da qualidade da assistência (ALVES et al, 2013).

No que tange o trabalho do enfermeiro na atenção básica na cidade de Campinas, de acordo com o Regimento interno de enfermagem da Prefeitura Municipal de Campinas (2014):

\begin{abstract}
"Art. $5^{\circ}$ - A Enfermagem que atua na Atenção Primária à Saúde (APS) tem como missão realizar um conjunto de ações de saúde, no âmbito individual e coletivo, que abrange a promoção e a proteção da saúde, a prevenção de agravos, 0 diagnóstico, o tratamento, a reabilitação, a redução de danos e a manutenção da saúde com o objetivo de desenvolver uma atenção integral que impacte na situação de saúde e autonomia das pessoas e nos determinantes e condicionantes de saúde das coletividades.
\end{abstract}

Além disso, segundo o regimento, são atribuições privativas do Enfermeiro: Realizar o processo de enfermagem aplicando todas as etapas: Histórico (investigação e exame físico), Diagnóstico de Enfermagem, Prescrição (planejamento com aprazamento), Evolução (implementação) e Avaliação; supervisionar e orientar os registros realizados pela equipe de enfermagem e atender de forma sistematizada e com prioridade aos grupos de risco e vulnerabilidade, definidos tanto pelas diretrizes da SMS como pelas características de cada local (CAMPINAS, 2014).

\title{
3.1. SISTEMAS CLASSIFICATÓRIOS OU TERMINOLOGIA EM ENFERMAGEM
}

Os sistemas de classificação da prática de enfermagem podem ser usados como instrumentos tecnológicos para SAE no SUS, requerendo do enfermeiro habilidades de raciocínio clínico, de modo a imprimir qualidade ao cuidado de enfermagem. O desenvolvimento de classificações de enfermagem tem sido 
importante para padronizar a linguagem e sistematizar a assistência (NÓBREGA et al, 2010, p. 169).

As classificações são um movimento recente na enfermagem e têm traz desafios ao processo de enfermagem, pois requer mudança em termos de raciocínio clínico. Sem o uso de classificações os enfermeiros valem-se e linguagem livre para expressar seus julgamentos e decisões clínicas (CRUZ, 2008).

A terminologia em enfermagem é considerada necessária, pois um dos motivos que dificulta o desenvolvimento da enfermagem como ciência é a falta de uma linguagem universal. É importante reconhecer que a utilização do sistema de classificação pode possibilitar a padronização de cuidado e consequentemente a melhoria da qualidade da assistência de enfermagem (ALBUQUERQUE; CUBAS, 2005).

Há diversas terminologias de enfermagem disponíveis na literatura e utilizadas na prática, entre elas: CIPE, NANDA, NIC, NOC e CIPESC.

Uma dessas linguagens é proposta pela NANDA (North American Nursing Association International) que é a mais antiga no mundo. Essa taxonomia inclui 13 domínios, 47 classes e 217 diagnósticos. Ela foi elaborada para promover o raciocínio clínico e precisão no diagnóstico, fornecendo suporte às decisões (PRONANDA, 2013).

NIC (Nursing Interventions Classification) engloba as intervenções de enfermagem que os enfermeiros executam na prática, incluindo cuidados diretos e indiretos. Foram planejadas para facilitar o processo de enfermagem e pode ser usado junto ou separado da NANDA e NOC (NÓBREGA et al, 2010, p. 159).

NOC (Nursing Outcomes Classification) é uma classificação abrangente e padronizada de resultados da clientela que são influenciados pelas intervenções de enfermagem. Esses resultados podem ser usados para avaliar o estado de saúde do cliente ou para avaliação das ações de enfermagem (NÓBREGA et al, 2010, p. 159).

CIPE® (Classificação internacional para prática de enfermagem) foi concebida pela CIE como instrumento de informação destinado a descrever a prática da enfermagem e torná-la visível. Os termos dos sete eixos são utilizados para elaborar diagnósticos, resultados e intervenções de enfermagem. Para tanto requer habilidade de raciocínio clínico (NÓBREGA et al, 2010, p. 160). 
Um dos instrumentos de trabalho para realizar a SAE é a CIPESC $\circledast$ (Classificação das práticas de enfermagem em saúde coletiva), que foi elaborado por enfermeiras brasileiras em conjunto com a $A B E n$ como contribuição brasileira à CIPE $\circledast$, com objetivo de contemplar a face da saúde coletiva. Esse sistema classificatório visa apoiar a sistematização de sua prática na assistência, gerência e de investigação em saúde coletiva. É também um instrumento pedagógico que pode contribuir para a formação e qualificação de enfermeiros que atuam no SUS (NICHIATA et al, 2012).

O Manual da Assistência de Enfermagem de Campinas (2014) que se propõe a direcionar o enfermeiro para SAE nas diversas linhas de cuidado, cita a existência de várias nomenclaturas: NANDA, NIC, NOC, CIPE e CIPESC. Entretanto, deixa livre a escolha do enfermeiro sobre qual nomenclatura usar, não garantindo assim a padronização da linguagem de enfermagem. 
4. OBJETIVOS 


\section{OBJETIVOS}

\subsection{OBJETIVO GERAL}

Realizar um diagnóstico situacional da SAE em uma Unidade Básica de Saúde a partir das percepções dos trabalhadores da equipe de enfermagem.

\subsection{OBJETIVOS ESPECÍFICOS}

1. Construir e validar um instrumento de diagnóstico situacional para reconhecimento da Sistematização da Assistência de enfermagem na perspectiva do profissional de enfermagem;

2. Descrever como é realizada a SAE em uma Unidade Básica de Saúde;

3. Reconhecer a percepção dos profissionais de enfermagem sobre a SAE;

4. Identificar, na percepção da equipe de enfermagem, as potencialidades e limitações para o uso da SAE em uma Unidade Básica de Saúde. 
5. MÉTODOS 


\section{MÉTODOS}

\subsection{CENÁRIO DA PESQUISA}

\subsubsection{Cidade de Campinas}

A cidade de Campinas tem população de pouco mais de um milhão de pessoas. O município possui uma forte economia e infraestrutura que impulsiona 0 desenvolvimento de toda a área metropolitana. A Região Metropolitana de Campinas é o terceiro maior centro industrial do país (atrás da região metropolitana de São Paulo e Rio de Janeiro), gerando $3 \%$ do Produto interno bruto (PIB) brasileiro (CAMPINAS, 2013).

Apresenta uma localização estratégica para escoamento de produção no Brasil, cercada por muitas rodovias, além do Aeroporto Internacional de Viracopos que é o maior aeroporto de carga da América Latina (CAMPINAS, 2013).

A cidade é um importante polo de universidades; $15 \%$ da produção científica nacional são geradas pela Universidade Estadual de Campinas (UNICAMP). Campinas é um destacado centro industrial e tecnológico, com 20 institutos de pesquisa e tecnologia (CAMPINAS, 2013).

\subsubsection{Atenção Básica em Campinas: estrutura da rede}

O município de Campinas adota a gestão plena do sistema de saúde. A complexidade do Sistema de Saúde em Campinas levou ao desenvolvimento de um sistema de Distritos, que é a descentralização administrativa por áreas com cerca de 200.000 habitantes. Esse processo consolidou cinco Distritos de Saúde em Campinas: Sudoeste, Norte, Sul, Leste e Noroeste (CAMPINAS, 2015).

Além de responsabilizar-se pela assistência à população do município, Campinas é um centro de referência regional para o setor saúde; muitas vezes absorve a demanda da região, consequentemente, sobrecarregando o seu próprio sistema municipal local tanto na atenção básica como na assistência secundária e terciária (CAMPINAS, 2015).

Conforme informações da Secretaria Municipal de Saúde, a rede de serviços é composta por unidades de saúde próprias, conveniadas e contratadas, incluindo a 
Atenção Básica e de Média e Alta Complexidade, buscando o funcionamento de forma organizada e hierarquizada (CAMPINAS, 2015).

A rede de atenção básica é composta por sessenta e três (63) UBS. É preconizado que essas unidades possuam território e população bem definidos. A partir dessas informações epidemiológicas e gerenciais e de protocolos assistenciais pactuados no SUS é realizado o planejamento das ações de saúde, contando com apoio de equipes técnicas distritais e centrais da SMS (CAMPINAS, 2012).

Em Campinas, a Secretaria de Saúde Municipal propõe uma UBS para aproximadamente cada 20.000 habitantes (CAMPINAS, 2012). Em nossa prática assistencial, percebemos que algumas equipes estão com sobrecarga de pessoas adstritas por equipe e a divisão de áreas de abrangência não acompanha 0 crescimento populacional e o surgimento de novos bairros.

$\mathrm{Na}$ atual circunstância há unidades de saúdes que atendem quase o dobro da população preconizada, as equipes de saúde estão incompletas, já que faltam médicos, Agentes Comunitários de Saúde (ACS), profissionais de enfermagem e profissionais da assistência farmacêutica. Há dificuldade de fixação de profissionais devido à sobrecarga de demanda, entre outras razões. Consequentemente o que vivenciamos na prática assistencial ainda são filas de espera, demanda excessiva de trabalho, incapacidade do sistema para atender às necessidades básicas de saúde. Todos esses desafios interferem diretamente na capacidade dos trabalhadores para realizar uma assistência integral e de qualidade.

\subsubsection{Modelo de atenção à saúde: atenção básica no município de Campinas}

O modelo de atenção à saúde em Campinas para Atenção Básica é diferenciado em relação ao restante do país, por isso é importante um tópico para contextualizá-lo.

O Brasil vem implantando a Estratégia de Saúde da Família (ESF) como modelo para a reorganização da atenção básica à saúde desde 1998. As Diretrizes da Política Nacional da Atenção Básica de 2006 determinavam existência de equipe multiprofissional responsável por 4.000 habitantes, com jornada de trabalho de 40 horas semanais para todos os seus integrantes e composta por, no mínimo, médico, enfermeiro, auxiliar de enfermagem ou técnico de enfermagem e Agentes Comunitários de Saúde (BRASIL 2006). 
Entretanto, em Campinas houve questionamentos sobre a composição das equipes de ESF, considerando que os recursos humanos seriam insuficientes, principalmente para grandes cidades. Os debates realizados em oficinas promovidas pela Secretaria Municipal de Saúde no ano de 2001 conduziram à conclusão que a realidade da rede já construída e as condições sócias- demográficas do município não permitiam a adoção de propostas rígidas de constituição das equipes tal qual proposto pelo Ministério da Saúde (CAMPINAS, 2001).

Assim sendo, a Secretaria Municipal de Saúde de Campinas na gestão 20012004 assumiu a implantação do Programa Saúde da Família - Paidéia para toda a rede municipal de saúde. O modelo de ESF foi adaptado para tentar atender a realidade local, sendo denominado Programa de Saúde da Família - Paidéia (PSF Paidéia) (CAMPINAS, 2001).

Segundo os definidores deste Programa em seus primórdios, Paidéia é um conceito antigo, clássico, e que significa desenvolvimento integral do ser humano que foi criado quando os gregos sonhavam com cidades democráticas. Para fundação de governos democráticos eram realizadas assembleias do povo e as pessoas decidiam o próprio destino. Trazendo para hoje, fala-se e cogestão, orçamento participativo, conselhos, etc. Entretanto, os gregos pensavam que para que eles fossem capazes de gerir a própria vida, era necessário um sistema de formação dos cidadãos, uma educação para a vida e daí a palavra Paidéia. Os idealizadores o programa pensava em instituições que respeitassem as necessidades tanto da coletividade quanto dos indivíduos (CAMPINAS, 2001).

Para implementar o programa, investiu-se em maciça capacitação dos trabalhadores da rede básica de saúde sobre o modelo PSF - Paidéia. A capacitação abordou aspectos como: territorialização, trabalho em equipe, clínica ampliada, projeto terapêutico. A proposta deste modelo implica em ampliar os meios de trabalho: modificando a escuta, a entrevista, a intervenção terapêutica, tirando o foco do uso quase que exclusivo de medicamentos ou de procedimentos cirúrgicos e utilizando com maior frequência de técnicas de educação em saúde, objetivando a prevenção e a reconstrução da subjetividade (CAMPINAS, 2001).

O PSF - Paidéia trouxe características conceituais próprias e novas tecnologias como: clínica ampliada, acolhimento e responsabilização, apoio matricial, sistema de cogestão, cadastro de saúde da população e vinculação de 
famílias à equipe local de referência e capacitação (NASCIMENTO, CORREA, NOZAWA, 2007).

Os centros de saúde do município foram organizados em equipes locais de referência, com duas composições distintas: a equipe clássica e a equipe ampliada. A primeira seria composta por um médico generalista, um enfermeiro, um dentista, dois auxiliares de consultório dentário e técnico de higiene dental, quando disponível, auxiliares de enfermagem e quatro ACS, com cobertura de 700 famílias ou 3.500 pessoas. Já a equipe ampliada conta com os profissionais da equipe clássica, acrescido de: um médico pediatra, um médico gineco-obstetra, um dentista, um técnico de higiene dental, para cobertura de 1.400 famílias ou 7.000 pessoas (NASCIMENTO, CORREA, NOZAWA, 2007).

A Política Nacional da Atenção Básica de 2011 tornou mais flexível o arranjo de equipes para incentivo federal, admitindo a composição de mais profissionais médicos por equipe de referência (BRASIL, 2011). Desta forma, tornou-se viável as modalidades de equipe propostas pelos idealizadores do PSF - Paidéia de Campinas.

Segundo ALMEIDA E ZANOLLI (2011) nesse modelo proposto o médico generalista teria como núcleo de competência e de responsabilidade exercer a clínica ampliada em relação aos adultos e, como campo de responsabilidade, a atenção às intercorrências e aos problemas mais frequentes em relação à criança $e$ mulher. $O$ especialista em pediatria continuaria com a atenção à saúde da criança e adolescente de uma forma geral e nessa mesma lógica, o ginecologista atende às mulheres. Ambos os profissionais pediatra e ginecologista atenderiam com uma agenda acessível à população, sem necessidade de encaminhamento.

Infelizmente, em sua prática profissional, a pesquisadora percebe que com o passar dos anos e com a alta rotatividade de profissionais a essência do modelo se perdeu. Hoje, percebe-se a falta de definição de um modelo de atenção e uma dificuldade de adequação às políticas ministeriais.

\subsubsection{Centro de Saúde de estudo}

Essa unidade pública de Saúde de estudo está localizada no distrito Noroeste e segue os princípios do SUS. A unidade foi escolhida por ser aquela na qual a pesquisadora atua em consonância com as diretrizes propostas pelo Programa de 
Pós Graduação do Mestrado Profissional em enfermagem na Atenção Básica no SUS, da Escola de Enfermagem da Universidade de São Paulo.

A área de abrangência desse Centro de Saúde contempla as seguintes localidades: Vila Castelo Branco, Parque dos Eucaliptos, Jardim Garcia, Jardim Londres, Vila Padre Manoel da Nóbrega, Favela Recanto dos Pássaros e Jardim Paulicéia (CAMPINAS, 2012). Possui uma população adstrita de 22.643 habitantes (CAMPINAS, 2010).

A Gestão da unidade é compartilhada, onde há apoio pelos Colegiados de Gestão e dos Conselhos Locais. Além disso, a unidade tem uma parceria com a Pontifícia Universidade Católica (PUC), sendo um importante campo de ensinoaprendizagem, recebendo estágios nas áreas de medicina, nutrição, psicologia e enfermagem.

A unidade possui três equipes ampliadas de ESF (Azul, Amarela e Vermelha).

No momento, a unidade não conta com uma programação de educação permanente.

\subsubsection{Processo de trabalho na unidade de estudo}

A organização do trabalho nessa unidade de saúde é funcional. Há reuniões de equipe para discutir os planos terapêuticos visando promover o trabalho em equipe; entretanto, a integralidade das ações nem sempre é alcançada.

O centro de saúde tem o horário de atendimento amplo, normalmente das 7 às 21 horas, as enfermeiras estão organizadas para cobrir todo horário de atendimento, sendo responsáveis pelo atendimento da equipe de enfermagem independente dos auxiliares de enfermagem disponíveis fazerem parte de sua equipe de ESF.

O atendimento é caracterizado como "porta aberta", utilizando a tecnologia do Acolhimento, objetivando realizar a humanização da assistência e a equidade para os usuários. Para a realização do acolhimento nessa unidade há um espaço físico (sala de acolhimento) para realizar a escuta qualificada dos usuários visando a uma resposta adequada às necessidades de quem procura a UBS por queixa aguda. Entretanto, o modelo médico-centrado ainda é predominante, fazendo com que o acolhimento na prática se torne equivocadamente uma triagem para $\mathrm{o}$ atendimento médico e não visa a longitudinalidade do cuidado. 
Ludovico (2014) relata que apesar da Secretaria Municipal de Saúde de Campinas não se posicionar oficialmente, com base no discurso dos trabalhadores fica claro que a "A Política Portas Abertas" é a única diretriz proposta pela gestão. Sendo que na percepção dos trabalhadores essa política é uma tentativa de amenizar a desestruturação da rede, a ineficácia e falta de resolutividade dos Pronto-atendimentos e Pronto-socorro, ficando a $A B$ fica como única possibilidade de atendimento. Isso interfere na rotina do trabalho, pois a demanda espontânea gera sobrecarga ao trabalhador e desorganiza a rotina, visto que algumas ações programáticas são deixadas de lado para que todos os usuários possam ser atendidos segundo a demanda espontânea.

Neste Acolhimento, o paciente que chega à unidade com uma queixa aguda é encaminhado para uma sala, onde um auxiliar de enfermagem ou um enfermeiro faz a primeira escuta do paciente e colhe os dados vitais, direcionando o paciente de acordo com a queixa. Na maioria das vezes a consulta médica é a principal oferta.

Essa observação foi confirmada por TAKAMOTO (2005) a pesquisadora encontrou achados semelhantes em seu estudo nas unidades básicas de Campinas, em que o acolhimento apareceu como garantia de acesso e atendimento da demanda espontânea. No entanto não possibilitou mudança de postura dos profissionais em relação às necessidades dos usuários, representando uma espécie de pronto-atendimento para as queixas agudas.

Outros serviços oferecidos à demanda espontânea são: dispensação e aplicação de medicamentos; vacinação; curativos; agendamentos de consulta. Além disso, há os atendimentos programáticos, que são agendados incluindo consulta médica, consulta de enfermagem, acuidade visual, eletrocardiograma, coleta de citologia oncótica, atendimento de psicologia, atendimento de terapeuta ocupacional, entre outras.

A Unidade conta com as seguintes especialidades: Enfermagem; Clínica Médica; Odontologia; Pediatria; Ginecologia/Obstetrícia; Nutrição; Fisioterapia; psicologia; terapia ocupacional.

O trabalhador encontra dificuldades estruturais para a realização de suas atividades, muitas vezes trazendo insatisfação e desmotivação. Esse tema foi abordado por LUDOVICO (2014), em seu trabalho realizado com trabalhadores da atenção básica de Campinas, o qual concluiu que o sofrimento do trabalhador da 
atenção básica está relacionada a questões políticas, aliado a falta de investimento e sobrecarga da demanda espontânea.

\subsubsection{Processo do trabalho de enfermagem na unidade}

As unidades de saúde de Campinas possuem autonomia para organizar seu processo de trabalho. Sendo assim, a equipe organiza seu processo de trabalho conforme as características da unidade.

O Centro de Saúde de estudo tem cinco enfermeiras, sendo uma delas a pesquisadora.

Os achados do estudo de Marques e Silva (2004) mostram que os depoimentos de alguns profissionais das três primeiras ESF de Campinas parecem indicar que no PSF, antes do PADÉIA, as ESF eram compostas essencialmente pela enfermagem e 0 processo de trabalho voltava-se para a comunidade e suas necessidades. Já no PSF - Paidéia, com a presença do médico nas equipes, o trabalho da enfermagem tornou-se complementar ao trabalho médico. Já nessa época aparece como dificuldade da enfermagem no PSF - Paidéia a sobrecarga de trabalho pela demanda e pela equipe desfalcada, gerando desmotivação para a equipe e insatisfação com o trabalho. Esses achados encontrados no início da implantação do PSF - Paidéia parece perdurar mais de uma década depois e são observados pela pesquisadora nessa unidade de estudo, em sua prática profissional.

O trabalho da enfermagem de nível médio, atualmente, é focado em procedimentos como: aplicação de medicamentos; vacinação; curativos; agendamentos de consulta; acuidade visual; eletrocardiograma; aferição de pressão arterial; processamentos de artigos; entre outros.

Já o trabalho do enfermeiro é voltado para consultas de enfermagem que podem ocorrer para atender um problema do usuário no momento, ou seguimento clínico programado. Além das atividades assistenciais, os enfermeiros realizam a supervisão da equipe de enfermagem, reuniões de equipe, vigilância à saúde, ações administrativas e ações de ensino.

A demanda espontânea é atendida pelo enfermeiro escalado na tarefa de Acolhimento, independente de equipe de referência em que ele atua ou a qual o paciente está vinculado. No momento, essa é a principal atividade assistencial dos 
enfermeiros. Situação semelhante com a encontrada na análise de TAKAMOTO (2005) a autora cita que a equipe de enfermagem de Campinas passou por algumas mudanças positivas com a implantação do PSF - Paidéia, entretanto não rompeu com o modelo biomédico, permanecendo com uma percepção restrita das necessidades de saúde da população, sendo focada principalmente pela demanda espontânea e acesso a consulta médica.

Os desafios para o desenvolvimento do processo de trabalho da enfermagem observados são relacionados à falta de recursos do próprio serviço. De modo semelhante aos achados MARQUES (2003) que em seu estudo, que aconteceu pouco depois da implantação do PSF - Paidéia foram desvendadas dificuldades apontadas pela equipe de enfermagem que ainda são atuais como: falta de recursos humanos em número suficientes, estrutura física inadequada, salário não satisfatório, sobrecarga de trabalho, falta de cadastro das famílias. Além disto, há dúvidas sobre o papel profissional nesse novo modelo assistencial. Hoje, passados mais de 10 anos, parecem que esses problemas persistem dificultando a atuação profissional.

\subsubsection{Sistematização da Assistência de Enfermagem e Processo de Enfermagem}

De acordo com a observação da pesquisadora, os enfermeiros do Centro de Saúde de estudo realizam poucas consultas de enfermagem, pois não há consultórios disponíveis e o foco do trabalho é a demanda espontânea, entre outros problemas institucionais. A SAE é realizada de forma ainda incipiente. São desenvolvidas algumas vezes as etapas do PE, como por exemplo, o histórico de enfermagem, o exame físico e as prescrições de enfermagem. Entretanto, na maioria das vezes os diagnósticos de enfermagem não são registrados no prontuário.

Não existe nomenclatura determinada como padrão para a rede de Campinas, sendo livre a escolha dos diagnósticos pelo profissional.

Recentemente, a fiscalização do Conselho Regional de Enfermagem do Estado de São Paulo (COREN-SP) exigindo a adequação da SAE e PE fez com que os enfermeiros se mobilizassem para se apropriar dos instrumentos. Foram 
realizadas reuniões, levantamento de materiais bibliográficos e alguns enfermeiros optaram por utilizar o CIPESC como nomenclatura. No entanto, os enfermeiros não demonstraram ter familiaridade com a ferramenta, ocasionando dúvidas e até a realização dos diagnósticos desconectados do raciocínio clínico, apenas para atender ao cumprimento das exigências legais.

\subsection{POPULAÇÃO E AMOSTRA}

Os sujeitos do estudo foram profissionais de enfermagem de uma unidade básica de Campinas que no momento da pesquisa contavam 27. Como a pesquisadora faz parte desse quadro, aplicando-se o critério de exclusão, a população definida foi de 26 profissionais. A amostra final foi composta de 21 profissionais que encontravam- se em período de atividade (sem férias ou licença) durante a coleta de dados e que aceitaram participar da pesquisa.

\subsection{CONSIDERAÇÕES ÉTICAS}

O projeto foi encaminhado para apreciação do Centro de Estudos dos Trabalhadores de Campinas (CETS), instância responsável pela avaliação dos projetos de pesquisa a serem realizados na SMS de Campinas. Após a autorização do CETS (ANEXO 1), o projeto foi apreciado pelo Comitê de Ética em Pesquisa (CEP) da Escola de Enfermagem da Universidade de São Paulo para resguardar o cumprimento das determinações legais do Conselho Nacional de Saúde. O parecer de aprovação foi de número 1.075.023 (ANEXO 2).

Os sujeitos da pesquisa receberam um convite para participarem da pesquisa de forma livre, sendo informados sobre os aspectos éticos da pesquisa. Aceitando participar, os mesmos assinaram o Termo de Consentimento Livre e Esclarecido (APÊNDICE A), de acordo com a Resolução 466/2012/CONEP, sendo garantido o sigilo e possibilidade de retirada de consentimento.

\subsection{PERCURSO DO MÉTODO}

Trata-se de uma pesquisa do tipo descritiva e exploratória de abordagem quantitativa. Conforme Gil (2006) a pesquisa exploratória é adequada para proporcionar um maior conhecimento para o pesquisador acerca do assunto, a fim 
de que esse possa formular problemas mais precisos ou criar hipóteses que possam ser pesquisadas por estudos posteriores na área científica.

Para a coleta dos dados foi utilizada a técnica de questionário estruturado, previamente validado, a fim de atender os objetivos propostos pelo estudo.

Os sujeitos da pesquisa foram os profissionais de enfermagem que atuam na unidade de estudo, que receberam o questionário e entregaram à pesquisadora depois de preenchido.

O estudo foi desenvolvido em duas etapas, a saber: 1) Elaboração e validação do instrumento de coleta de dados (questionário); 2) Aplicação do questionário e realização do diagnóstico situacional em uma Unidade Básica de Saúde.

\subsection{ETAPA 1- ELABORAÇÃO E VALIDAÇÃO DO INSTRUMENTO DE COLETA DE DADOS (QUESTIONÁRIO)}

\subsubsection{Elaboração do questionário}

Para elaboração do questionário seguimos os passos propostos por Alexandre e Coluci (2011) que orientam que o pesquisador deve inicialmente realizar pesquisa bibliográfica sobre o tema, consultar os estudiosos da área e os representantes da população de interesse. Além disso, sugerem que o desenvolvimento de instrumentos deve englobar três fases: identificação dos domínios, a elaboração dos itens e a construção do instrumento.

O questionário foi desenvolvido pela pesquisadora com base em pesquisa bibliográfica sobre Sistematização da Assistência de Enfermagem. Outras contribuições importantes para elaboração do instrumento foram: a experiência própria da autora em sua prática assistencial, as sugestões dos doutores na área durante o exame de qualificação e consulta a dois enfermeiros que trabalham na atenção primária.

O questionário foi composto inicialmente sete domínios e 69 questões, estando organizado em três partes:

- $\quad$ Primeira parte: Caracterização do participante;

- Segunda parte: Percepção individual sobre Sistematização da Assistência de Enfermagem (SAE) e sobre o Processo de enfermagem (PE), nos aspectos: conhecimento, dificultadores, benefícios e facilitadores; 
- $\quad$ Terceira Parte: Percepção individual sobre a situação da SAE e PE na unidade de trabalho do participante.

$\mathrm{Na}$ segunda e terceira parte optamos pela utilização de uma escala de tipo Likert, na qual o respondente avalia as afirmativas que expressam um ponto de vista sobre um assunto e assinala uma opção numa escala de valores, conforme seu o grau de concordância com as assertivas apresentadas. Este modelo de escala é uma escala sociopsicológica permite quantificar opiniões, percepções e atitudes (POLIT; BECK; HUNGLER, 2004, p. 434).

\subsubsection{Seleção e convite aos especialistas}

Para validação de conteúdo foram convidados quinze especialistas com experiência no assunto Sistematização da Assistência de enfermagem. Dentre os convidados, foram incluídos doutores na área acadêmica e especialistas que realizam assistência ou gerência em atenção primária. O contato foi realizado por telefone ou e-mail, no qual foi explicado o objetivo da pesquisa e solicitado ao especialista sua contribuição para validação do instrumento.

Aos dez especialistas que aceitaram o convite foram enviados: os materiais para apreciação, uma carta convite de apresentação (APÊNDICE B), o questionário elaborado pela pesquisadora (APÊNDICE C) e um formulário de julgamento a ser respondido pelo especialista (APÊNDICE D) com um prazo de 15 dias para devolução.

\subsubsection{Métodos para validação do questionário}

O questionário foi submetido à validação de conteúdo para seu aprimoramento por meio da consulta a peritos, utilizando como método de análise o Índice de Validação de Conteúdo (IVC).

Utilizamos como referência a definição de Polit \& Beck (2011, p.619) na qual a validade do conteúdo é definida como "o grau em que os itens de um instrumento representam adequadamente o universo do conteúdo para o conceito que está sendo medido". Nesse tipo de validação os peritos podem sugerir a retirada, acréscimo ou modificação dos itens. 
O IVC avalia a concordância dos especialistas quanto à representatividade da medida em relação ao conteúdo estudado. Os itens e o instrumento como um todo são considerados válidos se obtiverem um IVC de 0,80 (RUBIO et al, 2003).

Não há consenso na literatura para o número ideal de juízes que participam do processo de validação do instrumento, preconizam-se no mínimo cinco especialistas (ALEXANDRE; COLUCI, 2011).

Optou-se por submeter o questionário à apreciação de especialistas com experiência na área de enfermagem, que foram convidados a analisar o instrumento, avaliando os seguintes critérios:

- Pertinência: a questão é apropriada para o que se deseja avaliar?

- Clareza dos itens: é de fácil compreensão?

- Abrangência: os domínios compreendem todos os aspectos de sua temática?

Para julgar esses critérios o avaliador recebeu um instrumento e foi orientado a assinalar um "x" na coluna correspondente ao seu nível de concordância, a saber:

1. Concordo Plenamente,

2. Concordo,

3. Estou indeciso (a)

4. Discordo e

5. Discordo Plenamente.

Em seguida o especialista acrescentou seus comentários pessoais na coluna destinada a esta finalidade, quando julgou necessário.

Na primeira parte do julgamento foi solicitada uma análise do questionário como um todo referente aos sete domínios, em relação ao critério de abrangência.

$\mathrm{Na}$ segunda parte do julgamento, o avaliador julgou cada questão individualmente em relação aos critérios de pertinência e clareza.

Por fim, a terceira parte do julgamento foi aberta para comentários gerais sobre o questionário em texto livre.

A análise das questões foi feita de forma quantitativa. Um banco de dados foi construído e analisado pelo Microsoft Excel $\AA^{8}$ 2007, calculando o IVC para cada questão. Além disso, foi realizada a adequação das questões de acordo com a sugestão dos especialistas. 
Foi buscado o consenso de grupo, ou seja, opiniões convergentes dos especialistas. Para isso, consideramos o IVC de 0,80, de forma a se obter um nível de consenso de $80 \%$.

Desta forma, questões avaliadas em um (concordo totalmente) ou dois (concordo parcialmente) por no mínimo $80 \%$ dos especialistas foram mantidas no questionário. As questões que não obtiverem este nível de consenso foram analisadas usando o seguinte parâmetro:

- $\quad$ IVC $>0.70$ e $<0.80$ = Revisar a questão segundo a sugestão dos especialistas

- $\quad \mathrm{IVC}<0.70=$ Excluir a questão

Os dados foram apresentados por meio de ilustração com figuras e quadros.

\subsection{ETAPA 2- COLETA E ANÁLISE DE DADOS}

Os dados foram coletados pela pesquisadora seguindo todos os aspectos éticos já mencionados no item 5.3. Os profissionais de enfermagem foram abordados pessoalmente pela pesquisadora explicando o estudo e perguntando da possibilidade de participarem do mesmo. Nos casos de aceite, após a leitura e concordância com o termo de Consentimento Livre e esclarecido, foi entregue o questionário e o entrevistado devolvia após terminar seu preenchimento.

A coleta de dados foi realizada em junho de 2015 e alguns profissionais não foram abordados por estarem de férias ou afastamento por doença. Dos 23 profissionais abordados, apenas um recusou a participação. Dos 22 questionários aplicados, 21 foram devolvidos preenchidos.

Embora seja um trabalho acadêmico, é importante salientar que como a pesquisadora também faz parte do quadro de profissionais da unidade em questão, isso pode ter facilitado o retorno dos questionários preenchidos.

A análise das questões foi feita de forma quantitativa. Um banco de dados foi construído e analisado pelo Microsoft Excel® 2007, utilizando-se a distribuição absoluta e relativa das respostas relacionadas às variáveis estudadas.

Para melhor visualização, os dados foram apresentados por meio de ilustração com figuras, tabelas e quadros. 
6. RESULTADOS 


\section{RESULTADOS}

\subsection{RESULTADOS DA ETAPA 1- VALIDAÇÃO DO INSTRUMENTO DE COLETA DE DADOS (QUESTIONÁRIO)}

\subsubsection{Caracterização dos especialistas}

Apenas sete especialistas devolveram 0 instrumento preenchido corretamente. Foram recebidos dois instrumentos preenchidos inadequadamente, impossibilitando o cálculo do IVC, culminando no descarte destes resultados. Um dos especialistas que não devolveu o questionário justificou que o questionário era longo e o instrumento avaliativo era trabalhoso.

A amostra de especialistas foi composta de: quatro enfermeiras doutoras, duas enfermeiras mestrandas e uma enfermeira sanitarista, sendo que três atuam como docentes em universidades, uma gerente de um convênio da atenção básica e três enfermeiras assistenciais na atenção primária.

A Idade das avaliadoras variou entre 26 e 51 anos e as cidades de atuação profissional dessas especialistas são: Campinas, São Paulo, Botucatu e Curitiba.

\subsubsection{Validação de conteúdo quanto à abrangência dos domínios}

Os domínios foram avaliados quanto à abrangência sobre 0 assunto, alcançando os seguintes resultados apresentados no Quadro 2 
Quadro 2 - Índice de Validade de Conteúdo (IVC) obtido a partir da avaliação de juízes com relação à abrangência dos domínios do questionário sobre Diagnóstico Situacional da Sistematização da Assistência de Enfermagem. Campinas, 2015.

\begin{tabular}{|lc|}
\hline \multicolumn{1}{|c|}{ Domínios do questionário } & IVC \\
\hline $\begin{array}{l}\text { 1-Percepção sobre Conceitos referentes à Sistematização da Assistência de } \\
\text { Enfermagem (SAE) e Processo de enfermagem (PE) } \\
\text { 2-Percepção sobre capacitação para realização da SAE e PE }\end{array}$ & 1,00 \\
3-Percepção sobre as dificuldades na realização da SAE e PE na sua unidade & 0,86 \\
4-Percepção sobre os benefícios que o uso da SAE e PE pode trazer & 1,00 \\
5-Percepção sobre o que poderia facilitar a aplicação da SAE na unidade & 0,71 \\
6-Percepção sobre o a realização da SAE na sua unidade & 0,86 \\
\hline 7-Percepção quanto a sua atuação profissional individual em relação ao PE & 1,00 \\
\hline
\end{tabular}

Fonte: elaborado pela autora.

Apenas o domínio cinco não alcançou IVC > 0,80. Uma especialista apontou a falta de um item para contemplar o prontuário eletrônico como ferramenta que poderia facilitar a aplicação da SAE/ PE. Outra sugestão foi melhorar a redação do título do domínio passando a ser: "Percepção sobre o que poderia facilitar a implantação/implementação da SAE e realização do PE na unidade".

Sendo assim a pesquisadora optou por realizar as modificações sugeridas e após as modificações considerar como validado o conteúdo do domínio em questão. O título do domínio passou a ser: "Sua percepção sobre o que poderia facilitar a implementação da SAE e realização do PE na sua unidade" e foi acrescentada ao domínio 5 a seguinte questão:

41- A existência de prontuário eletrônico facilita a implantação da SAE/ PE. 


\subsubsection{Validação de conteúdo das questões quanto ao critério pertinência}

Os especialistas avaliaram a pertinência de cada questão, cujos resultados de IVC estão apresentados no Quadro 3.

Quadro 3 - Índice de Validade de Conteúdo (IVC) obtido a partir da avaliação de juízes com relação a pertinência de cada item do questionário sobre Diagnóstico Situacional da Sistematização da Assistência de Enfermagem. Campinas, 2015.

\begin{tabular}{|c|c|}
\hline $\begin{array}{l}\text { D1- Sua percepção sobre Sistematização da assistência de enfermagem (SAE) e } \\
\text { Processo de enfermagem (PE) }\end{array}$ & IVC \\
\hline 1- Não sei o que é SAE e PE & 0,86 \\
\hline 2- Tenho dificuldade para entender o que é SAE e PE & 0,86 \\
\hline 3- A SAE é um instrumento para planejar e organizar a assistência. & 1,00 \\
\hline 4- A SAE define atribuições aos membros da equipe de enfermagem. & 0,71 \\
\hline 5- A SAE é realizada através do PE & 0,71 \\
\hline 6- A documentação do PE é exigência legal. & 0,86 \\
\hline $\begin{array}{l}\text { 7- O PE é composto por cinco etapas: coleta de dados, diagnóstico, planejamento, } \\
\text { implementação e avaliação. }\end{array}$ & 1,00 \\
\hline 8- A SAE é realizada privativamente pelo enfermeiro. & 0,86 \\
\hline 9- A realização da SAE ajuda a tornar a prática de enfermagem visível. & 0,86 \\
\hline $\begin{array}{l}\text { 10- Um dos motivos que dificultam o desenvolvimento da enfermagem como ciência é } \\
\text { a falta de uma linguagem universal padronizada para o registro de suas ações }\end{array}$ & 1,00 \\
\hline $\begin{array}{l}\text { 11- O PE tem como objetivo descrever de maneira padronizada o cuidado de } \\
\text { enfermagem prestado às pessoas. }\end{array}$ & 1,00 \\
\hline $\begin{array}{l}\text { 12- A Consulta de Enfermagem nas unidades básicas de saúde é a mesma coisa que } \\
\text { PE }\end{array}$ & 0,86 \\
\hline 13-Os auxiliares e técnicos de enfermagem participam da execução do PE & 1,00 \\
\hline D2- Sua percepção sobre capacitação sobre SAE e PE & IVC \\
\hline 14- A formação acadêmica ensina de modo satisfatório sobre SAE e PE. & 0,71 \\
\hline $\begin{array}{l}\text { 15- A formação acadêmica prepara o profissional para a realização da SAE no } \\
\text { contexto da atenção primária. }\end{array}$ & 0,71 \\
\hline 16- A educação permanente facilita a aplicação da SAE. & 1,00 \\
\hline $\begin{array}{l}\text { 17- Os cursos de técnicos e auxiliares contemplam a SAE e PE durante a formação } \\
\text { profissional. }\end{array}$ & 0,71 \\
\hline
\end{tabular}




\begin{tabular}{|c|c|}
\hline $\begin{array}{l}\text { 18- Tenho conhecimento para realizar a parte que me cabe como profissional na } \\
\text { efetivação da SAE e PE. }\end{array}$ & 1,00 \\
\hline 19- Preciso de capacitação para realizar a SAE na prática & 1,00 \\
\hline $\begin{array}{l}\text { D3- Sua percepção sobre as dificuldades na realização da SAE e PE na sua } \\
\text { unidade: }\end{array}$ & IVC \\
\hline xistam dificuldades par & 1,00 \\
\hline $\begin{array}{l}\text { 21- A pressão da demanda, com excesso de pacientes é um dificultador para a } \\
\text { realização da SAE }\end{array}$ & 1,00 \\
\hline 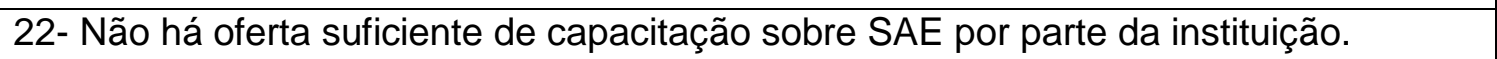 & 0,86 \\
\hline $\begin{array}{l}\text { 23- As interrupções por parte da equipe no momento da consulta de enfermagem } \\
\text { prejudicam o desenvolvimento do PE }\end{array}$ & 1,00 \\
\hline 24- Não & 1,00 \\
\hline 25- Os e & 0,86 \\
\hline 26- A alta & 0,86 \\
\hline $\begin{array}{l}\text { 27- Os profissionais não valorizam a consulta de enfermagem, pois a assistência é } \\
\text { focada no médico }\end{array}$ & 0,86 \\
\hline $\begin{array}{l}\text { 28- A população não valoriza a consulta de enfermagem, exige apenas atendimento } \\
\text { do médico }\end{array}$ & 1,00 \\
\hline 29- A instituição não oferece estrutura adequada para a realização da SAE & 0,86 \\
\hline $\begin{array}{l}\text { 30- A indefinição do papel do enfermeiro e da extensão de sua autonomia e } \\
\text { responsabilidades é um dificultador para a realização da SAE. }\end{array}$ & 1,00 \\
\hline 31- Os enfermeiros têm pouca familiaridade com as nomenclaturas existentes & 0,86 \\
\hline $\begin{array}{l}\text { 32- A inexistência de um guia, em papel, dos diagnósticos e intervenções é um } \\
\text { dificultador para a realização da SAE. }\end{array}$ & 0,71 \\
\hline $\begin{array}{l}\text { 33- O uso de nomenclatura padronizada induz o profissional enfermeiro a "decorar" } \\
\text { alguns diagnósticos e aplicá-los sem um profundo raciocínio clínico }\end{array}$ & 0,71 \\
\hline benefícios que o uso da SAE e PE pode & IVC \\
\hline 34- Não acredito que a SAE traga benefícios para o paciente & 1,00 \\
\hline 35- A utilização do PE melhora a qualidade da consulta de enfermagem & 1,00 \\
\hline $\begin{array}{l}\text { 36- A implantação da nomenclatura na consulta de enfermagem favorece a } \\
\text { documentação do trabalho do enfermeiro }\end{array}$ & 0,86 \\
\hline $\begin{array}{l}\text { 37-A execução do PE favorece o desenvolvimento do raciocínio clínico dos } \\
\text { enfermeiros }\end{array}$ & 0,86 \\
\hline
\end{tabular}




\begin{tabular}{|c|c|}
\hline $\begin{array}{l}\text { 38- A realização da SAE aumenta a autonomia do enfermeiro em seu processo de } \\
\text { trabalho }\end{array}$ & 1,00 \\
\hline 39- Elevação da qualidade da assistência de enfermagem & 0,57 \\
\hline $\begin{array}{l}\text { 40- Pode trazer benefícios para equipe e para o paciente, através da individualização } \\
\text { do cuidado }\end{array}$ & 0,71 \\
\hline D5- Sua percepção sobre o que poderia facilitar a aplicação da SAE na unidade & IVC \\
\hline $\begin{array}{l}\text { 41- A elaboração de um impresso com diagnósticos e prescrições de enfermagem } \\
\text { facilita a aplicação da SAE }\end{array}$ & 0,86 \\
\hline 42- Oferecer capacitações sobre SAE para equipe facilita sua efetivação & 0,86 \\
\hline $\begin{array}{l}\text { 43- A instituição oferecer espaço para educação permanente para os enfermeiros, } \\
\text { com foco em SAE e discussão de casos clínicos, facilita a aplicação da SAE e PE }\end{array}$ & 0,86 \\
\hline $\begin{array}{l}\text { 44- Garantia de estrutura como: número adequado de recursos humanos e a } \\
\text { organização da agenda do enfermeiro com no mínimo } 20 \text { minutos por paciente, } \\
\text { facilita a aplicação da SAE e PE }\end{array}$ & 0,71 \\
\hline $\begin{array}{l}\text { 45- Quando o enfermeiro é envolvido com o trabalho, facilita a implementação da } \\
\text { SAE }\end{array}$ & 0,86 \\
\hline 46- A adoção de uma linguagem padronizada facilita a aplicação da SAE e PE & 1,00 \\
\hline 47- Adoção de protocolos facilita a implementação da SAE & 1,00 \\
\hline $\begin{array}{l}\text { 48- Quando o enfermeiro tem conhecimento sobre SAE e PE facilita sua } \\
\text { implementação }\end{array}$ & 1,00 \\
\hline D6- Sua percepção sobre o que ocorre na sua unidade & IVC \\
\hline 49- É realizada a consulta de enfermagem, utilizando o PE & 1,00 \\
\hline 50- A SAE é utilizada para todas as ações de enfermagem & 1,00 \\
\hline 51- Os enfermeiros registram o PE no prontuário do paciente de forma completa. & 1,00 \\
\hline 52- A equipe de enfermagem valoriza a SAE e checa as prescrições do enfer & 0,86 \\
\hline 53- A equipe de enfermagem da unidade participa da realização do PE & 1,00 \\
\hline 54- A SAE é realizada de acordo com as normas do COFEN & 1,00 \\
\hline 55- O enfermeiro tem apoio institucional para realizar a SAE na unidade. & 1,00 \\
\hline 56- A unidade possui número de enfermeiros suficientes para realização da SAE & 1,00 \\
\hline $\begin{array}{l}\text { 57- Na situações de fiscalização do órgão de classe (COREN) são encontradas } \\
\text { irregularidades na execução da SAE e PE na unidade }\end{array}$ & 1,00 \\
\hline
\end{tabular}




\begin{tabular}{|l|l|}
\hline $\begin{array}{l}\text { D7- Sua percepção quanto a sua atuação profissional individual em relação ao } \\
\text { PE }\end{array}$ & IVC \\
\hline 58- Você realiza exame físico do paciente & 0,71 \\
\hline 59- Você faz anamnese do paciente & 0,71 \\
\hline 60- Você faz levantamentos de problemas do paciente & 0,57 \\
\hline 61 - Você faz o diagnóstico de enfermagem & 0,86 \\
\hline 62- Você prescreve os cuidados para todos os pacientes & 0,86 \\
\hline 63- Você segue as prescrições do enfermeiro e checa as ações realizadas & 0,86 \\
\hline $64-$ Você avalia o cuidado prestado & 1,00 \\
\hline $65-$ Você registra no prontuário do paciente todas etapas que executa & 1,00 \\
\hline $66-$ Os diagnósticos que você utiliza são baseados na nomenclatura NANDA & 0,86 \\
\hline $67-$ Os diagnósticos são baseados na nomenclatura CIPE & 0,86 \\
\hline $68-$ Os diagnósticos são baseados na nomenclatura CIPESC & 0,86 \\
\hline $\begin{array}{l}\text { 69-Você utiliza uma nomenclatura não padronizada para elaboração de diagnósticos } \\
\text { de enfermagem }\end{array}$ & 0,86 \\
\hline
\end{tabular}

Fonte: elaborado pela autora

Verificamos que mais de $80 \%$ das questões obtiveram IVC maior que 0,80 quanto o critério de pertinência, como mostra a Figura 1.

Figura 1 - Distribuição percentual dos itens validados, segundo o Índice de Validade de Conteúdo (IVC) obtido a partir da avaliação de juízes com relação a da pertinência de cada item do questionário sobre Diagnóstico Situacional da Sistematização da Assistência de Enfermagem. Campinas, 2015.

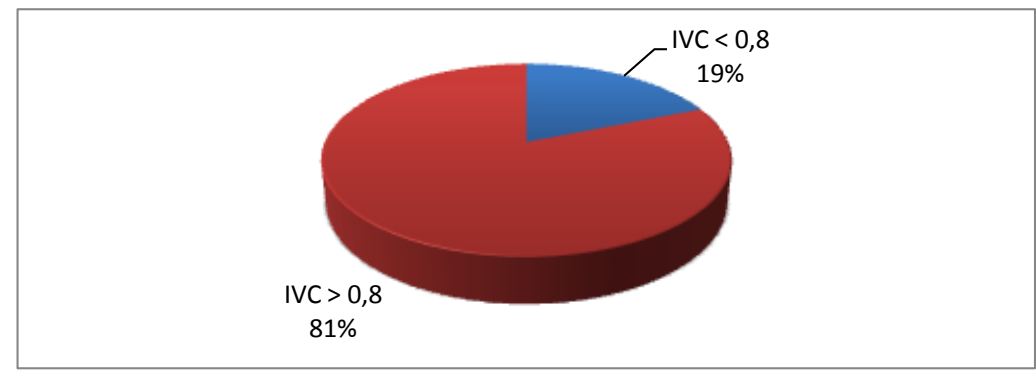

Fonte: elaborado pela autora. $\mathrm{N}$ itens avaliados $=69$

As questões com IVC <0,8 serão discutidas individualmente no Quadro 4. 
Quadro 4 - Sugestão dos especialistas, comentários e decisão da pesquisadora para as questões que obtiveram com Índice de Validade de Conteúdo (IVC) $<0,8$, quanto ao critério pertinência avaliado por juízes, referente ao questionário sobre Diagnóstico Situacional da Sistematização da Assistência de Enfermagem. Campinas, 2015.

\begin{tabular}{|c|c|c|c|c|c|}
\hline $\begin{array}{c}\mathbf{N} \\
\text { Questão }\end{array}$ & Questão & IVC & $\begin{array}{l}\text { Sugestão das } \\
\text { especialistas }\end{array}$ & $\begin{array}{c}\text { Comentários da } \\
\text { pesquisadora }\end{array}$ & $\begin{array}{c}\text { Decisão da } \\
\text { pesquisadora }\end{array}$ \\
\hline 4 & $\begin{array}{l}\text { A SAE define } \\
\text { atribuições aos } \\
\text { membros da } \\
\text { equipe de } \\
\text { enfermagem }\end{array}$ & 0,71 & $\begin{array}{l}\text { Dois especialistas } \\
\text { assinalaram a opção } 3 \\
\text { (estou indeciso), } \\
\text { mostrando dúvida em } \\
\text { relação a pertinência da } \\
\text { questão, entretanto não } \\
\text { fizeram nenhuma } \\
\text { sugestão para sua } \\
\text { melhoria. }\end{array}$ & $\begin{array}{c}\text { Tendo em vista que os } \\
\text { especialistas } \\
\text { demonstraram dúvida } \\
\text { sobre a pertinência da } \\
\text { questão e não } \\
\text { ofereceram subsídios } \\
\text { para discussão, julgamos } \\
\text { que não houve } \\
\text { elementos para realizar a } \\
\text { revisão da questão. }\end{array}$ & $\begin{array}{l}\text { Excluir a } \\
\text { questão. }\end{array}$ \\
\hline 5 & $\begin{array}{c}\text { A SAE é } \\
\text { realizada } \\
\text { através do PE }\end{array}$ & 0,71 & $\begin{array}{l}\text { Dois especialistas } \\
\text { afirmaram que esta } \\
\text { questão limita o } \\
\text { entendimento do que } \\
\text { seja SAE, pois coloca } \\
\text { SAE como sinônimo de } \\
\text { PE. Uma especialista } \\
\text { sugeriu revisão da frase: } \\
\text { A SAE é um instrumento } \\
\text { mais amplo que PE. }\end{array}$ & $\begin{array}{l}\text { Considerando que os } \\
\text { comentários dos } \\
\text { especialistas são } \\
\text { pertinentes, pois SAE } \\
\text { não é sinônimo de PE, } \\
\text { optamos por revisão da } \\
\text { frase, conforme sugestão } \\
\text { do especialista. }\end{array}$ & $\begin{array}{c}\text { Revisar a } \\
\text { questão } \\
\text { conforme } \\
\text { sugestão do } \\
\text { especialista. }\end{array}$ \\
\hline 14 & $\begin{array}{l}\text { A formação } \\
\text { acadêmica } \\
\text { ensina de } \\
\text { modo } \\
\text { satisfatório } \\
\text { sobre SAE e PE }\end{array}$ & 0,71 & $\begin{array}{c}\text { Especialistas } \\
\text { argumentam que os } \\
\text { auxiliares e técnicos não } \\
\text { tem embasamento para } \\
\text { responder, pois não } \\
\text { tiveram formação } \\
\text { acadêmica. }\end{array}$ & $\begin{array}{l}\text { Considerando que a } \\
\text { argumentação das } \\
\text { especialistas que } \\
\text { reprovaram a questão é } \\
\text { pertinente, concluímos } \\
\text { que a questão pode ser } \\
\text { mantida, desde que } \\
\text { aplicada à respectiva } \\
\text { categoria profissional. }\end{array}$ & $\begin{array}{l}\text { Revisar a } \\
\text { questão, } \\
\text { aplicando à } \\
\text { respectiva } \\
\text { categoria } \\
\text { profissional, } \\
\text { conforme } \\
\text { sugestão das } \\
\text { especialistas. }\end{array}$ \\
\hline 15 & $\begin{array}{l}\text { A formação } \\
\text { acadêmica } \\
\text { prepara o } \\
\text { profissional } \\
\text { para a } \\
\text { realização da } \\
\text { SAE no } \\
\text { contexto da } \\
\text { atenção } \\
\text { primária. }\end{array}$ & 0,71 & $\begin{array}{c}\text { Essas perguntas } \\
\text { poderiam ser } \\
\text { direcionadas ao } \\
\text { profissional enfermeiro, } \\
\text { ou serem substituídas } \\
\text { por genéricas, podendo- } \\
\text { se, assim, excluir a } \\
\text { questão } 17 . \text { Uma } \\
\text { avaliadora sugeriu } \\
\text { acrescentar PE na frase. }\end{array}$ & $\begin{array}{l}\text { Considerando que a } \\
\text { argumentação dos } \\
\text { especialistas que } \\
\text { reprovaram a questão é } \\
\text { pertinente, concluímos } \\
\text { que a questão pode ser } \\
\text { mantida, desde que } \\
\text { aplicada à respectiva } \\
\text { categoria profissional. }\end{array}$ & $\begin{array}{l}\text { Revisar a } \\
\text { questão, } \\
\text { aplicando à } \\
\text { respectiva } \\
\text { categoria } \\
\text { profissional, } \\
\text { conforme } \\
\text { sugestão da } \\
\text { especialista. }\end{array}$ \\
\hline
\end{tabular}




\begin{tabular}{|c|c|c|c|c|c|}
\hline 17 & $\begin{array}{l}\text { Os cursos } \\
\text { técnicos e } \\
\text { auxiliares } \\
\text { contemplam a } \\
\text { SAE e PE } \\
\text { durante a } \\
\text { formação } \\
\text { profissional. }\end{array}$ & 0,71 & $\begin{array}{l}\text { Essa afirmação poderá } \\
\text { só ser adequadamente } \\
\text { respondida pelo auxiliar } \\
\text { ou técnico de } \\
\text { enfermagem. }\end{array}$ & $\begin{array}{l}\text { Considerando que a } \\
\text { argumentação dos } \\
\text { especialistas que } \\
\text { reprovaram a questão é } \\
\text { pertinente, concluímos } \\
\text { que a questão pode ser } \\
\text { mantida, desde que } \\
\text { aplicada à respectiva } \\
\text { categoria profissional. }\end{array}$ & $\begin{array}{l}\text { Revisar a } \\
\text { questão, } \\
\text { aplicando à } \\
\text { respectiva } \\
\text { categoria } \\
\text { profissional, } \\
\text { conforme } \\
\text { sugestão da } \\
\text { especialista. }\end{array}$ \\
\hline 32 & $\begin{array}{c}\text { A inexistência } \\
\text { de um guia em } \\
\text { papel dos } \\
\text { diagnósticos e } \\
\text { intervenções é } \\
\text { um dificultador } \\
\text { para a } \\
\text { realização da } \\
\text { SAE }\end{array}$ & 0,71 & $\begin{array}{l}\text { Nessa questão dois } \\
\text { juízes sugeriram trocar } \\
\text { palavra SAE por PE e um } \\
\text { juiz orientou } \\
\text { complementar a frase } \\
\text { com PE. }\end{array}$ & $\begin{array}{l}\text { Consideramos que os } \\
\text { especialistas que } \\
\text { reprovaram a questão } \\
\text { fizeram sugestões de } \\
\text { melhorias, apontando } \\
\text { que a questão pode ser } \\
\text { aprimorada. }\end{array}$ & $\begin{array}{c}\text { Revisar a } \\
\text { questão, } \\
\text { conforme } \\
\text { sugestão da } \\
\text { especialista. }\end{array}$ \\
\hline 33 & $\begin{array}{c}\text { O uso da } \\
\text { nomenclatura } \\
\text { padronizada } \\
\text { induz o } \\
\text { profissional } \\
\text { enfermeiro a } \\
\text { decorar os } \\
\text { diagnóstico e } \\
\text { aplicá-lo sem } \\
\text { um profundo } \\
\text { raciocínio } \\
\text { clínico }\end{array}$ & 0,71 & $\begin{array}{c}\text { A nomenclatura } \\
\text { padronizada pode } \\
\text { induzir a um frágil ou } \\
\text { inexistente raciocínio } \\
\text { clínico, mas a ausência } \\
\text { dele é uma deformação } \\
\text { da formação. Se ele } \\
\text { estiver presente, a } \\
\text { nomenclatura } \\
\text { padronizada dos } \\
\text { principais diagnósticos } \\
\text { poderá ser objeto de } \\
\text { agilidade no } \\
\text { atendimento e para o } \\
\text { serviço, sem prejuízo da } \\
\text { qualidade deste } \\
\text { atendimento. }\end{array}$ & $\begin{array}{l}\text { Tendo em vista que os } \\
\text { especialistas } \\
\text { demonstraram dúvida } \\
\text { sobre a pertinência da } \\
\text { questão e não } \\
\text { ofereceram subsídios } \\
\text { para discussão, julgamos } \\
\text { que não houve } \\
\text { elementos para realizar a } \\
\text { revisão da questão. }\end{array}$ & $\begin{array}{l}\text { Excluir a } \\
\text { questão. }\end{array}$ \\
\hline 39 & $\begin{array}{l}\text { Elevação da } \\
\text { qualidade de } \\
\text { enfermagem }\end{array}$ & 0,57 & $\begin{array}{l}\text { Falta introdução para } \\
\text { dar sentido. }\end{array}$ & $\begin{array}{l}\text { De acordo com a posição } \\
\text { dos juízes, a questão não } \\
\text { é clara ou pertinente. }\end{array}$ & $\begin{array}{l}\text { Excluir a } \\
\text { questão. }\end{array}$ \\
\hline
\end{tabular}




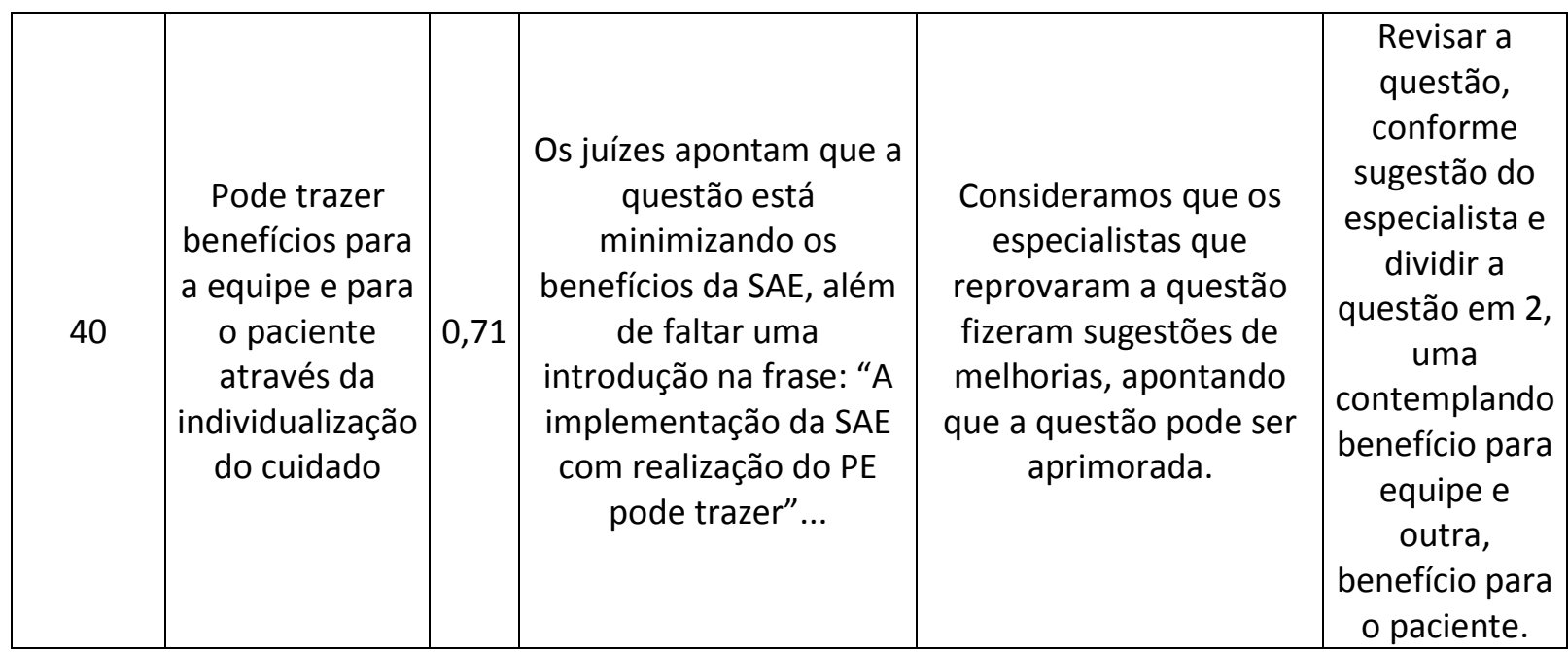

Fonte: elaborado pela autora. Siglas: Sistematização da Assistência de enfermagem (SAE), Processo de enfermagem (PE), Índice de Validação de Conteúdo (IVC). 


\subsubsection{Validação de conteúdo das questões quanto ao critério clareza.}

Figura 2 - Distribuição percentual dos itens validados, segundo o Índice de Validade de Conteúdo (IVC) obtido a partir da avaliação de juízes com relação ao critério clareza das questões do questionário sobre Diagnóstico Situacional da Sistematização da Assistência de Enfermagem. Campinas, 2015.

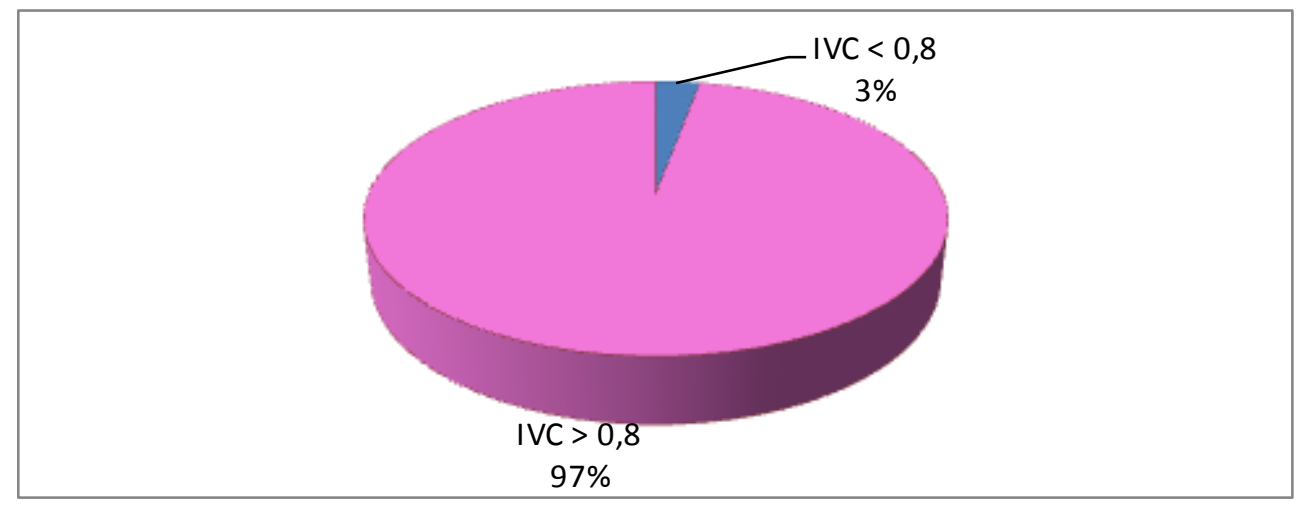

Fonte: elaboração da autora. Campinas, 2015. $\mathrm{N}$ itens avaliados $=69$

Apenas duas questões obtiveram IVC $<0,8$ : questão 4 e questão 39 , sendo que as duas já haviam sido revisadas em função das considerações obtidas no critério pertinência. Portanto, julgamos que o questionário proposto não apresentou problemas quanto ao critério de clareza dos itens.

\subsubsection{Revisão das questões validadas com IVC $>0.8$}

Consideramos que todas as sugestões dos especialistas podem contribuir para a melhoria do instrumento. Sendo assim todos os comentários foram analisados e buscou-se responder positivamente a todos, mesmo nas questões validadas pelo critério de IVC $>0,8$.

Portanto muitos itens do instrumento foram revisados sendo acrescentado $\mathrm{SAE} / \mathrm{PE}$ na frase quando julgamos que caberiam os dois conceitos. Outras vezes substituímos SAE por PE quando se tratava da assistência direta aos pacientes, sempre entendendo que a SAE oferece subsídios para a realização do PE. Nesse contexto optamos por realizar mudanças de acordo com as sugestões dos especialistas, quando julgamos que poderia contribuir para evitar conflitos conceituais, melhorando a coerência e praticidade do instrumento. A intenção foi organizar o questionário de forma que todos os itens estejam embasados no 
referencial teórico adotado pela autora nesse trabalho conforme discutido no Quadro 1.

Algumas questões sofreram modificações ortográficas, semânticas e gramaticais, ou pequenas revisões, não alterando o sentido inicial da frase.

Uma questão foi revisada para melhorar a clareza para o que se pretende captar, já que dois juízes demonstraram dúvidas nos comentários dessa questão. Sendo assim modificamos a seguinte questão conforme sugestão do especialista:

\begin{tabular}{|l|l|}
\hline Frase inicial: & Frase revisada: \\
26- A alta complexidade dos pacientes & $\begin{array}{l}\text { 25- A baixa complexidade dos pacientes } \\
\text { dificulta a realização da SAE. }\end{array}$ \\
& $\begin{array}{l}\text { torna a SAE/PE dispensável na atenção } \\
\text { básica. }\end{array}$ \\
\hline
\end{tabular}

Como pretendemos identificar o motivo pelo qual a SAE não é realizada, optamos por seguir a sugestão de uma especialista, buscando identificar uma possível concepção equivocada: de que os pacientes da atenção básica não são complexos devido à cronicidade dos casos, tornado a SAE e PE dispensáveis.

Outra questão foi modificada de acordo com sugestão dos juízes:

\begin{tabular}{|l|l|}
\hline Frase inicial & Frase revisada \\
8- A SAE é realizada privativamente pelo & \\
enfermeiro. & - Cabem privativamente ao enfermeiro \\
& $\begin{array}{l}\text { 0 Diagnóstico e a Prescrição de } \\
\text { Enfermagem }\end{array}$ \\
\hline
\end{tabular}

Optamos por revisar a frase, pois a Resolução COFEN no 272/2002 que considerava a SAE como atividade privativa do enfermeiro, foi revogada pela Resolução COFEN no 358/2009. Nessa última resolução é incumbida ao enfermeiro a liderança da execução e avaliação do Processo de Enfermagem, cabendo-Ihe, privativamente, o diagnóstico de enfermagem e as prescrição das ações ou intervenções de enfermagem a serem realizadas.

Além disso, ao domínio 7 direcionamos algumas questões à categoria profissional por sugestão dos especialistas, quando a ação é considerada privativa. 


\subsubsection{Síntese dos resultados de validação do questionário}

Conforme mostra a análise de conteúdo, 13 questões foram reprovadas pelo critério de IVC $<0,8$. Entretanto, essas questões foram avaliadas individualmente ponderando as sugestões dos especialistas para o processo decisório.

Entre as questões propostas, $81 \%$ foram validadas quanto ao critério de pertinência e $97 \%$ quanto ao critério de clareza com IVC> 0,8 . Tendo em conta a análise das considerações dos juízes as seguintes ações foram estabelecidas de modo a aprimorar o questionário:

- Cinco questões foram retiradas do questionário

- $\quad$ Oito questões tiveram seu conteúdo reformulado, de acordo com a sugestão dos juízes, possibilitando sua validação.

- Foi acrescentada uma questão para aprimorar o domínio cinco quanto ao critério de abrangência.

- O título do domínio cinco foi modificado conforme sugestão do especialista.

- A questão 40 foi dividida em duas questões, de acordo com sugestão do especialista, pois contemplava dois assuntos em sua elaboração inicial.

- $\quad$ Algumas questões apesar de validadas pelo critério de IVC foram revisadas quanto a sua redação, de acordo com as sugestões dos especialistas. Quando houve mais de uma sugestão para mesma questão foi considerada a que mais se aproxima dos objetivos da pesquisa.

O questionário após validação ficou estruturado em sete domínios e 66 questões. (APÊNDICE E)

\subsection{RESULTADOS DA ETAPA 2- APLICAÇÃO DO QUESTIONÁRIO E REALIZAÇÃO DO DIAGNÓSTICO SITUACIONAL EM UMA UNIDADE BÁSICA DE SAÚDE DE CAMPINAS-SP}

\subsubsection{Caracterização dos participantes}

A maioria (95\%) dos participantes da pesquisa foi do sexo feminino.

As Figuras 3, 4, 5, 6 e 7 referem-se à idade, escolaridade, tempo de formação profissional, categoria profissional e tempo de atuação profissional na Prefeitura Municipal de Campinas. 
Figura 3 - Distribuição percentual dos membros da equipe de enfermagem participantes da pesquisa sobre Diagnóstico Situacional da Sistematização da Assistência de Enfermagem em uma Unidade Básica de Saúde, segundo faixa etária. Campinas, 2015.

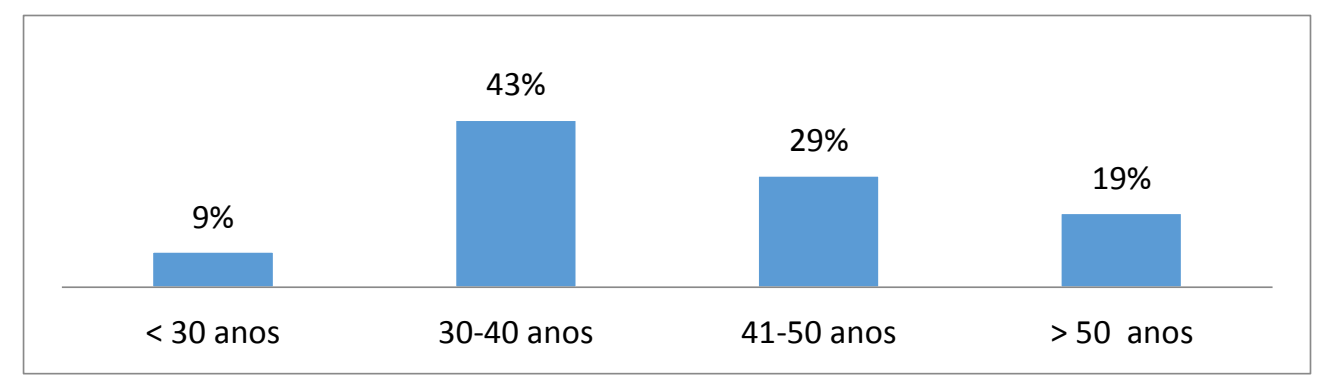

Fonte: elaborado pela autora. $\mathrm{N}$ participantes $=21$

Observou-se que a idade dos participantes variou de 24 a 67 anos, sendo que a maioria dos entrevistados tinha de 30 a 40 anos. A média de idade foi de 47 anos e a mediana de 41 anos.

Figura 4 - Distribuição percentual dos membros da equipe de enfermagem participantes da pesquisa sobre Diagnóstico Situacional da Sistematização da Assistência de Enfermagem em uma Unidade Básica de Saúde, segundo escolaridade. Campinas, 2015.

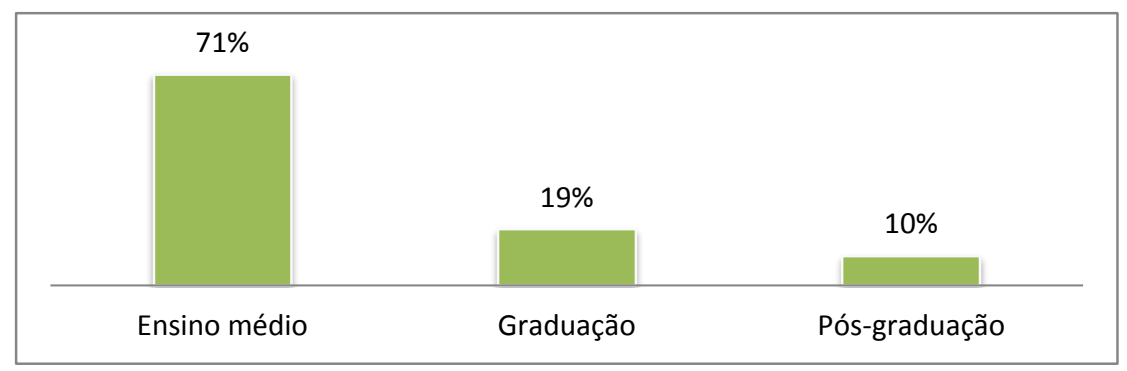

Fonte: elaborado pela autora. $\mathrm{N}$ participantes $=21$

Quanto à escolaridade, 71\% afirmaram ter ensino médio, 19\% graduação e $10 \%$ pós-graduação. Vale salientar que apenas $19 \%$ atuam como enfermeiros, sendo que 10\%, mesmo com nível de graduação ou pós-graduação, atuam em 
cargo de nível médio. Entre os enfermeiros entrevistados, $50 \%$ possuem pósgraduação.

Figura 5 - Distribuição percentual dos membros da equipe de enfermagem participantes da pesquisa sobre Diagnóstico Situacional da Sistematização da Assistência de Enfermagem em uma Unidade Básica de Saúde, segundo tempo de formação profissional. Campinas, 2015.

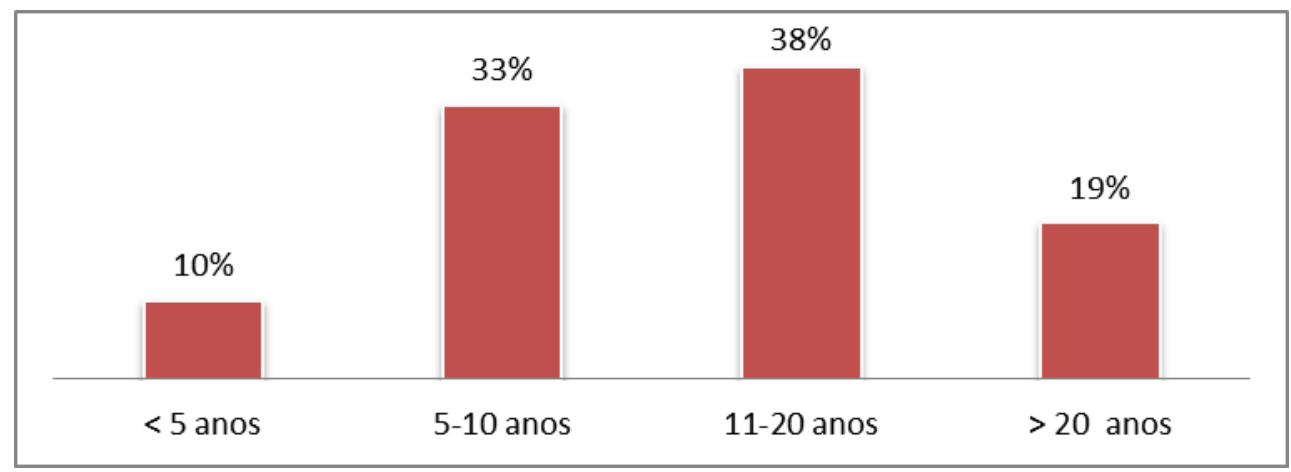

Fonte: elaborado pela autora. $\mathrm{N}$ participantes $=21$

No que se refere ao tempo de formação profissional verificou-se que a média de anos de formado é de 14 anos. Mais de 57\% da equipe possui mais de 10 anos de formados e apenas $10 \%$ apresentam menos de cinco anos de formados. Vale ressaltar que os participantes consideraram a última titulação em enfermagem, sendo assim alguns auxiliares de enfermagem concluíram curso técnico ou graduação recentemente, mas atuam na área há mais anos.

Figura 6 - Distribuição percentual dos membros da equipe de enfermagem participantes da pesquisa sobre Diagnóstico Situacional da Sistematização da Assistência de Enfermagem em uma Unidade Básica de Saúde, segundo categoria profissional Campinas, 2015.

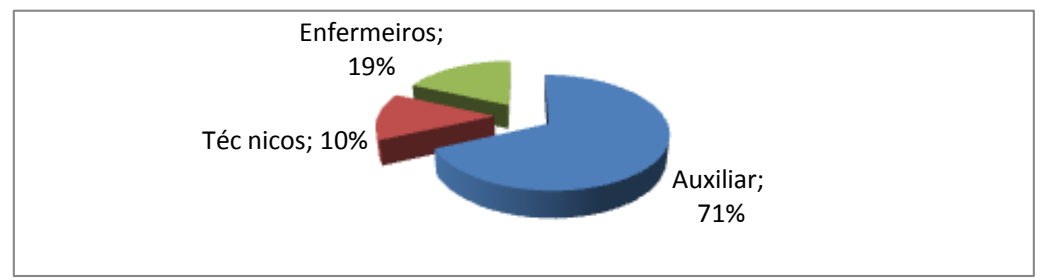

Fonte: elaborado pela autora. $\mathrm{N}$ participantes $=21$. 
Quanto à categoria profissional percebemos que $71 \%$ atuam como auxiliares de enfermagem, 19 \% são enfermeiros, seguidos de $10 \%$ dos participantes que são técnicos de enfermagem.

Figura 7 - Distribuição percentual dos membros da equipe de enfermagem participantes da pesquisa sobre Diagnóstico Situacional da Sistematização da Assistência de Enfermagem em uma Unidade Básica de Saúde, segundo tempo de atuação na instituição. Campinas, 2015.

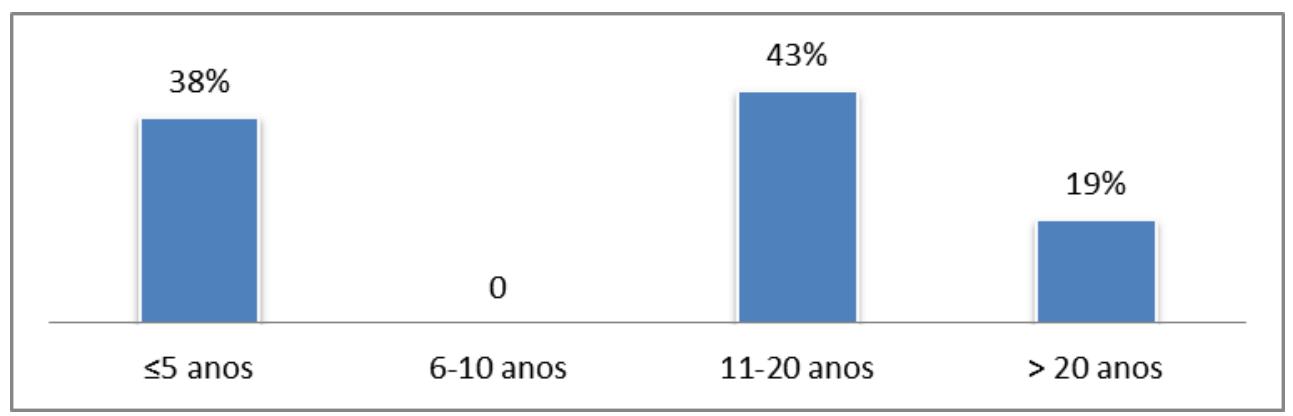

Fonte: elaborado pela autora. $\mathrm{N}$ participantes $=21$

O tempo de trabalho na prefeitura de Campinas variou entre 3 a 37 anos. Sendo que a maioria (62\%) da equipe possui mais de 10 anos na Instituição.

\subsubsection{Domínio 1 - Percepção sobre Sistematização da Assistência de enfermagem (SAE) e Processo de Enfermagem (PE)}

Nesse domínio buscou-se analisar o conceito que a equipe de enfermagem possui sobre SAE e PE, tendo em vista que o entendimento da equipe sobre 0 assunto é essencial para a implementação da SAE.

A estruturação do questionário foi desenvolvida de tal modo que quanto maior o grau de concordância do participante com a assertiva apresentada, maior o entendimento sobre SAE e PE de acordo com o referencial teórico utilizado. Apresentamos a distribuição das respostas da equipe de enfermagem de cada questão do domínio 1 na Tabela 1. 
Tabela 1 - Distribuição das respostas da equipe de enfermagem em uma Unidade Básica de Saúde de acordo com a Percepção sobre Sistematização da Assistência de Enfermagem e Processo de Enfermagem. Campinas, 2015.

Questão

$\begin{array}{lllll}\text { Discordo } & \text { Discordo } & \text { Estou em } & \text { Concordo } & \text { Concordo } \\ \text { totalmente } & \text { parcialmente } & \text { dúvida } & \text { parcialmente } & \text { totalmente }\end{array}$

$\begin{array}{lllllllllll}\mathrm{n} & \% & \mathrm{n} & \% & \mathrm{n} & \% & \mathrm{~N} & \% & \mathrm{n} & \%\end{array}$

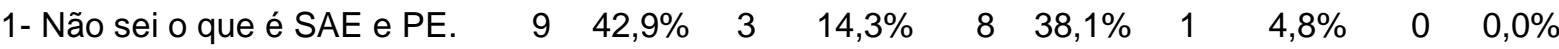

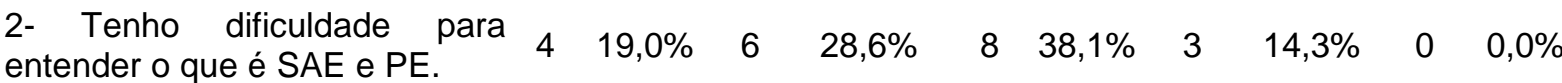

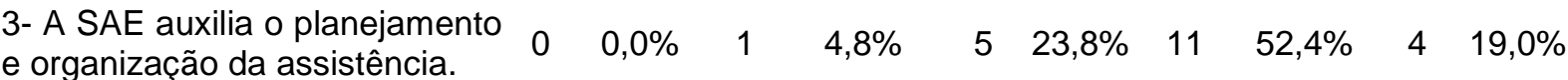

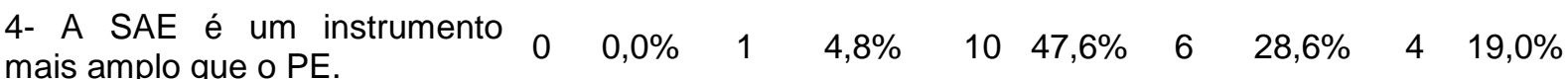

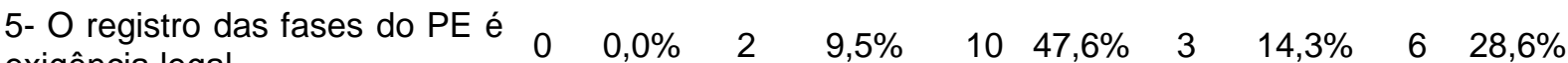
exigência legal.

6- O PE é composto por cinco etapas: coleta de dados de enfermagem, diagnóstico de enfermagem, planejamento de enfermagem, implementação e avaliação de enfermagem.

7- Cabem privativamente ao

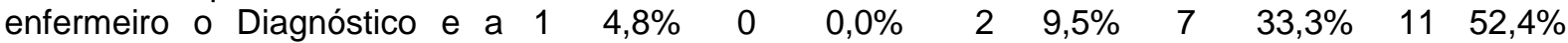
Prescrição de Enfermagem.

8- A SAE ajuda a tornar a prática de enfermagem visível.

1

$4,8 \%$

$7 \quad 33,3 \% \quad 7$

$33,3 \% \quad 5 \quad 23,8 \%$

9- Um dos motivos que dificultam o desenvolvimento da enfermagem como ciência é a falta de uma linguagem universal padronizada para o registro de suas ações.

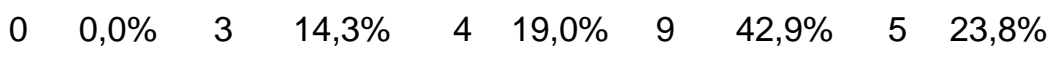


Questão

$\begin{array}{ccccc}\text { Discordo } & \text { Discordo } & \text { Estou em } & \text { Concordo } & \text { Concordo } \\ \text { totalmente } & \text { parcialmente } & \text { dúvida } & \text { parcialmente } & \text { totalmente }\end{array}$
n $\%$
n $\%$
n $\%$
n $\%$
n $\%$

10- O PE tem como objetivo descrever de maneira padronizada a assistência de $\begin{array}{llllllllll}0 & 0,0 \% & 2 & 9,5 \% & 4 & 19,0 \% & 9 & 42,9 \% & 6 & 28,6 \%\end{array}$ enfermagem prestada

11- A Consulta de Enfermagem realizada nas unidades básicas de saúde e ambulatórios é considerada a mesma coisa

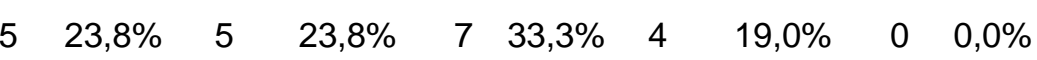
que PE.

12- Os auxiliares e técnicos de enfermagem participam da $5 \quad 23,8 \% \quad 5 \quad 23,8 \% \quad 2 \quad 9,5 \% \quad 6 \quad 28,6 \% \quad 3 \quad 14,3 \%$ execução do PE.

Fonte: Elaborada pela autor 
Os resultados apresentados na Tabela 1 demonstram que uma parcela importante da equipe de enfermagem discorda que não sabe o que seja SAE e PE ou que tenha dificuldade para entender o que é SAE e PE (respectivamente, 57,1\% e $47,6 \%$ de discordo e discordo totalmente).

Entretanto, é importante destacar que em ambas as questões, uma percentagem relevante (38\%) optou pela resposta "estou em dúvida".

Ainda, chama a atenção as porcentagens de participantes que optaram pela opção "estou em dúvida" nas questões de 1 a 6 , as quais variaram entre $24 \%$ a $48 \%$.

A concordância parcial ou total de alguns aspectos favoráveis da SAE do ponto de vista gerencial foi demonstrada pelos resultados das questões "A SAE auxilia o planejamento e organização da assistência" $(71,4 \%)$ e "A SAE ajuda a tornar a prática de enfermagem visível" (81\%).

Sobre o PE a maioria da equipe de enfermagem concordou total ou parcialmente sobre sua composição por cinco etapas: coleta de dados de enfermagem, diagnóstico de enfermagem, planejamento de enfermagem, implementação e avaliação de enfermagem $(57,1 \%)$ e quanto ao seu objetivo de descrever de maneira padronizada a assistência de enfermagem prestada $(71,4 \%)$. Além disso, a equipe entende que cabem privativamente ao enfermeiro o Diagnóstico e a Prescrição de Enfermagem (85,7\%).

Outro resultado importante é que a maior parte da equipe concorda que "Um dos motivos que dificultam o desenvolvimento da enfermagem como ciência é a falta de uma linguagem universal padronizada para o registro de suas ações" (67\%).

Conforme mostram os resultados da Tabela 1 , em relação aos conceitos, grande parte dos entrevistados demonstram dúvidas sobre as seguintes afirmações: "A SAE é um instrumento mais amplo que o PE" $(47,6 \%)$ e "O registro das fases do $P E$ é exigência legal" $(47,6 \%)$.

Além disso, os resultados evidenciados na Tabela 1 mostram que não houve consenso de respostas da equipe de enfermagem nas seguintes questões: "A Consulta de Enfermagem realizada nas unidades básicas de saúde e ambulatórios é considerada a mesma coisa que PE" e "Os auxiliares e técnicos de enfermagem participam da execução do PE". 


\subsubsection{Domínio 2 - Percepção sobre capacitação sobre SAE e PE}

Esse domínio busca compreender a percepção da equipe de enfermagem sobre capacitação sobre SAE e PE, buscando identificar se esses temas foram apresentados durante a formação profissional e se os participantes se sentem capacitados para utilização dessas ferramentas. Os resultados são apresentados na Tabela 2.

Tabela 2 - Distribuição das respostas das questões sobre Percepção sobre capacitação sobre Sistematização da Assistência de Enfermagem e Processo de Enfermagem. Campinas, 2015.

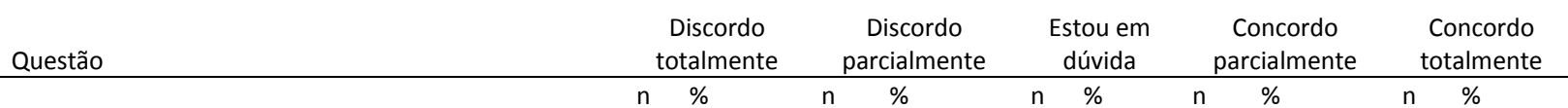

$\begin{array}{lllllllllll}\text { A formação acadêmica ensina de } & 2 & 50 \% & 1 & 25 \% & 1 & 25 \% & 0 & 0 \% & 0 & 0 \%\end{array}$

A formação acadêmica prepara o

profissional para a realização da
SAE no contexto da atenção primária.*

Os cursos técnicos e auxiliares

$\begin{array}{lllllllllll}\text { contemplam a SAE e PE durante a } & 2 & 12 \% & 7 & 41 \% & 4 & 24 \% & 3 & 18 \% & 1 & 6 \%\end{array}$ formação profissional **

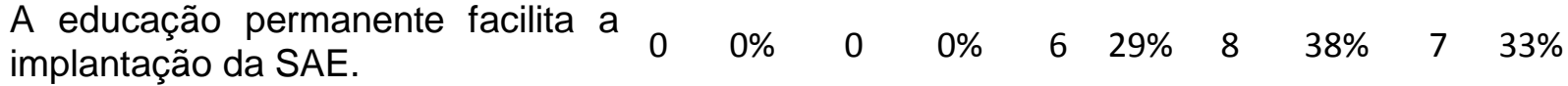

Tenho conhecimento para realizar a $\begin{array}{llllllllllll}\text { parte que me cabe } & \text { como } \\ \text { profissional na efetivação da SAE e } & 1 & 5 \% & 2 & 10 \% & 7 & 33 \% & 9 & 43 \% & 2 & 10 \%\end{array}$ PE.

$\begin{array}{llllllllllll}\text { Preciso de capacitação para } & 0 & 0 \% & 0 & 0 \% & 4 & 19 \% & 9 & 43 \% & 8 & 38 \%\end{array}$ implantar a SAE e realizar PE na prática.

Fonte: elaborado pela autora

*questão aplicada somente para enfermeiro. $\mathrm{N}$ total $=4{ }^{* *}$ questão aplicada somente para técnicos e auxiliares. $\mathrm{N}$ total $=17$ 
As duas primeiras questões foram respondidas apenas por enfermeiros, sendo que a percepção dos mesmos é de que a formação acadêmica não ensina de modo satisfatório sobre SAE e PE, sendo que três (75\%) afirmam que não ensina e um $(25 \%)$ refere que tem dúvidas se a formação acadêmica ensina de modo satisfatório sobre SAE e PE.

Por unanimidade, quatro (100\%) dos enfermeiros afirmam que a formação acadêmica não prepara o profissional para a realização da SAE no contexto da atenção primária, como mostra a Tabela 2.

Já na percepção dos auxiliares e técnicos entrevistados não há convergência de opinião, $53 \%$ dos entrevistados acham que os cursos para técnicos e auxiliares não contemplam SAE e PE durante a formação profissional, 29\% referem que tem dúvidas se contempla esse assunto e $24 \%$ acham que os cursos de técnicos e auxiliares ensinam sobre SAE e PE.

A maior parte dos entrevistados (71\%) considera que a educação permanente facilita a implantação da SAE.

Pouco mais da metade dos profissionais de enfermagem (53\%) consideram que possuem conhecimento suficiente para realizar a SAE e PE na atenção primária. Entretanto, a grande maioria dos entrevistados (81\%) concorda que precisa de capacitação para implantar a SAE e realizar PE na prática.

\subsubsection{Domínio 3 - Percepção sobre as dificuldades na implementação da SAE e realização do PE na sua unidade.}

Nesse domínio identificamos as principais dificuldades reconhecidas para implementação da SAE e para realização do PE. Os resultados serão mostrados através da Figura 8. 
Figura 8 - Percentual de concordância (respostas concordo totalmente e concordo parcialmente) da equipe de enfermagem em relação aos dificultadores para implementação da SAE e realização do PE. Campinas. 2015.

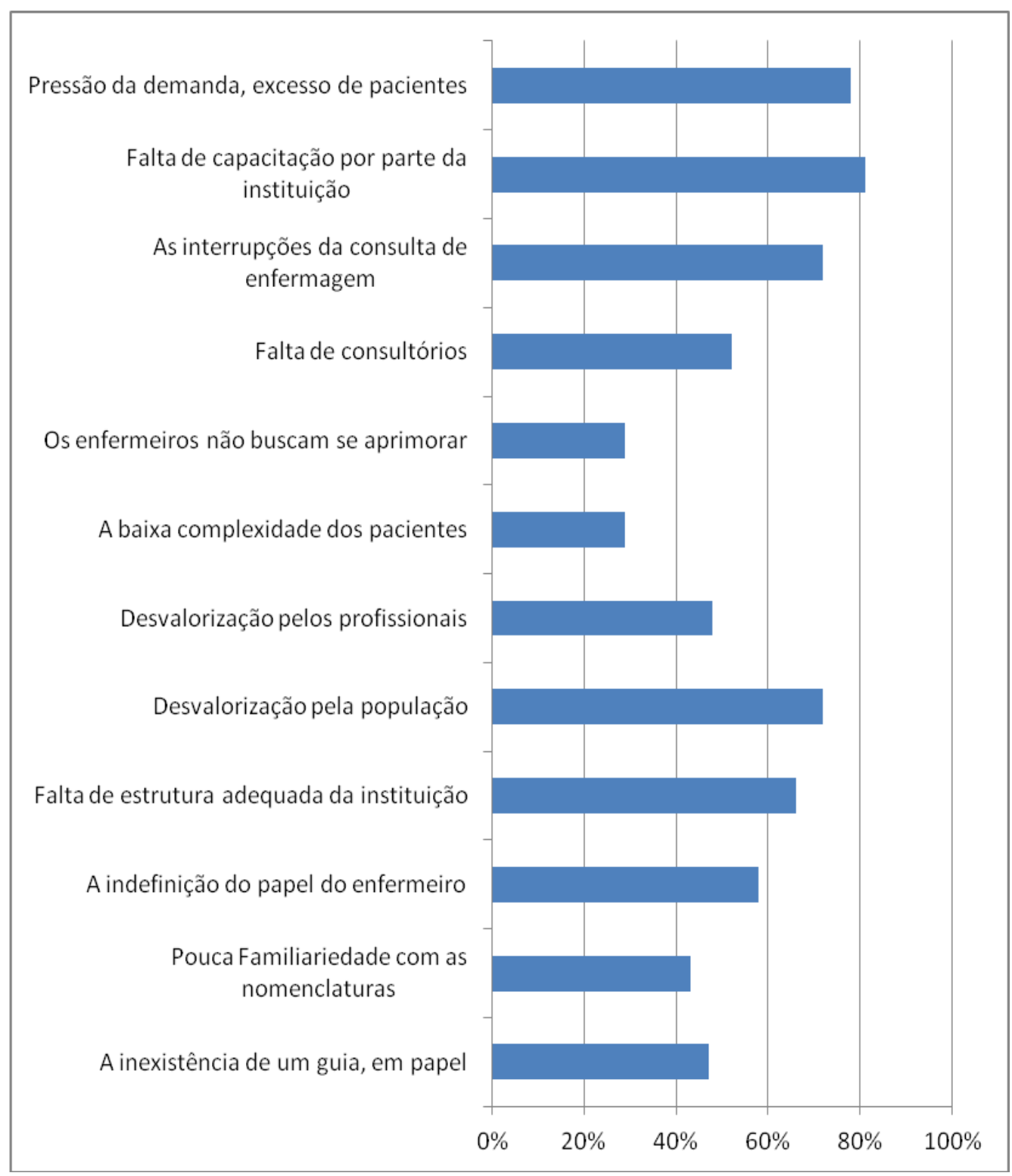

Fonte: elaborada pela autora

No resultado desse domínio percebemos que a equipe de enfermagem identificou como principais dificultadores para implementação da SAE e realização do PE: a pressão da demanda, com excesso de pacientes; falta de capacitação por parte da instituição; as interrupções por parte da equipe no momento da consulta de enfermagem; a desvalorização da consulta de enfermagem pela população; falta de estrutura da instituição e a indefinição do papel do enfermeiro na atenção básica. 
Entretanto, uma parcela importante da equipe (33\%) demonstrou dúvida em relação às seguintes assertivas: "Os enfermeiros têm pouca familiaridade com as nomenclaturas existentes" e "A inexistência de um guia, em papel, dos diagnósticos e intervenções de enfermagem é um dificultador para realização da PE".

Vale salientar que a equipe em sua maioria discordou das afirmativas: "Os enfermeiros não sabem fazer o PE e/ou não buscam se aprimorar" e "A baixa complexidade dos pacientes torna a SAE/PE dispensáveis na atenção básica" (respectivamente, $62 \%$ e $57 \%$ de discordo e discordo totalmente).

Além disso, a equipe não apresentou consenso nas respostas sobre a questão: Os profissionais de saúde não valorizam a consulta de enfermagem, pois a assistência é focada no médico. Sendo que $48 \%$ concordam (total ou parcialmente) e $48 \%$ discordam (total ou parcialmente).

\subsubsection{Domínio 4 - Sua percepção sobre os benefícios que a SAE e PE podem trazer.}

Apenas $19 \%$ dos participantes concordaram com a afirmação de que a SAE e PE não traz benefício para o paciente. Todavia, quando questionados individualmente sobre cada benefício, a grande maioria concorda, total ou parcialmente, com vários benefícios da SAE e PE. Como mostra a Figura 9. 
Figura 9 - Percentual de concordância (respostas concordo totalmente e concordo parcialmente) da equipe de enfermagem em relação aos benefícios que a SAE e PE podem trazer. Campinas, 2015.

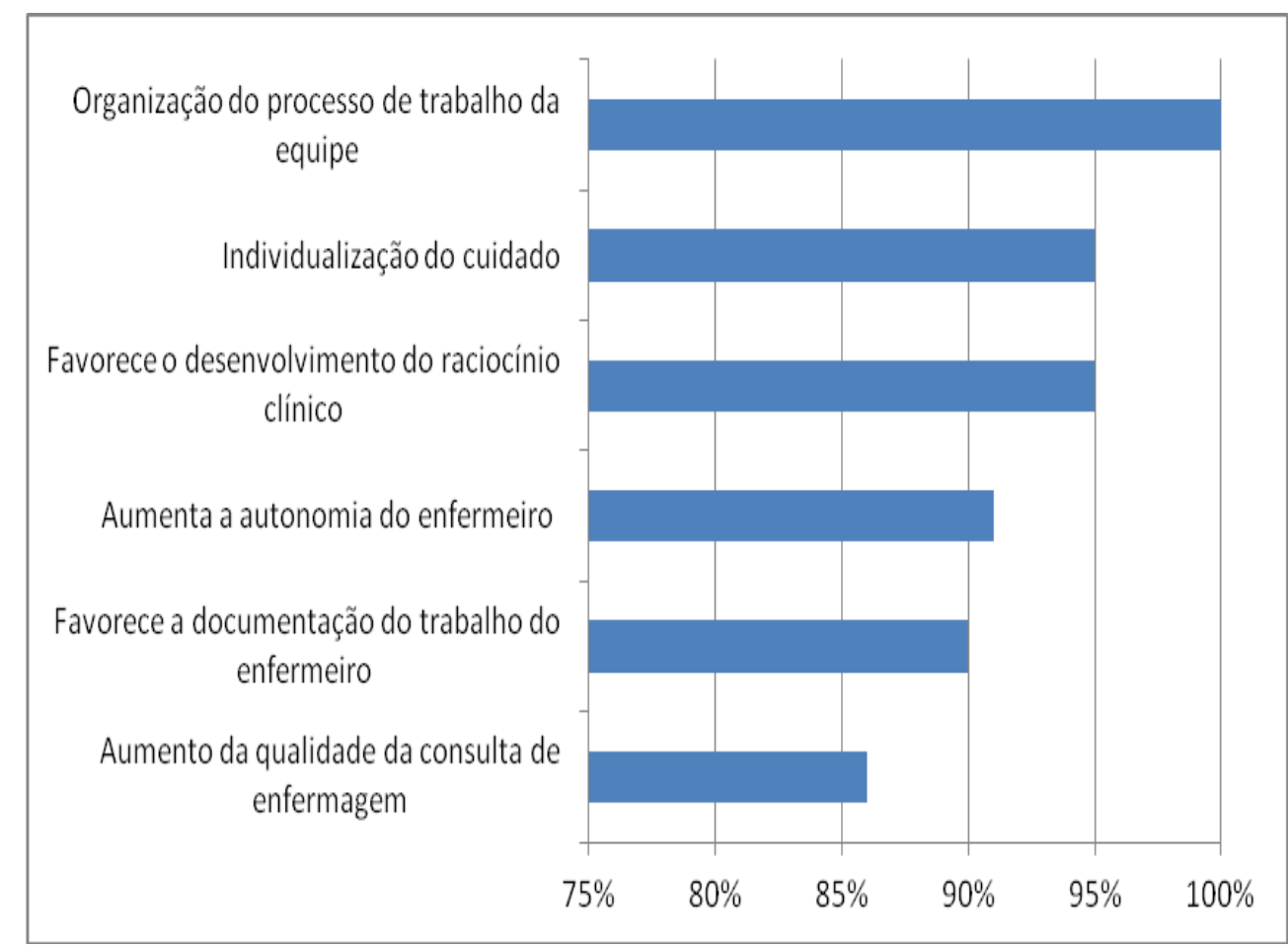

Fonte: elaborado pela autora

Pode-se concluir que a grande maioria da equipe concorda que a SAE e PE pode trazer vários benefícios para equipe e paciente, entre eles: aumenta a qualidade da consulta de enfermagem; favorece a documentação do trabalho do enfermeiro; favorece o raciocínio clínico do enfermeiro; aumenta a autonomia do enfermeiro em seu processo de trabalho; traz benefício para o paciente através da individualização do cuidado e traz benefício para a equipe, pois possibilita a organização do processo de trabalho.

\subsubsection{Domínio 5 - Sua percepção sobre o que poderia facilitar a implementação da SAE e realização do PE na sua unidade.}

A Figura 10 mostra os fatores que poderiam facilitar a implantação da SAE e PE na unidade, segundo a percepção da equipe de enfermagem. As porcentagens referem-se às respostas concordo plenamente e concordo parcialmente. 
Figura 10 - Percentual de concordância (respostas concordo totalmente e concordo parcialmente) dos fatores que podem facilitar a implantação da SAE $\mathrm{PE}$, segundo a percepção da equipe de enfermagem

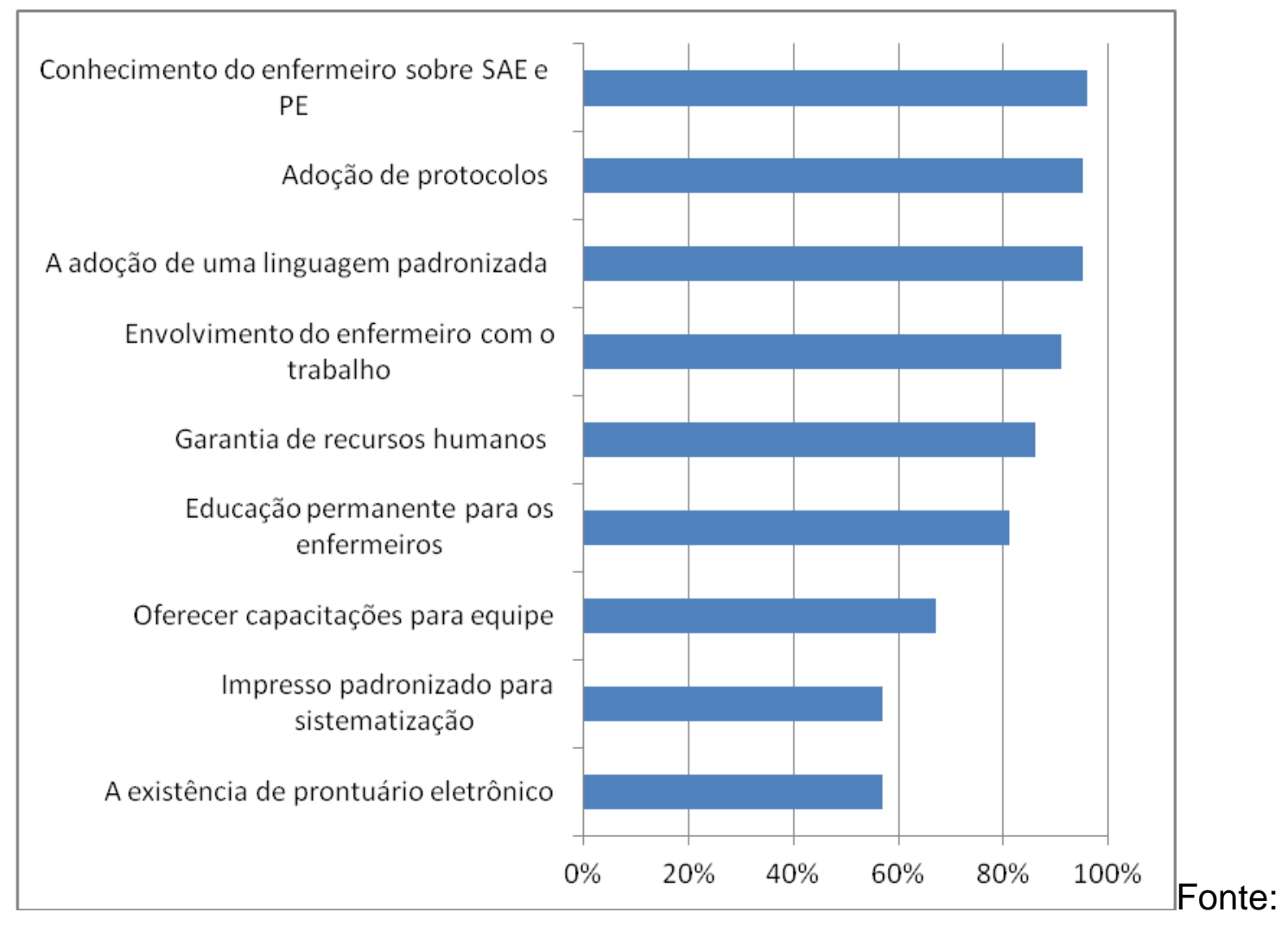

Fonte: elaborado pela autora

A análise dos dados mostrou que a maioria da equipe concordou que os elementos citados no questionário podem favorecer a implantação da SAE e PE. De acordo com a percepção dos mesmos, a adoção de protocolos e o fato de 0 enfermeiro ter conhecimento sobre SAE e PE facilita a implantação da SAE e PE. Além disso, concordam que oferecer capacitação para equipe ajuda na efetivação da SAE.

Sobre o PE, a maior parte dos participantes concorda que a elaboração de um impresso com diagnósticos e prescrições de enfermagem poderia facilitar sua implantação e acreditam que a adoção de uma linguagem padronizada facilitaria a sua aplicação. De forma geral, a equipe de enfermagem acha que quando o enfermeiro é envolvido com o trabalho, facilita a implementação da SAE/PE. 
Outros elementos que poderiam facilitar a implantação da SAE e PE que apareceram com um grau de concordância um pouco menor na percepção da equipe de enfermagem foram: adoção de prontuário eletrônico; educação permanente para os enfermeiros; garantia de recursos humanos em número adequado ao preconizado pelo Ministério da Saúde.

\subsubsection{Domínio 6 - Sua percepção sobre o que ocorre na sua unidade.}

Nesse domínio buscamos analisar a percepção da equipe de enfermagem sobre como é realizada a SAE e PE na Unidade Básica de Saúde de estudo, a fim de conhecer a realidade atual. Os resultados demonstram são mostrados na Figura 11.

Figura 11 - Distribuição das respostas das questões sobre como é realizado a SAE e PE na unidade, segundo a percepção da equipe de enfermagem. Campinas, 2015.

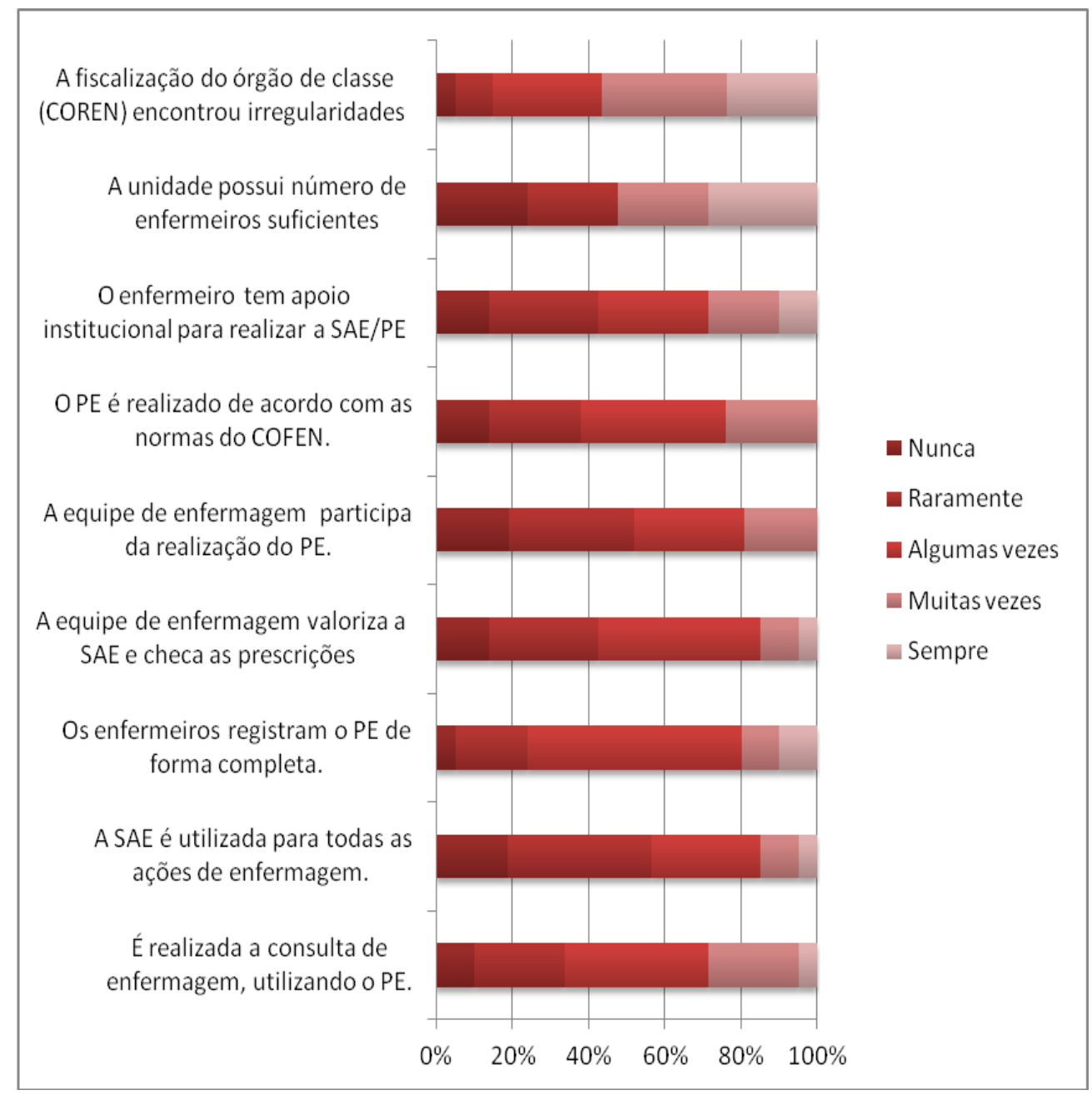

Fonte: elaborado pela autora 
No que concerne à realização de consultas de enfermagem utilizando o PE, a soma dos critérios às vezes (38\%), raramente (24\%) e nunca (10\%) tem como resultado $71 \%$.

Em relação ao uso da SAE para todas as ações de enfermagem: 19\% acham que nunca é usada, 38\% acham que raramente e $29 \%$ responderam algumas vezes, sendo que a soma desses critérios é igual a $86 \%$.

Quando perguntados se os enfermeiros registram o PE no prontuário do paciente de forma completa, $57 \%$ dos entrevistados acreditam que é registrado de forma completa algumas vezes, 19\% responderam que raramente, 5\% nunca, sendo que a somatória desses itens equivale a $81 \%$.

Sobre a valorização da SAE pela equipe e checagem das prescrições de enfermagem, $43 \%$ dos participantes acreditam que algumas vezes a equipe valoriza a SAE e checa a prescrição de enfermagem, 29\% afirmam que raramente isso acontece e 14\% acha que nunca acontece. Somando-se esses critérios temos o resultado de $86 \%$.

Quanto à participação da equipe de enfermagem da unidade na realização do PE. A soma dos critérios algumas vezes (29\%), raramente (33\%) e nunca (19\%) tem como resultado $81 \%$.

Nenhum participante da pesquisa acha que o PE sempre é realizado de acordo com as normas do COFEN. Entre os participantes 14\% acham que nunca é realizado o PE de acordo com as normas do COFEN, 24\% acha que raramente, $38 \%$ responderam algumas vezes, sendo que a somatória desses itens equivale a $76 \%$.

No que diz respeito ao apoio institucional para a realização da SAE e PE, $71 \%$ da equipe acredita que o enfermeiro não tem apoio institucional para realizar a SAE/PE na unidade na maioria das vezes.

Ao discutir a questão "A unidade possui número de enfermeiros suficientes para realização da SAE/PE", percebemos o quanto é controverso a percepção de qual é número de enfermeiros suficientes para a realização da SAE e PE. A opinião da própria equipe varia em relação a esse tema. Sendo que pouco mais da metade (52\%) acredita que há número suficiente muitas vezes e sempre. Entretanto, 24\% acreditam que nunca há número de enfermeiros suficientes para a realização da SAE e PE, $24 \%$ acham que raramente. 
A equipe em sua maioria mostra conhecimento da ocorrência de fiscalização do órgão de classe (COREN) com achados de irregularidades na execução da SAE e PE na unidade.

\subsubsection{Domínio 7 - Sua percepção quanto a sua atuação profissional individual em relação ao $\mathrm{PE}$}

Nesse domínio há algumas questões que foram direcionadas à categoria profissional, tendo em vista que há algumas fases do processo de enfermagem que são privativas do enfermeiro. Portanto, analisamos as respostas dos enfermeiros separadamente das demais, tendo em vista que o enfermeiro tem maior responsabilidade para realização do $\mathrm{PE}$.

Através da análise das respostas dos enfermeiros, podemos perceber que 0 processo de enfermagem ainda é incipiente na unidade. Sendo que as fases não são realizadas sistematicamente. Os resultados são apresentados na Figura 12.

Figura 12 - Percepção dos enfermeiros quanto sua atuação profissional individual em relação ao PE. Campinas, 2015.

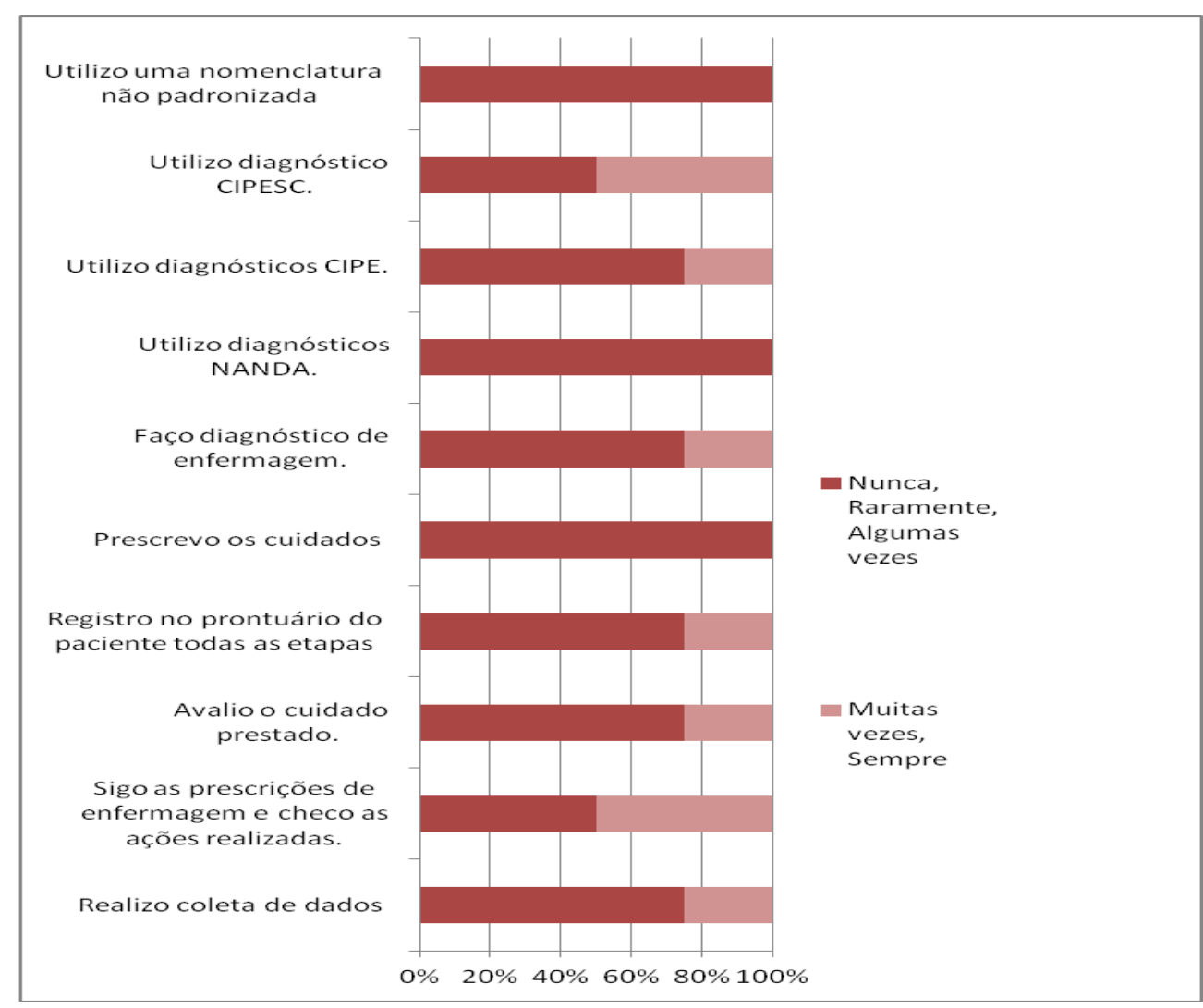

Fonte: elaborado pela autora 
Em relação às fases do processo de enfermagem os enfermeiros afirmam que realizam as ações com as seguintes frequências:

- Coleta de dados- um enfermeiro (25\%) respondeu que raramente faz a coleta de dados de enfermagem, dois enfermeiros $(50 \%)$ responderam algumas vezes e um enfermeiro (25\%) respondeu que realiza muitas vezes.

- Sigo as prescrições de enfermagem e checo as ações realizadas- dois enfermeiros $(50 \%)$ responderam raramente seguem prescrição de enfermagem e dois enfermeiros $(50 \%)$ responderam que seguem as prescrições e checam muitas vezes.

- Avalio o cuidado prestado- dois enfermeiros (50\%) responderam que raramente avaliam o cuidado prestado, um enfermeiro (25\%) afirmou que avalia algumas vezes e um enfermeiro (25\%) respondeu que avalia muitas vezes.

- Registro as etapas que executo- dois enfermeiros (50\%) responderam raramente registram as etapas que executam, um enfermeiro (25\%) respondeu que registra algumas vezes e um enfermeiro (25\%) respondeu muitas vezes.

Nas etapas privativas do enfermeiro obtivemos os seguintes resultados:

- Prescrevo os cuidados de enfermagem- um enfermeiro (25\%) respondeu que raramente faz prescrições de enfermagem e três enfermeiros (75\%) afirmam que prescrevem algumas vezes.

- Prescrevo os cuidados de enfermagem- um enfermeiro (25\%) respondeu que raramente faz prescrições de enfermagem e três enfermeiros (75\%) afirmam que prescrevem algumas vezes.

- Faço diagnóstico de enfermagem- um enfermeiro (25\%) afirma que raramente faz diagnóstico de enfermagem, dois enfermeiros (50\%) responderam que fazem diagnóstico algumas vezes e um enfermeiro (25\%) respondeu muitas vezes.

Em relação à nomenclatura utilizada, percebe-se que não há padronização. Os profissionais afirmam que utilizam NANDA, CIPE, CIPESC e até diagnósticos não padronizados. A nomenclatura que aparece ser utilizada com mais frequência é a CIPE em que um enfermeiro (25\%) afirma que sempre usa e a CIPESC em que 
dois $(50 \%)$ dos enfermeiros afirmam que sempre usam. Além disso, dois enfermeiros (50\%) afirmam que às vezes utiliza nomenclatura não padronizada.

É interessante que os resultados encontrados por meio da análise das respostas dos auxiliares e técnicos de enfermagem são bem diferentes dos enfermeiros. A análise mostra que na percepção dos auxiliares de enfermagem, a maior parte dos participantes, acha que realiza as partes que the cabe no processo de enfermagem na maioria das vezes. Os resultados de cada fase do processo são mostrados na Figura 13 para melhor visualização:

Figura 13 - Percepção dos auxiliares e técnicos de enfermagem quanto sua atuação profissional individual em relação ao PE. Campinas, 2015.

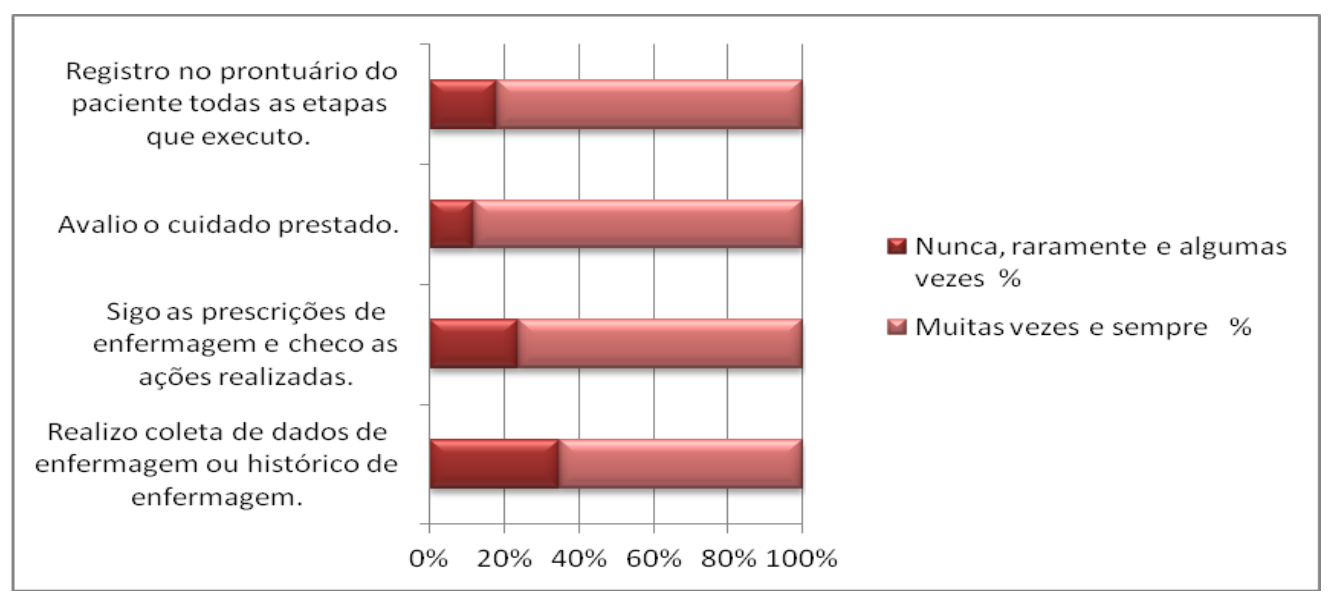

Fonte: Fonte: elaborado pela autora. $\mathrm{N}=17$

- Coleta de dados- um dos profissionais de enfermagem de nível médio (6\%) afirmou que nunca faz coleta de dados de enfermagem, dois (11\%) afirmaram que raramente executam esse passo do processo de enfermagem, três (18\%) afirmaram que realizam algumas vezes, quatro (24\%) referem que fazem muitas vezes e sete $(41 \%)$ referem que sempre realizam coleta de dados de enfermagem. Sendo que a somatória das respostas "muitas vezes" e "sempre" equivalem a $65 \%$.

- Sigo as prescrições de enfermagem e checo as ações realizadas- um dos profissionais de enfermagem de nível médio (6\%) afirmou que nunca segue as prescrições, um (6\%) afirmou que raramente, dois (11\%) afirmaram que seguem algumas vezes, cinco (29\%) relatam que seguem muitas vezes e oito 
- $(47 \%)$ relatam que sempre seguem e checam as prescrições de enfermagem. Sendo que a somatória dos itens "muitas vezes" e "sempre" é igual a 76\%.

- Avalio o cuidado prestado- um dos profissionais de enfermagem de nível médio (6\%) afirmou que raramente avalia o cuidado prestado, um (6\%) referiu que avalia algumas vezes e oito (47\%) afirmam que avaliam muitas vezes e sete $(41 \%)$ sempre avaliam o cuidado prestado. Somando-se as respostas "muitas vezes" e "sempre", obtemos $88 \%$.

- Registro as etapas que executo- três $(18 \%)$ dos profissionais de enfermagem de nível médio (6\%) afirmaram que algumas vezes registram as etapas que executam, seis $(35 \%)$ responderam que registram muitas vezes e oito $(47 \%)$ referem que sempre registram as etapas que executam. Sendo que a somatória dos critérios "muitas vezes" e "sempre" equivalem a $82 \%$. 
7. DISCUSSÃO 


\section{DISCUSSÃO}

A SAE é uma ferramenta de organização do trabalho que deve ser utilizada pela enfermagem para planejamento e execução do cuidado, além do gerenciamento da assistência da enfermagem (BARBOSA et al, 2012).

Embora a Sistematização da Assistência de Enfermagem tenha sido discutida no Brasil por volta da década de 70 , percebe-se que este tema é bastante atual e que sua implementação ainda é incipiente.

Segundo Garcia e Nóbrega (2000) o PE, ou processo de cuidar em enfermagem, pode ser entendido como um instrumento metodológico que nos possibilita identificar, compreender, descrever, explicar e/ou predizer como nossa clientela responde aos problemas de saúde ou aos processos vitais, possibilitando determinar uma intervenção profissional de enfermagem quando necessário.

Em nossa revisão bibliográfica encontramos poucos artigos relacionando SAE/PE e atenção básica. A maioria dos estudos foi realizada em âmbito hospitalar, mostrando a importância desse estudo voltado para a atenção primária.

\subsection{ETAPA 1- VALIDAÇÃO DO INSTRUMENTO DE COLETA DE DADOS (QUESTIONÁRIO)}

Alexandre e Coluci (2009) afirmam que um instrumento é considerado válido quando ele consegue avaliar realmente seu objetivo. Entre as estratégias para validação, pode-se utilizar a verificação da validade de conteúdo.

Segundo os mesmos autores, para avaliar o instrumento como um todo, não existe um consenso na literatura. Entretanto para verificar a validade de novos instrumentos de uma forma geral, alguns autores sugerem uma concordância mínima de 0,80 . Portanto pode-se concluir que o objetivo de validar o questionário em nosso estudo foi atingido, pois o instrumento como um todo alcançou IVC de 0,81 de concordância quanto ao critério de pertinência e IVC de 0,97 quanto ao critério de clareza.

Além disso, os avaliadores julgaram o instrumento coerente e com potencial para ser aplicado em outras unidades e contribuir para estudos futuros.

Como ponto negativo, alguns especialistas julgaram que o questionário é extenso, podendo dificultar a aplicação do mesmo. 
Durante o processo de lapidação do questionário um importante ponto identificado foi a dubiedade de conceitos relacionados à SAE e PE. Este fato pode ser explicado pela falta de consenso na própria literatura nacional, o que foi revelado pela revisão bibliográfica realizada pela autora para a construção do questionário. Essa divergência conceitual também foi verificada nos comentários dos próprios juízes, que não demonstraram consenso em algumas considerações apresentadas. Como, por exemplo, na mesma frase enquanto um juiz considerava que se tratava de SAE, outro julgava que poderia se aplicar tanto a SAE como a PE.

O estudo de Argenta (2011) fomenta essa questão. As autoras concluíram que as Instituições de Ensino Superior não tem clareza sobre os conceitos de SAE e $\mathrm{PE}$, existindo uma confusão conceitual que é encontrada também na literatura. Esse fato mostra o quanto precisamos avançar nesse tema, sendo importante a realização de um amplo debate nacional para o ajuste de terminologia.

Não encontramos questionário semelhante na literatura voltado para atenção básica. Acreditamos que o questionário validado pode contribuir para realização do diagnóstico situacional da SAE em outras unidades básicas de saúde.

\subsection{ETAPA 2- DIAGNÓSTICO SITUACIONAL DA SAE DE UMA UNIDADE BÁSICA DE SAÚDE DE CAMPINAS-SP}

\subsubsection{Caracterização dos participantes}

A equipe de enfermagem da unidade é uma equipe predominantemente feminina, condizente com o perfil da equipe de enfermagem em São Paulo onde 83,3\% são mulheres (COFEN, 2015).

Os membros da equipe têm mais de 30 anos, sendo a média de idade de 47 anos. A maioria da equipe possuiu mais de 10 anos de instituição, o que permite inferir que possuem relativa experiência. Outro fato importante é que mais de $60 \%$ da equipe possuiu mais de 10 anos de formação, esse fato é importante, pois a SAE e PE são assuntos que só foram inseridos na formação profissional de forma mais completa recentemente.

Quanto à qualificação profissional, $10 \%$ da equipe atuam em funções de nível médio, mas possui graduação ou pós-graduação. Esse resultado está de acordo com o perfil de São Paulo, pois segundo o COFEN (2015) mais de 1/3, ou seja, 
$37,9 \%$ de todo o contingente trabalhadores de nível médio (técnicos e auxiliares), fizeram ou estão fazendo curso de graduação.

\subsubsection{Domínio 1 - Percepção sobre Sistematização da Assistência de enfermagem (SAE) e Processo de Enfermagem (PE)}

De acordo com Garcia e Nóbrega (2009), a prática de enfermagem na maioria das vezes não é sistematizada. Segundo estas autoras nas publicações nacionais da área dos últimos dez anos, identificou-se que termos como Consulta de Enfermagem, Metodologia da Assistência de Enfermagem, Metodologia do Cuidado em Enfermagem, Planejamento da Assistência de Enfermagem, Processo de Assistência de Enfermagem, Processo de Atenção em Enfermagem, Processo de Cuidar em Enfermagem, Processo de enfermagem e Processo do Cuidado de Enfermagem são utilizados com traços semânticos distintos, semelhantes ou associados. Para as autoras, atualmente os termos começam a ser entendidos como termos distintos, sendo que a SAE organiza as condições necessárias à sua realização e o Processo de Enfermagem, define as necessidades, direciona 0 cuidado e documenta os resultados obtidos com as intervenções executadas. Sendo assim, a SAE é mais ampla que PE.

Nesse tópico, que trata de conceitos relacionados à SAE e PE, uma parcela importante dos entrevistados assinalou a opção "estou em dúvida" nas questões de 1 a 6 . Esse tipo de resposta pode indicar que o respondente não sabe ou não tem experiência sobre $o$ assunto, tendo dificuldade para se posicionar. Inclusive chama atenção o fato de que boa parte dos participantes demonstraram dúvidas se sabem o que é SAE e PE.

Acreditamos que a dificuldade de posicionamento em relação aos conceitos pode ser influenciada pela falta de consenso na própria literatura como explica Fuly, Leite e Lima (2008) em sua pesquisa de revisão bibliográfica sobre a sistematização da assistência de enfermagem. Estes autores verificaram que existem disparidades de conceitos entre os autores e esse fato pode causar desarticulação da teoria com a prática. Além disso, os autores afirmam que atualmente existem muitos profissionais que acreditam na similaridade entre os termos, chegando a confundir vocabulários padronizados para o registro de enfermagem com o próprio processo de enfermagem por assim dizer. 
Outros fatores que podem contribuir para que a equipe não consiga se posicionar diante dessas questões é a não realização da SAE e PE na prática profissional diária e a deficiência na formação profissional.

A falta de conhecimento sobre os aspectos conceituais relacionados à SAE e PE aparece em outros estudos. Souza, Santos e Monteiro (2013) demonstraram em seu estudo em um hospital de ensino que os conhecimentos da equipe de enfermagem, sobre o processo de enfermagem ainda são escassos, necessitando de aprofundamento no tema. Outro estudo realizado com enfermeiros e técnicos de enfermagem em um hospital universitário identificou resultados parecidos. Sendo que $50 \%$ dos participantes do estudo responderam que a PE é sinônimo de SAE, $40 \%$ que não são sinônimos e $10 \%$ não souberam responder. Assim, percebe-se que não há consenso entre profissionais da unidade sobre os aspectos conceituais de PE e SAE (OLIVEIRA et al, 2012).

A maior parte da equipe concordou que a SAE ajuda a tornar a prática de enfermagem visível. Isso é um achado importante, pois Garcia e Nóbrega (2000) afirmam que o descaso com o registro sistemático do diagnóstico, das ações, intervenções e resultados de enfermagem pode resultar, em ausência de visibilidade e de reconhecimento profissional, além de dificuldade de avaliação de sua prática.

Segundo a Resolução 358/2009 a execução do Processo de Enfermagem deve ser registrada formalmente e sistematicamente, contendo um resumo dos dados coletados, os diagnósticos de enfermagem, as ações ou intervenções de enfermagem e os resultados alcançados.

Ainda, de acordo com essa mesma resolução, o Processo de Enfermagem, quando realizado em instituições prestadoras de serviços ambulatoriais de saúde, domicílios, escolas, associações comunitárias, entre outros, corresponde ao usualmente denominado nesses ambientes como Consulta de Enfermagem. Além disso, o Processo de Enfermagem é organizado em cinco etapas inter-relacionadas: Coleta de dados de Enfermagem (ou Histórico de Enfermagem), Diagnóstico de Enfermagem, Planejamento de Enfermagem, Implementação e Avaliação de Enfermagem (COFEN, 2009). Entretanto, as fases e números de etapas do processo de enfermagem podem variar de acordo com referencial teórico, podendo causar dificuldade de entendimento. 
Sobre a participação de auxiliares e técnicos no processo de enfermagem, as respostas da equipe não foram homogêneas. Percebemos que esse achado coerente com os demais, pois se as pessoas não têm certeza se sabem sobre o PE e SAE, logo é esperado que tivessem dúvidas sobre a quem cabe qual papel.

Essas dúvidas sobre a competência dos auxiliares e técnicos de enfermagem na execução do PE podem estar relacionadas ao fato de que as resoluções existentes não deixam clara a parte que cabe a esses profissionais no processo. Segundo a resolução COFEN 358/2009: "O Técnico de Enfermagem e o Auxiliar de Enfermagem, em conformidade com o disposto na Lei oㅜ 7.498, de 25 de junho de 1986, e do Decreto 94.406, de 08 de junho de 1987, que a regulamenta, participam da execução do Processo de Enfermagem, naquilo que Ihes couber, sob a supervisão e orientação do Enfermeiro". Sendo assim, a legislação possibilita múltiplos entendimentos.

Um estudo realizado em um hospital escola reforça essa associação, pois analisando a opinião de auxiliares e técnicos de enfermagem concluiu-se que a participação dos auxiliares e técnicos de enfermagem nesta metodologia ainda é obscura, pois os mesmos não percebem suas atribuições. Os autores atribuem o fato à compreensão dúbia da legislação, evidenciando necessidade da inclusão deste tema na grade curricular dos cursos de auxiliares e técnicos de enfermagem, para que se possa esclarecer as atribuições e responsabilidades de cada membro da equipe de enfermagem (RAMOS, CARVALHO; CARNINI, 2009).

Podemos concluir através do domínio analisado que entre as dez questões conceituais analisadas, a equipe concordou com seis. Sendo assim percebemos que a equipe possui um entendimento razoável sobre SAE e PE, apesar de grande parte da equipe não estar convicta de que possui conhecimento suficiente sobre esse tema. Os entrevistados também manifestaram muitas dúvidas e conflitos de entendimento sobre os conceitos. Assim sendo, vale salientar a necessidade de aprofundamento sobre esse tema, através de capacitações e educação permanente, principalmente para os enfermeiros. É importante fomentar discussões que favoreça o alcance de um consenso brasileiro sobre conceitos de SAE e PE. 


\subsubsection{Domínio 2 - Percepção sobre capacitação sobre SAE e PE}

Nesse domínio, os resultados mostram que uma grande parcela dos participantes da pesquisa consideram que a formação acadêmica e cursos técnicos e auxiliares não preparam o profissional para prática. Isso se deve ao fato de que ainda existe uma lacuna entre ensino e a prática do profissional de enfermagem. SILVA C. et al (2011) realizou uma pesquisa em um hospital universitário no sul do Brasil, onde foram entrevistados professores e alunos de enfermagem. $O$ trabalho concluiu que existem dicotomias no ensino da SAE e mostrou a necessidade permanente de capacitação do corpo docente e da utilização de metodologias de ensino que articulem teoria e prática visando instrumentalizar os futuros enfermeiros para a utilização deste instrumento de trabalho. Estes autores consideram que conhecimento insuficiente acerca da SAE é uma barreira para a implantação, adesão e execução desta nas instituições de saúde.

Além disso, os resultados apontam necessidade de estruturar uma parceria academia-serviço para desenvolver projetos de formação de pessoal que atenda às necessidades das exigências atuais do exercício da profissão.

Isso converge com os resultados de outros estudos, como, por exemplo, um estudo realizado sob a ótica dos docentes de enfermagem que mostra que apesar da mudança da diretriz curricular, o ensino da enfermagem continua desarticulado e o processo de enfermagem é ensinado de forma fragmentada (AMORIM, 2009).

Em outro estudo, docentes apontaram como razões para dificuldade de ensino do PE o fato de algumas instituições de saúde envolvidas no processo de formação não terem, ainda, uma assistência sistematizada, dificultando o ensino na prática assistencial (TRIGUEIRO, 2013).

Os enfermeiros, por unanimidade, acham que a formação acadêmica não prepara para realização da SAE/PE no contexto da atenção primária. Acreditamos que isso envolve a expectativa na formação do enfermeiro, pois o mesmo precisa adquirir habilidades mais complexas para o exercício pleno da SAE/PE, portanto não é suficiente fazer uma abordagem superficial. É preciso associar o processo de formação com a prática para que o enfermeiro saia da graduação com conhecimentos suficientes para implantação da SAE e aplicação de todas as fases do PE na prática profissional, não só a nível hospitalar, como também na atenção primária em que a implantação da SAE mostra-se ainda mais incipiente. 
TAKAHASHI et al (2008) em um estudo em um hospital de ensino concluíram apesar da maioria das enfermeiras referirem ter aprendido e executado as fases do processo de enfermagem na graduação, as dificuldades na prática são expressivas. Fato que demonstra a insuficiência do preparo teórico e prático para a sistematização da assistência de enfermagem.

Sobre esse domínio é importante a reflexão dos autores GRANDO e ZUSE (2014):

"A quase inexpressiva participação da academia no preparo dos profissionais enfermeiros lançados no mercado de trabalho é um fator que merece atenção por parte dos órgãos de classe, pois, como esperar dos profissionais enfermeiros que após a conclusão de sua formação acadêmica, estejam aptos para pôr em prática todo o seu saber teórico, se na sua base formativa a SAE não esteve presente, ou se esteve, foi de forma ineficiente?"

No tocante a formação de auxiliares e técnicos, percebe-se que de alguma forma, os técnicos e auxiliares acreditam que este assunto é abordado durante a formação dos profissionais. Supomos que a expectativa em relação à abordagem deste assunto no âmbito do ensino médio seja menor, já que as habilidades exigidas são mais limitadas e as etapas a serem cumpridas pelo nível médio no que se refere a SAE/PE possuem menor complexidade.

Entretanto, um estudo que buscou a perspectiva do técnico de enfermagem que atua em hospital universitário e encontrou resultados que sugerem que existem lacunas, na sua formação inicial e ao longo da sua trajetória profissional, sobre a concepção da SAE, dificultando seu entendimento e valorização (CRUZ; ALMEIDA, 2010).

A equipe de enfermagem aponta a educação permanente como facilitador para implementação da SAE. Fato que também apareceu em um estudo em Belo horizonte, em uma unidade de internação, em que os participantes destacaram a necessidade de educação permanente para a efetiva implantação da SAE (OLIVEIRA et al, 2012).

A Política Nacional de Educação Permanente em Saúde propõe que o enfoque da Educação Permanente represente uma importante mudança na concepção e nas práticas de capacitação dos trabalhadores dos serviços. A intenção é integrar o ensino e o aprendizado ao cotidiano das organizações, problematizando 
o próprio fazer e fazendo com que as pessoas reflitam sua prática, sendo construtores do conhecimento e não apenas receptores (BRASIL, 2009). Portanto, acreditamos que esse modelo de educação permanente será realmente facilitador para implantação da SAE, julgando que a equipe dessa unidade de saúde possui muitos anos de experiência e a melhor capacitação será a que considere os saberes prévios dos profissionais.

Pouco mais da metade dos profissionais de enfermagem consideram que possuem conhecimento suficiente para a realização da SAE e PE. Em relação aos profissionais de nível médio, um estudo encontrou resultado semelhante evidenciando que a maioria dos auxiliares e técnicos não se considera em condições de participar das atividades das diferentes fases da SAE e não tem autonomia legal para desenvolvê-las (RAMOS; CARVALHO; CANINI, 2009).

Já em relação aos enfermeiros, um trabalho analisou o conhecimento dos enfermeiros sobre a Sistematização da Assistência de Enfermagem (SAE) em um hospital de grande porte em Recife, Pernambuco. Verificou-se que 50 (69\%) não tinham conhecimentos sobre a SAE e especialmente sobre os diagnósticos de enfermagem (SILVA, E. et al, 2011).

Portanto, conclui-se que é necessário rever as metodologias de ensino da SAE e PE na formação dos profissionais, de forma a articular com a prática, preparando o aluno para vida profissional e cumprimento dessa exigência legal. Além disso, as instituições de saúde devem oferecer espaços de discussão e capacitação para aprimoramento dessa metodologia.

\subsubsection{Domínio 3- Percepção sobre as dificuldades na implementação da SAE e realização do PE na sua unidade}

A equipe de enfermagem identificou como principais desafios para implementação da SAE e PE problemas institucionais como: a pressão da demanda, com excesso de pacientes; falta de capacitação por parte da instituição; as interrupções por parte da equipe no momento da consulta de enfermagem; falta de estrutura da instituição e a indefinição do papel do enfermeiro na atenção básica.

Outro desafio apontado é a desvalorização da consulta de enfermagem pela população, entretanto talvez isso esteja relacionado ao modelo médico hegemônico que perdura historicamente na unidade. 
Esse resultado concorda com outros estudos, entre eles um que captou de forma qualitativa, utilizando um questionário semiestruturado, a percepção dos enfermeiros da atenção básica do município de Belo Horizonte que apontam alguns desafios que dificultam a sua efetivação da SAE como: a grande demanda de usuários que é maior que o preconizado para cada equipe; pouco tempo para o atendimento dos pacientes, a sobrecarga de trabalho e ausência de educação permanente (SANTANA et al, 2013). Ao que parece, algumas barreiras são simulares em ambiente hospitalar, pois em outro estudo, em um hospital de grande porte, os enfermeiros citaram como principais razões para não trabalharem com a SAE: a sobrecarga de trabalho e escassez de formulários (SILVA E. et al, 2011).

CRUZ E CARVALHO (2010) em uma revisão bibliográfica a encontraram autores que destacam como desafios e limitações para efetivação da SAE a estrutura organizacional desfavorável das instituições de saúde, falta de tecnologia de informação, de instrumentos de coleta de dados dos serviços de enfermagem padronizados; carência de pessoal, tanto em relação à quantidade quanto a qualificação.

Um estudo mostrou que na perspectiva dos enfermeiros gerentes de enfermarias uma das maiores dificuldades para a implantação da Sistematização da Assistência de Enfermagem são os recursos humanos. Destacando dentro desse aspecto a resistência para a implementação, a sobrecarga de trabalho, a falta de recursos humanos e a dicotomia entre as funções gerenciais e assistenciais do enfermeiro (PENEDO, SPIRI, 2014).

CARVALHO et al (2007) apontam três categorias de dificuldades para utilização do PE. A primeira está relacionada a fatores inerentes a sua própria estrutura, que é de grande complexidade. Dentro dessa categoria, pode-se citar a falta de uniformidade em cada uma das etapas do processo de Enfermagem e o fato de haver múltiplas abordagens teóricas e diversas taxonomias de classificação da prática, o que dificulta a compreensão por parte dos profissionais. A segunda categoria está relacionada ao cenário de ensino-aprendizagem, pois o ensino do Processo de Enfermagem é recente, predominando a abordagem em disciplinas isoladas e não há padronização do ensino de suas etapas. A terceira categoria refere-se ao no cenário da prática assistencial que muitas vezes tem um modelo de 
assistência médico-centrado, aliada à precarização do trabalho, estrutura inadequada e ao número insuficiente de enfermeiros.

Percebe-se que os desafios apontados com maior relevância pela equipe de enfermagem estão relacionados à falta estrutura e organização da instituição, além do não investimento para melhores condições de trabalho e capacitações para os profissionais. Acreditamos que o próprio modelo híbrido adotado em Campinas para atenção básica pode interferir na efetivação da SAE, uma vez que a falta de uma definição clara do papel do enfermeiro dificulta a organização e padronização do processo de trabalho.

A falta de compromisso das instituições de saúde com o desenvolvimento dos seus recursos humanos, aliado a condições precárias de trabalho, aumenta o nível de incertezas no cotidiano da prática de Enfermagem e é um grande obstáculo para efetivação da SAE. Nesse sentido, é preciso revolucionar o modelo de gestão destas instituições, inicialmente é necessária a revisão das atividades desenvolvidas pelo enfermeiro, definindo suas prioridades e competências. Além de investimentos que assegurem melhores condições de trabalho (CARVALHO et al, 2007).

Segundo Menezes; Priel e Pereira (2001) que em sua revisão bibliográfica concluíram que os artigos analisados apontam que em instituições onde as condições de trabalho são precárias, com falta de infraestrutura e de pessoal há dificuldades na implantação da SAE. Pode-se afirmar que a estrutura e a cultura organizacional da instituição influenciam os resultados da aplicabilidade da SAE. Dessa forma, é importante que a gerência de enfermagem demonstre seu real interesse em dar viabilidade ao processo, estabelecendo estrutura organizacional, missão, filosofia e objetivos do serviço, liderando a implantação dessa metodologia.

Além disso, a falta de definição de uma teoria de enfermagem e a não padronização de uma nomenclatura são importantes desafios para o avanço dessa metodologia de trabalho. Carvalho et al (2007) aponta a importância do estabelecimento de normas institucionais envolvendo o uso, o desenvolvimento e indicadores de resultados do Processo de Enfermagem, tais como utilização de taxonomias de classificação da prática, protocolos e instrumentos. 
Em 2014 a coordenação da assistência de enfermagem do município coordenou uma equipe, da qual a autora do presente projeto fez parte, com a missão de elaborar o Manual da Assistência de Enfermagem de Campinas que foi colocado em consulta pública e publicado em 2014. Esse manual começa a discutir SAE e PE de forma incipiente, montando exemplos de PE por linhas de cuidado. Entretanto, a coordenação da enfermagem do município optou por não formalizar uma nomenclatura no manual, justificando da seguinte forma no próprio manual: "A intenção é apenas direcionar e desenvolver o raciocínio clínico e não engessar a Sistematização da assistência de Enfermagem. O enfermeiro tem autonomia para usar a nomenclatura de sua preferência" (CAMPINAS, 2014).

Diante dos desafios apontados percebemos que para implantação efetiva da SAE é preciso primeiramente reconhecer que há diversos fatores que vão desde a estrutura e política da instituição, a liderança de enfermagem, até o conhecimento do profissional sobre o tema. Isto impõe a necessidade de uma força conjunta para sua implementação efetiva, iniciando com investimento em treinamento e educação permanente.

\subsubsection{Domínio 4 - Percepção sobre os benefícios que o uso da SAE e PE podem trazer}

Verificou-se que a maior parte da equipe de enfermagem concorda que a SAE e PE podem trazer vários benefícios para equipe e paciente, convergindo para o que já foi apontado por MENEZES, PRIEL, PEREIRA (2011). De acordo com esses autores, os benefícios associados à prática da SAE são válidos para o paciente, para a profissão e para a instituição. Para o paciente o principal benefício é a assistência individualizada, favorecendo a humanização da assistência. No que tange a profissão, a SAE favorece a autonomia do enfermeiro. Já para a Instituição a mesma possibilita a organização do trabalho da equipe e ajuda alcançar metas de qualidade.

Em uma revisão bibliográfica sobre $\mathrm{SAE}$, os autores mostraram a qualidade como principal vantagem que aparece nos artigos sobre o tema. A SAE possibilita a gestão do processo de qualidade. Através da sistematização alcançamos melhorias para o cuidado, garantindo o atendimento com critérios padronizados e oferecendo meios de avaliação (CRUZ; CARVALHO, 2010). 
Entre as potencialidades identificadas pelos enfermeiros de um hospital público para a aplicação da SAE destaca-se a valorização e reconhecimento da enfermagem profissional e qualificação da assistência de enfermagem. Segundo os participantes, ao estabelecer um método de assistência, consegue-se desenvolver um raciocínio clínico, de modo a estabelecer um plano de cuidados específico para cada paciente, consequentemente ocasionando melhora dos registros de enfermagem no prontuário do paciente (KRAUZER, 2009).

Diante dos possíveis benefícios apontados, faz-se urgente que as instituições de saúde e a equipe de enfermagem busquem formas de superar os obstáculos e alcançar sua implantação efetiva.

\subsubsection{Domínio 5 - Sua percepção sobre o que poderia facilitar a implementação da SAE e realização do PE na sua unidade}

$\mathrm{Na}$ percepção da equipe de enfermagem, a implantação da SAE/PE na unidade poderia ser facilitada pela a adoção de protocolos, capacitação para equipe, o conhecimento do enfermeiro sobre SAE e PE e seu envolvimento com o trabalho. No tocante ao PE, a equipe acredita que a elaboração de um impresso com diagnósticos e prescrições de enfermagem poderia facilitar sua implantação e a adoção de uma linguagem padronizada facilitaria a sua aplicação.

Resultado semelhante foi encontrado em uma revisão bibliográfica onde foram relatados seis fatores facilitadores: capacitação dos profissionais, instrumentos de registro da assistência de enfermagem, modelo de gestão e padronização da linguagem de enfermagem, experiência profissional e adoção de protocolos (BISETTO et al, 2011).

Os fatores facilitadores identificados pela equipe devem ser valorizados pela gestão da instituição e pela coordenação de enfermagem do município, uma vez que podem auxiliar na implantação da SAE na unidade. Como contribuição da formação do Mestrado Profissional na Atenção Básica no SUS, os resultados do presente estudo serão enviados à Coordenação de Enfermagem do município para conhecimento e identificação de possíveis intervenções com vistas a favorecer a efetivação da SAE/PE.

Entretanto, há alguns pontos que podem ser trabalhados pela própria equipe da unidade, destacando-se como ponto fundamental, o oferecimento de educação 
permanente e a elaboração de instrumentos por linha de cuidado, para facilitar a realização do PE. A proposta é fortalecer a autonomia do enfermeiro através de grupos de estudo, criação dos impressos, buscando envolvê-lo ainda mais para a efetivação da SAE e PE.

\subsubsection{Domínio 6 - Sua percepção sobre o que ocorre na sua unidade}

Pode-se concluir pelos achados desse estudo que a SAE e PE não fazem parte da rotina diária da equipe e não há um processo institucional estabelecido que permita a prática de maneira homogênea. O uso dessa metodologia é incipiente, com práticas pontuais e assistemáticas. O fato de que a maioria das respostas dos participantes escolheram respostas "nunca", "raramente" e "algumas vezes" na maioria das questões reforça a irregularidade do processo.

O resultado revela que na concepção da equipe há consultas de enfermagem, mas nem sempre o processo de enfermagem é realizado de forma completa. Segundo POKORSK et al (2009) no Brasil e em outros países vários estudos mostram dificuldades no estabelecimento e utilização do PE, sendo que na prática nem todas as etapas são realizadas de forma sistemáticas.

Em nosso estudo, verificou-se que a SAE não é utilizada para todas as ações de enfermagem na maioria das vezes. Consequentemente, os participantes acreditam que muitas vezes não há valorização da SAE pela equipe, e nem mesmo checagem das prescrições de enfermagem.

Ao que parece não é apenas essa unidade que possui dificuldade para implantação da SAE, conforme o relato a seguir:

"Um trabalho de fiscalização do COREN-SP nas instituições de saúde do Estado, após investimento desse órgão em capacitação dos enfermeiros para a realização da SAE, revela que $65 \%$ das instituições não souberam como implantar a SAE, 38\% estavam em fase de implantação, em 15\% houve relutância e/ou impedimento dos profissionais de saúde e em 10\% houve impedimento por parte da instituição" (HERMIDA E ARAÚJO, 2006).

Além disso, a equipe participa pouco na realização do PE na unidade. Acreditamos que isso se deva ao fato de que não existe uma rotina estabelecida, mas sim práticas isoladas, ainda incompletas. Soma-se o fato de que na realidade 
de formação desses profissionais, estes conhecimentos ainda não estavam incluídos ou não prepararam os profissionais para prática.

RAMOS; CARVALHO; CANINI (2009) salientam que para vencer barreiras da operacionalização da SAE, é necessária a integração das diferentes categorias de enfermagem, respeitadas as exigências legais, a reflexão quanto à finalidade da SAE e a participação de cada um em suas fases. Souza, Santos e Monteiro (2013) afirmam a importância de se englobar todos os membros da equipe de Enfermagem na implementação das etapas do processo de enfermagem, já que esses são responsáveis por grande parte da execução de suas etapas.

É importante salientar que opinião da equipe não apresentou convergência sobre número de enfermeiros suficientes e nem sobre o apoio institucional para a realização da SAE.

Em relação ao número de enfermeiros suficientes, foi realizado 0 dimensionamento da equipe de enfermagem pela responsável técnica da unidade e protocolado na prefeitura de Campinas. De acordo com o cálculo de dimensionamento de pessoal, baseado nas recomendações do COREN-SP (2010), o número de enfermeiros suficientes para a unidade seriam oito enfermeiros. Se levarmos em consideração o preconizado pelo Ministério da Saúde para equipe de saúde da família, de acordo com a população dessa área de cobertura, seria considerado seis o número ideal de enfermeiros. No entanto, no momento há cinco enfermeiros na unidade, o que demonstra que por qualquer critério possuímos déficit de enfermeiros na unidade.

Quanto ao apoio institucional, Hermida e Araújo (2006) referem que a falta de vontade das chefias e da instituição associado à organização institucional burocrática que valoriza apenas o cuidado médico são apontadas como fatores que dificultam a implementação da SAE, sendo assim, é bastante pertinente que se realize amplas discussões no âmbito institucional afim de "vender" a proposta da $\mathrm{SAE}$, antes de se partir para as demais etapas do processo de implantação dessa metodologia.

Diante do exposto fica clara a importância do papel institucional para efetivação da SAE nessa unidade, uma vez que para o uso dessa metodologia dependemos de estrutura física e de recursos humanos suficientes. É necessário interesse institucional pela proposta para sua viabilidade prática com objetivo de 
estabelecer uma rotina, instituir uma nomenclatura única e capacitar os enfermeiros e equipe de enfermagem para a realização do PE de forma completa e sistemática, visando à melhoria da qualidade da assistência.

\subsubsection{Domínio 7 - Sua percepção quanto a sua atuação profissional individual em relação ao $\mathrm{PE}$}

Pelas respostas dos enfermeiros em relação a sua atuação individual, podemos perceber que a utilização do PE não está vinculada à rotina de trabalho na unidade. E quando realizado, é feito de forma assistemática ou incompleta.

Esse resultado converge com outros estudos, como por exemplo: uma pesquisa realizada em um hospital universitário de Campinas identificou-se que o PE não é realizado de forma sistemática, pois os participantes realizam as fases do PE de forma independente, podendo comprometer a qualidade e continuidade dos cuidados (MARTINO et al, 2014). REPETTO; SOUZA (2005) constataram deficiência no cumprimento de algumas fases do processo de enfermagem e na documentação das mesmas em um hospital universitário. Além disso, outro estudo realizado em hospital de ensino demonstrou que as enfermeiras em sua prática profissional possuem dificuldade para executar as fases do processo de enfermagem. Os dados demonstram que o diagnóstico foi a fase em que as enfermeiras sentem mais dificuldades, seguindo-se as fases de evolução e planejamento da assistência (TAKAHASHI et al, 2008).

Já voltado para atenção básica, um estudo em Belo Horizonte notou que os profissionais não colocavam em prática todas as etapas do PE em seu ambiente de trabalho. Os autores relacionaram a não utilização da SAE pelos profissionais ao distanciamento entre o pensar e o fazer, pois há mais preocupação com o atendimento quantitativo à demanda do serviço do que com a qualidade da assistência (SANTANA et AL, 2013).

Em relação a não padronização das nomenclaturas percebemos que essa dificuldade é evidente na área da saúde coletiva, conforme discute o estudo de SENSSULINI, FOSSA (2008). Segundo o autor, no Brasil são poucas as experiências com os diagnósticos de enfermagem na saúde coletiva. Há dificuldades de utilização da terminologia NANDA e o desconhecimento da CIPE/CIPESC pode retardar o processo de implementação do PE nas unidades. 
Já em relação aos auxiliares e técnicos, o resultado é diferente dos enfermeiros, pois os mesmos avaliam que na maioria das vezes realizam as partes que the cabem do processo de enfermagem. Acreditamos que essa percepção pode estar associada ao fato de que geralmente os participantes realizam as funções determinadas pelos enfermeiros, mesmo que verbalmente. Além disso, sua função é determinada pelas atividades desenvolvidas no setor em que estiver alocado a cada dia, sendo bem delimitada. Por exemplo, quando obtém os dados no acolhimento à demanda espontânea, está designado apenas para colher o histórico de enfermagem do paciente, não acumulando outras atribuições ao mesmo tempo. Vale ressaltar que há dúvidas se todos possuem entendimento adequado do que seria realizar essas ações no Processo de Enfermagem, dificultando o julgamento sobre sua atuação profissional em relação ao $\mathrm{PE}$.

Conclui-se através do domínio analisado que os enfermeiros não realizam a SAE e PE de forma sistemática na unidade em questão. Apesar dos fatores dificultadores identificados, relacionados à falta de estrutura da instituição. Faz-se necessário que os enfermeiros reflitam sobre a temática e identifiquem os processos de trabalho que permeiam as suas atividades, buscando adquirir competências e habilidades para desenvolver o cuidado de forma sistematizada, atendendo à legislação vigente e alcançando a autonomia desejada.

\subsubsection{Possíveis desdobramentos do mestrado profissional}

Como a proposta do mestrado profissional é agregar melhorias à prática, a pesquisadora tem intenção de utilizar o diagnóstico situacional para intervir na prática profissional.

Pretende-se utilizar os resultados dessa pesquisa para efetivar a implementação da SAE e PE na unidade, tendo em vista que toda a equipe concorda que a utilização dessa tecnologia de cuidado organiza o processo de trabalho e melhora a qualidade da assistência.

Primeiramente é essencial buscar apoio junto à coordenação de enfermagem do município, tendo em vista que o apoio institucional é essencial para a viabilidade dessa proposta. A intenção é buscar uma ação integrada com gestão da $A B$ para superar os obstáculos e estimular os elementos facilitadores na nossa unidade. Além disso, com o apoio institucional o questionário validado pode ser aplicado em 
outras unidades, para o diagnóstico da SAE na rede e fornecer subsídios para sua efetivação.

É pouco provável que a implantação efetiva da SAE ocorra sem o preparo da equipe de enfermagem, sob o ponto de vista do conhecimento técnico- científico. Portanto, a intenção inicial é oferecer uma proposta de capacitação para toda equipe, uma vez que na percepção dos mesmos é um facilitador para efetivar a SAE e PE. A metodologia para capacitação deve ser guiada pelos princípios da educação permanente, considerando a bagagem dos profissionais.

Outro ponto a ser fortalecido é a integração serviço- ensino, trazendo benefícios para ambas às partes. Já que a parceria com a PUC pode ajudar a capacitar da equipe para a efetivação da SAE e elaboração de instrumentos para realização do PE. Em contrapartida, a instituição com a SAE efetivada, pode contribuir para a para a formação dos futuros profissionais.

Outra proposta que já está em andamento é a confecção de impressos com diagnósticos e intervenções de enfermagem para as diversas linhas de cuidado, para favorecer a realização do PE nas consultas programáticas e nas visitas domiciliares.

Esse estudo buscou identificar as dificuldades da equipe utilização da SAE e PE, tendo em vista auxiliar o enfermeiro a transpor obstáculos institucionais. Todavia, os fatores facilitadores encontrados representam pontos a serem observados para viabilizar a implementação da SAE e servir de subsídios para melhorar a qualidade da assistência de enfermagem. 
8. CONCLUSÕES 


\section{CONCLUSÕES}

Os resultados deste estudo permitem considerar que os objetivos norteadores da pesquisa foram alcançados, já que foi possível a construção e validação um instrumento de diagnóstico situacional para avaliação da Sistematização da Assistência de enfermagem na perspectiva do profissional de enfermagem e realização do diagnóstico situacional da SAE em uma unidade de saúde através da aplicação do mesmo.

O questionário desenvolvido foi validado quanto ao seu conteúdo com IVC de 0,81 de concordância quanto ao critério de pertinência e IVC de 0,97 quanto ao critério de clareza, portanto pode ser indicado também para aplicação em outras unidades.

Embora os participantes apontem a SAE e PE como melhoria da qualidade da assistência, os mesmos ainda não são executados em sua totalidade. Através da análise das respostas da equipe, podemos perceber que o processo de enfermagem ainda é incipiente na unidade, sendo que as fases são realizadas de forma assistemática.

É pertinente ressaltar que a equipe possui entendimento relativo sobre SAE e PE. Os participantes da pesquisa concordam que um dos motivos que dificultam o desenvolvimento da enfermagem como ciência é a falta de uma linguagem universal padronizada para o registro de suas ações. A equipe acredita que a SAE ajuda a tornar a prática de enfermagem visível e auxilia o planejamento e organização da assistência. Além disso, os participantes concordam que o PE tem como objetivo descrever de maneira padronizada a assistência de enfermagem.

Em relação aos dificultadores, a equipe de enfermagem identificou como principais desafios para implementação da $S A E$ e realização do PE fatores institucionais como: a pressão da demanda; falta de capacitação por parte da instituição; as interrupções por parte da equipe no momento da consulta de enfermagem; a desvalorização da consulta de enfermagem pela população; falta de estrutura da instituição e a indefinição do papel do enfermeiro na atenção básica.

Os elementos apontados como facilitadores para implantação da SAE e PE formam: adoção de protocolos; o enfermeiro ter conhecimento; capacitação para equipe; elaboração de um impresso com diagnósticos e prescrições de enfermagem; 
adoção de uma linguagem padronizada e envolvimento do enfermeiro com o trabalho.

O estudo fornece subsídios para implementação da SAE e PE na unidade de estudo, podendo contribuir para melhoria da prática de enfermagem.

Espera-se que os resultados deste estudo possam contribuir para que se repense as práticas organizacionais, assistenciais e docentes. Acreditamos que 0 caminho para valorização da enfermagem é buscando métodos científicos de melhoria da assistência e a SAE pode contribuir nesse processo.

Há que se salientar a necessidade de novos estudos, principalmente voltados para atenção primária. A divulgação de experiências de implantação de SAE pode auxiliar a operacionalização da SAE e a implementação do PE na atenção básica. 
9. REFERÊNCIAS 


\section{REFERÊNCIAS}

ABRANTES, R. M. Sistematização da assistência de enfermagem na ótica de enfermeiros de unidades de terapia intensiva. 2010. Dissertação (Mestrado em Enfermagem) - Centro de Ciências da Saúde, Universidade Federal da Paraíba, João Pessoa.

ALBUQUERQUE, L. M. Percepção das enfermeiras acerca da utilização da base CIPESC ${ }^{\circledR}$ na consulta de enfermagem. 2006. Dissertação (Mestrado em Enfermagem) - Setor de Ciências da Saúde, Universidade Federal do Paraná, Curitiba.

ALBUQUERQUE, L. M.; CUBAS, M. R. Cipescando em Curitiba: construção e implementação da nomenclatura de diagnósticos e intervenções de enfermagem na rede básica de saúde. Curitiba: ABEn, 2005

ALEXANDRE, N.M.C; COLUCI, M.Z.O. Validade de conteúdo nos processos de construção e adaptação de instrumentos de medidas. Ciênc. saúde coletiva v. 16, n. 7 , p. 3061-3068, jul. 2011. Disponível em: < http://www.scielo.br/scielo.php?script=sci arttext\&pid=S141381232011000800006\&lng=en\&nrm=iso $>$. Acesso em: $21 \mathrm{abr}$. 2015.

ALMEIDA, P.V.B.; ZANOLLI, M.L. O papel do pediatra no PSF-Paidéia de Campinas (SP). Ciênc. saúde coletiva v. 16, n. 1, p. 1479-1488, de Agosto 2015. Disponível em: < http://www.scielo.br/scielo.php?script=sci arttext\&pid=S1413$81232011000700083>$. Acesso em: 21 abr. 2015.

ALVES, K. Y. A et al. Vivenciando a classificação internacional de práticas de enfermagem em saúde coletiva: relato de experiência. Esc. Anna Nery v. 17, n. 2, p. $\begin{array}{lll}381-388 \quad \text { jun. } & 2013 . & \text { Disponíve } \\ \text { http://www.scielo.br/scielo.php?script=sci arttext\&pid=S1414- }\end{array}$ 81452013000200025\&lng=en\&nrm=iso >. Acesso em: 4 de agosto 2015.

AMORIM, F. C.M. $O$ ensino do processo de Enfermagem sob a ótica docente. 2009. Dissertação (Mestrado em Enfermagem) - Centro de Ciências da Saúde, Universidade Federal do Piauí, Teresina.

ANDRADE, J. S.; VIEIRA, M. Prática assistencial de enfermagem: problemas, perspectivas e necessidade de sistematização. Rev Bras Enferm, v. 58, n. 3, p. 261-265, 2005. Disponível em: http://www.scielo.br/pdf/reben/v58n3/a02v58n3.pdf . Acesso em: 05 jul. 2015.

ANTUNES, M. J. M.; GUEDES, M. V. C. Integralidade nos processos assistenciais na atenção básica. In: GARCIA, T. R.; EGRY, E. Y. Integralidade da atenção no SUS e sistematização da assistência de enfermagem. Porto Alegre: Artmed,2010, p. 19-28.

ARGENTA, M. I. Congruência entre o ensino da sistematização da assistência 
de enfermagem e o processo de trabalho do enfermeiro. 2011. Tese (Doutorado em enfermagem) - Universidade Federal de Santa Catarina, Florianópolis.

BACHION, M. M.; RAMOS, F. R. S.; ANTUNES, M. J. M. Integralidade das ações de saúde e aplicação de terminologias à sistematização da prática de enfermagem. In: GARCIA, T. R.; EGRY, E. Y. Integralidade da atenção no SUS e sistematização da assistência de enfermagem. Porto Alegre: Artmed, 2010. p. 327-335.

BARBOSA, E. P. et al. Sistematização da assistência de enfermagem em cuidados paliativos na oncologia: visão dos enfermeiros. Pesperctiva, v. 36, n. 133, p. 41-51, mar. 2012. Disponível em: < http://www.uricer.edu.br/site/pdfs/perspectiva/133 249.pdf>. Acesso em 30 de Agosto de 2015.

BARROS, D.G.; CHIESA, A.M. Autonomia e necessidades de saúde na sistematização da assistência de Enfermagem no olhar da saúde coletiva. Rev. esc. enferm. USP, v. 41, n. 1, p. 793-798 , Dezembro de 2007. Disponível em: $<$ http://www.scielo.br/pdf/reeusp/v41nspe/v41nspea08.pdf $>$. Acesso em 18 de jun de 2015.

BISETTO, L. H. L. ; VERBOSKI, B. ; NASCIMENTO, A.K ; COSTA, F. ; MOMBACH, C. B. Fatores facilitadores e dificultadores ä implementação da Sistematização da Assistência de Enfermagem. In: 16 Seminário Nacional de Pesquisa em Enfermagem, 2011, Campo Grande - MS. 16 SENPE: Ciência da Enfermagem em tempos de interdisciplinaridade. Brasília: ABEN - Nacional, 2011. Disponível em: < http://www.abeneventos.com.br/16senpe/senpe-trabalhos/files/0246.pdf >. Acesso em: 24 de maio, 2015

BRASIL. Portaria no 2.488, de 21 de outubro de 2011. Dispõe sobre a aprovação da Política Nacional de Atenção Básica, estabelecendo a revisão de diretrizes e normas para a organização da Atenção Básica, para a Estratégia Saúde da Família (ESF) e o Programa de Agentes Comunitários de Saúde (PACS). Diário Oficial da União, Brasilia, DF, 22 out. $2011 . \quad$ Disponível em:< http://bvsms.saude.gov.br/bvs/saudelegis/gm/2011/prt2488 $21 \quad 10$ 2011.html >.

Acesso em: 24 de maio, 2015.

Brasil. Ministério da Saúde. Secretaria de Atenção à Saúde. Departamento de Atenção Básica. Política nacional de atenção básica / Ministério da Saúde, Secretaria de Atenção à Saúde, Departamento de Atenção à Saúde. - Brasília : Ministério da Saúde, 2006. Disponível em:< http://bvsms.saude.gov.br/bvs/publicacoes/politica nacional atencao basica 2006.p df $>$ Acesso em: 24 de maio, 2015.

BRASIL. Ministério da Saúde, Secretaria de Gestão do Trabalho e da Educação na Saúde, Departamento de Gestão da Educação em Saúde. Política Nacional de Educação Permanente em Saúde. Brasília: Ministério da Saúde, 2009. Disponível em:

$<$ http://bvsms.saude.gov.br/bvs/publicacoes/politica nacional educacao permanent e saude.pdf>. Acesso em: 24 de maio, 2015. 
CAMPINAS (SP). Secretaria Municipal de Saúde. Unidades de saúde. Centros de saúde. 2012. Disponível em: <http://2009.campinas.sp.gov.br/saude/>. Acesso em: 18 nov. 2013.

CAMPINAS (SP). Secretaria Municipal de Saúde. Sistema de informação em saúde - Tabnet ISMS- Campinas. Disponível em: $<$ http://2009.campinas.sp.gov.br/saude/tabnet-home/index.htmf $>$.Acesso em: $12 \mathrm{de}$ dezembro, 2013.

CAMPINAS (SP). Colegiado de Gestão da Secretária Municipal de Saúde. Diretrizes para Atenção Básica à Saúde. Projeto Paidéia de Saúde da Família Campinas/2001. Campinas: $\quad$ SMS, $2001 . \quad$ Disponível em:<http://2009.campinas.sp.gov.br/saude/diretrizes.htm>. Acesso em: 20 novembro, 2013.

CAMPINAS (SP). Secretaria Municipal de saúde de Campinas. Regimento interno de enfermagem. 2014. Disponível em: <http://2009.campinas.sp.gov.br/saude/>. Acesso em: 18 de novembro, 2013.

CAMPINAS (SP). Informações turísticas. 2013. Disponível em: $<$ http://www.campinas.sp.gov.br/sobre-campinas/informacoes-turisticas.php $>$ .Acesso em: 12 de novembro, 2013.

CAMPINAS (SP). Secretaria Municipal de saúde de Campinas. Manual de assistência de enfermagem. 2014. Disponível em: < http://2009.campinas.sp.gov.br/saude/>. Acesso em: 12 de novembro, 2013.

CAMPINAS (SP). Secretaria Municipal de saúde. SUS em Campinas. 2015. Disponível em: <http://www.campinas.sp.gov.br/governo/saude/sus-em-campinas/>. Acesso em: 01 ago. 2015.

CAVALCANTE, R. B. et al. Experiências de sistematização da assistência de enfermagem no Brasil: um estudo bibliográfico. Revista de Enfermagem da UFSM, Santa Maria, v. 1, n. 3, p. 461-471, 2011.Disponível em: $<$ http://cascavel.ufsm.br/revistas/ojs-

2.2.2/index.php/reufsm/article/viewFile/2832/2396>. Acesso em: 15 de março, 2015.

CARVALHO, E. C. et al. Obstáculos para a implementação do processo de enfermagem no Brasil. Rev. enferm. UFPE, online, Recife, v. 1, n. 1, p. 95-99, 2007. Disponível

em: $<$ http://www.researchgate.net/profile/Maria Bachion/publication/47807368 Obstc ulos para a implementao do processo de enfermagem no brasil/links/02bfe511 3b67bcb151000000.pdf>. Acesso em: 4 de julho de 2015.

CONSELHO REGIONAL DE ENFERMAGEM DE SÃO PAULO (COREN-SP). Dimensionamento de pessoal. 2010. Disponível em: http://www.portalcorenrs.gov.br/docs/Dimensionamento/livreto de dimensionamento.pdf. >. Acesso em: 23 de junho, 2015. 
CONSELHO FEDERAL DE ENFERMAGEM. Resolução Cofen nº 358/2009. Dispõe sobre a Sistematização da Assistência de Enfermagem e a implementação do Processo de Enfermagem em ambientes, públicos ou privados, em que ocorre o cuidado profissional de Enfermagem. COFEN, Brasília, DF, 15 out. 2009. Disponível em:<http://www.cofen.gov.br/resoluo-cofen-3582009 4384.html>. Acesso em: 14 de abril de 2015

CONSELHO FEDERAL DE ENFERMAGEM. COFEN lança o Perfil da enfermagem em São Paulo. 2015. Disponível em:< http://www.cofen.gov.br/cofenlanca-perfil-de-enfermagem-em-sao-paulo 33451.html>. Acesso em: 14 de abril de 2015

CONSELHO REGIONAL DE ENFERMAGEM DE MINAS GERAIS (COREN-MG). Unidade de fiscalização. Diagnóstico administrativo/situacional de enfermagem/saúde, subsídios para elaboração. Belo Horizonte, 2010. Disponível em:< http://www.corenmg.gov.br/anexos/modelDiagnosticos.pdf $>$ Acesso em: 15 de março de 2015.

CRUZ, C.S.; CARVALHO, M.R.R.A. Sistematização da Assistência de Enfermagem: evidências de pesquisa e contribuições para o HCPM. Revista de Pesquisa: Cuidado é Fundamental Online, v. 2, n. Suplementar, p. 352-357 , 2010. Disponível em:

http://www.seer.unirio.br/index.php/cuidadofundamental/article/viewArticle/1006>.

Acesso em jun 2015.

CRUZ, A.M.P.; ALMEIDA,M.B. Competências na formação de Técnicos de Enfermagem para implementar a Sistematização da Assistência de Enfermagem. Revista da Escola de Enfermagem da USP, v. 44, n. 4, p. 921-927, dez 2010. Disponível em: < http://www.scielo.br/pdf/reeusp/v44n4/09.pdf>. Acesso em: mar 2015.

CRUZ, D. A. L. M. Processo de enfermagem e classificações. In: GAIDZINSKI, R. R.; SOARES, A. V. N.; LIMA, A. F. C.; GUTIERREZ, B. A. O.; CRUZ, D. A. L. M.; ROGENSKI, N. M. B. Diagnóstico de Enfermagem na prática clínica. Porto Alegre: Artmed, 2008, p. 25-37.

CUBAS, M. et al. Aplicação do inventário vocabular CIPESC CIE ABEn nas unidades básicas de saúde em Curitiba-PR. Integralidade das ações de saúde e aplicação de terminologias à sistematização da prática de enfermagem. In: GARCIA, T. R.; EGRY, E.Y. Integralidade da atenção no SUS e sistematização da assistência de enfermagem. Porto Alegre: Artmed, 2010, p. 318-323.

CUNHA, S.M.B. Análise da implementação da Sistematização da Assistência de Enfermagem, segundo o Modelo Conceitual de Horta. Rev. Bras. Enferm v. 58, n. 5, p. 2005. 200-72 Disponível em: < http://www.scielo.br/pdf/reben/v58n5/a13v58n5.pdf>. Acesso em abr 2014.

DANTAS, C.N. Caracterização das dissertações e teses brasileiras acerca da interface processo de enfermagem e atenção primária. Revista Mineira de Enfermagem v. 18, n. 2, p. 295-309 , 2014. Disponível em: 
http://www.reme.org.br/artigo/detalhes/928>. Acesso em: 14 jun. 2015.

DE BARROS, A. L. B. L.; LOPES, J. A legislação e a sistematização da assistência de enfermagem. Enfermagem em foco v. 1, n. 2, p. 63-65, 2010. Disponível em: < http://revista.portalcofen.gov.br/index.php/enfermagem/article/view/17>. Acesso em: 14 jun. 2015.

FOSCHIERA, F. ; VIERA, C. S. O diagnóstico de enfermagem no contexto das ações de enfermagem: percepção dos enfermeiros docentes e assistenciais. Revista Eletrônica de Enfermagem, v. 6, n. 2, p.189-198, 2004. Disponível em: < http://h200137217135.ufg.br/index.php/fen/article/view/817 $>$. Acesso em: 14 de junho, 2015.

FULY, P.S.C. ; LEITE, J. L. ; LIMA, S.B.S. Correntes de pensamento nacionais sobre sistematização da assistência de enfermagem: revisão. Rev. Bras. Enferm, v. 61, n. 6, p. $\quad$ 883-887, $2008 . \quad$ Disponível em: $<$ http://www.scielo.br/pdf/reben/v61n6/a15v61n6.pdf $>$. Acesso: 15 de agosto, 2015.

GARCIA, T.R.; NÓBREGA, M.M.L. Sistematização da assistência de enfermagem: há acordo sobre o conceito? Rev. Eletr. Enferm, v.11, n.2, p.233, 2009. Disponível em: $<$ http://www.fen.ufg.br/revista/v11/n2/v11n2a01.htm>. Acesso: 15 de agosto, 2015 .

GARCIA, T. R.; NÓBREGA, M. M. L. Sistematização da Assistência de Enfermagem: reflexões sobre o processo. In: CON BRA DE ENF, 52., 2000, Recife/Olinda, PE. 2000. Disponível em:< file:///C:/Users/Usuario/Downloads/sistematizacaodaassistencia.pdf> Acesso em 18 de agosto de 2015.

GIL, A. C. Como delinear uma pesquisa bibliográfica. In: Gil A. C. Como elaborar projetos de pesquisa. São Paulo: Atlas, p. 59-86, 2006.

GOMES, L.A.; BRITO, D. S. Desafios na implantação da sistematização da assistência de enfermagem: uma revisão de literatura. Revista Interdisciplinar UNINOVAFAPI, Teresina, v.5, n.3, p.64-70, 2012. Disponível em: < http://www.novafapi.com.br/sistemas/revistainterdisciplinar/v5n3/rev/rev5 v5n3.pdf $>$. Acesso em: 30 de julho, 2015.

GRANDO, T.; ZUSE, C.L. Dificuldades na implantação da assistência de enfermagem no exercício profissional- Revisão Integrativa. Revista Contexto \& Saúde, v. 14, n. 26, p. 28-35, 2014. Disponível em:< https://www.revistas.unijui.edu.br/index.php/contextoesaude/article/view/2886>.

Acesso em: 12 de agosto, 2015.

HERMIDA, P. M. Desvelando a implementação da sistematização da assistência de enfermagem. Rev bras enferm, v. 57, n. 6, p. 733-7, 2004. Disponível em: < http://www.scielo.br/pdf/reben/v57n6/a21. . Acesso em 15 de julho, 2015. 
HERMIDA, P. M. V.; ARAUJO, I. E. M. Sistematização da assistência de enfermagem: subsísios para implantação. Rev. Bras. Enferm, v. 59, n. 5, p. 675679, set./out. 2006. Disponível em: http://www.scielo.br/pdf/reben/v59n5/v59n5a15.pdf. Acesso em: 10 de agosto, 2015.

KRAUZER, I. M. Sistematização da assistência de enfermagem: um instrumento de trabalho em debate. 2009. Tese (Doutorado em enfermagem). Centro de Ciências da Saúde, Universidade Federal de Santa Catarina, Florianópolis.

LEOPARDI, M. T. Teoria e Metodologia em Assistência de Enfermagem. Florianópolis: Editora Soldasoft, 2006.

LUDOVICO, A. C.D.R. A organização da atenção básica de saúde de Campinas/SP: perspectivas, desafios e dificuldades na visão do trabalhador. 2014. Dissertação (Mestrado em Enfermagem) - Faculdade de Ciências Médicas, Unicamp, Campinas.

MARQUES, D. A trajetória do Programa Saúde da Família em Campinas e a contribuição da enfermagem. 2003. Dissertação (Mestrado em Enfermagem) Faculdade de Ciências Médicas, Unicamp, Campinas.

MARQUES, D.; SILVA, E.M. A enfermagem e o Programa Saúde da Família: uma parceria de sucesso. Rev. Bras. Enferm, Brasília, v. 57, n. 5, p. 545-50, 2004. Disponível em: <http://www.scielo.br/pdf/reben/v57n5/a06v57n5.pdf>. Acesso em 15 de julho, 2015.

MARTINO, M. M. F. et al. ANÁLISE DA APLICAÇÃO DO PROCESSO DE ENFERMAGEM EM UM HOSPITAL GOVERNAMENTAL. Journal of Nursing UFPE/Revista de Enfermagem UFPE, v. 8, n. 5, p. :1247-53, 2014. Disponível em:< http://www.revista.ufpe.br/revistaenfermagem/index.php/revista/article/view/5367/pdf 5061 >. Acesso em 15 de julho, 2015.

MENEZES, S.R.T.; PRIEL, M.R.; PEREIRA, L.L.. Autonomia e vulnerabilidade do enfermeiro na prática da Sistematização da Assistência de Enfermagem. Revista da Escola de Enfermagem da USP, São Paulo, v. 45, n. 4, p. 953-958, 2011. Disponível em: < file:///C:/Users/grasielle/Downloads/40789-48602-1-PB.pdf>. Acesso em: 23 de julho, 2015.

MONTENEGRO, L.C.; BRITO, M.J.M. Aspectos que facilitam ou dificultam a formação do enfermeiro em atendimento primário à saúde. Invest. Educ. Enferm., Antioquia, v.29, n. 2, p.238-47, 2011. Disponível em: < http://aprendeenlinea.udea.edu.co/revistas/index.php/iee/article/view/6425/9195>.

Acesso em: 15 de julho, 2015.

NASCIMENTO, K. C. et al. Sistematização da assistência de enfermagem: vislumbrando um cuidado interativo, complementar e multiprofissional. Revista da Escola de Enfermagem da USP, São Paulo, v. 42, n. 4, p.643-648, dez. 2008. Disponível em: <http://www.scielo.br/pdf/reeusp/v42n4/v42n4a04.pdf>. Acesso em: 28 de maio, 2015. 
NASCIMENTO, E.P.L.; CORREA, C.R.S.; NOZAWA, M.R. . O município de Campinas e a organização da Secretaria Municipal de Saúde. Revista de Ciências Médicas, Campinas, v. 16, n. 3, 2007. Disponível em : http://periodicos.puccampinas.edu.br/seer/index.php/cienciasmedicas/article/view/1059/1035. Acesso em: 13 de junho, 2015.

NEVES, R.S.; R.; SHIMIZUI, H.E. Análise da implementação da Sistematização da Assistência de Enfermagem em uma unidade de reabilitação. Rev. Bras. Enferm., Brasília, v. 63, n. 2, p. 222-229, 2010. Disponível em: < http://www.scielo.br/pdf/reben/v63n2/09 >. Acesso em: 23 de julho, 2015.

NICHIATA, L. Y. I. et al. Classificação Internacional das Práticas de Enfermagem em Saúde Coletiva-CIPESC®: instrumento pedagógico de investigação epidemiológica. Revista da Escola de Enfermagem da USP, São Paulo, v. 46, n. 3, p. 766-771, 2012. Disponível em: < http://www.scielo.br/scielo.php?pid=S008062342012000300032\&script=sci_arttext >. Acesso em: 23 de julho, 2015.

NÓBREGA, M. M. L. et al. Estrutura da CIPE, da NANDA e da NOC. In: Garcia, T.R.; Egry, E. Y. Integralidade da atenção no SUS e Sistematização da Assistência de Enfermagem. Porto Alegre: Artmed, p. 157-171, 2010.

OLIVEIRA et al. Percepção da equipe de enfermagem sobre a implementação do processo de enfermagem em uma unidade de um hospital universitário. Rev. Min. Enferm, Belo Horizonte, v.16, n.2, p.258-263, Abr/Jun, 2012. Disponível em:< http://www.reme.org.br/artigo/detalhes/527ário>. Acesso em 18 de julho, 2015.

PENEDO, R. M.; SPIRI, W. C. Significado da Sistematização da Assistência de Enfermagem para enfermeiros gerentes. Acta Paul Enferm, São Paulo, v. 27, n. 1, p. 86-92, 2014. Disponível em: http://www.scielo.br/pdf/ape/v27n1/pt 0103-2100ape-27-01-00086.pdf. Acesso em: jun 2015.

POLIT, D. F.; BECK, C. T.; HUNGLER, B. P. Fundamentos de pesquisa em enfermagem: métodos, avaliação e utilização. 5. ed. Porto Alegre: Artmed, 2004. $487 \mathrm{p}$.

PRONANDA. Programa de atualização em Diagnósticos de Enfermagem: Conceitos Básicos (organizado pela) NANDA Internacional, Inc. ; organizadora-geral: T.Heather Herdman- Porto Alegre: Artmed (2013): 36

POKORSKI, S. et al . Processo de enfermagem: da literatura à prática. O quê de fato nós estamos fazendo?. Rev. Latino-Am. Enfermagem, Ribeirão Preto, v. 17, n. 3, p. 302-307, Jun $2009 \quad$. $\quad$ Disponível em:< http://www.scielo.br/scielo.php?script=sci arttext\&pid=S0104-

11692009000300004\&lng=en\&nrm=iso >. Acesso em: 26 Jun. 2015.

RAMOS, L.A.R.; CARVALHO, E.C.; CANINI, S.R.M.S. Opinião de auxiliares e técnicos de enfermagem sobre a sistematização da assistência de enfermagem. Rev. Eletr. Enf., Goiânia, v.11, n.1, p.39-44, 2009. Disponível em: 
$<$ https://www.fen.ufg.br/fen revista/v11/n1/pdf/v11n1a05.pdf $>$. Acesso em: 23 de junho, 2015.

REPPETTO, M. A.; SOUZA, M.F.. Avaliação da realização e do registro da sistematização da assistência de enfermagem (SAE) em um hospital universitário. Rev. Bras. Enferm., Brasília, v. 58, n. 3, p. 325-9, 2005. Disponívelem:http://www.scielo.br/pdf/reben/v58n3/a14v58n3.pdf. Acesso em: 15 de agosto de 2015.

SANTANA ET al. Percepção dos enfermeiros acerca da Sistematização da Assistência de Enfermagem na atenção básica de belo horizonte. Enfermagem revista.v.15, n.11, p. 4-16, 2013. Disponível em:< http://periodicos.pucminas.br/index.php/enfermagemrevista/article/view/5281>.

Acesso em: 22 jul. 2015.

SALVADOR, P. T. C. O.; SANTOS, V. E. P.; DANTAS, C. N. Caracterização das dissertações e teses brasileiras acerca da interface processo de enfermagem e atenção primária. Revista Mineira de Enfermagem, v. 18, n. 2, p. 295-309, 2014.Disponível em:< http://www.reme.org.br/artigo/detalhes/928>. Acesso em: 18 jul. 2015.

SILVA, C. C. et al. O ensino da Sistematização da Assistência na perspectiva de professores e alunos. Revista Eletrônica de Enfermagem, v. 13, n. 2, p. 174-81, jun. $2011 . \quad$ Disponível em: $<$ http://www.revistas.ufg.br/index.php/fen/article/view/12390/9618 $>$. Acesso em: 22 Mai. 2015.

SILVA, E. G. C. et al. O conhecimento do enfermeiro sobre a Sistematização da Assistência de Enfermagem: da teoria à prática. Rev Esc Enferm USP, São Paulo, v. 45, n. 6, p. 1380-6, 2011. Disponível em:< www.ee.usp.br/reeusp/>. Acesso em: 18 jul. 2015.

SOUZA, M. F. G.; SANTOS, A. D. B.; MONTEIRO, A. I. O processo de enfermagem na concepção de profissionais de Enfermagem de um hospital de ensino. Rev. Bras. Enferm., Brasília , v. 66, n. 2, p. 167-173, Abr. 2013 . Disponível em: < http://www.scielo.br/scielo.php?script=sci arttext\&pid=S003471672013000200003\&lng=en\&nrm=iso >. Acesso em: 24 Jun 2015.

RUBIO, D. M.; BERG-WEGER, M.; TEBB, S. S.; LEE, E.S.; RAUCH, S. Objectifying content validity: conducting a content validity study in social work research. Soc. Work. Res., Oxford, v. 27, n. 2, p. 94-111, 2003. Disponível em: < http://swr.oxfordjournals.org/content/27/2/94.short>. Acesso em: 24 Jun 2015.

SENSULINI, V.L; FOSSA, A.M. A Sistematização Da Assistência De Enfermagem (SAE): dificuldades e facilidades para sua implantação e operacionalização com gestantes, puérperas e crianças menores de um ano na estratégia saúde da família $16^{\circ}$ Congresso de Iniciação Científica. 2008. FAPIC/UNIMEP. Disponível em:< http://www.unimep.br/phpg/mostraacademica/anais/6mostra/1/426.pdf >. Acesso em: 15 Jun 2015. 
TAKAHASHI, A. A. et al. Dificuldades e facilidades apontadas por enfermeiras de um hospital de ensino na execução do processo de enfermagem. Acta Paul. Enferm., São Paulo, v. 21, n. 1, p. 32-8, 2008. Disponível em: <http://www.scielo.br/pdf/ape/v21n1/pt 04.pdf>. Acesso em: 24 Jul 2015.

TAKEMOTO, M. L. S. O trabalho de enfermagem em centros de saúde e a mudança do modelo de atenção no Município de Campinas-SP. 2005. Dissertação (mestrado em Enfermagem) - Faculdade de Ciências Médicas, Unicamp, Campinas.

TRIGUEIRO, E.V. Ensino do processo de enfermagem: significados e percepção dos docentes na formação do enfermeiro. 2013. Dissertação (mestrado em Enfermagem) - Universidade Federal do Rio Grande do Norte, Natal.

WITTMANN-VIEIRA, R.; GOLDIM, J. R. Bioética e Processo de Enfermagem. In: ALMEIDA, M. A. et al. Processo de enfermagem na prática clínica: estudos clínicos realizados no Hospital de Clínicas de Porto Alegre. Porto Alegre: Artmed, p. 67-75, 2011.

VENTURINI, D. A.; MATSUDA, L. M.; WAIDMAN, M. A. P. Produção científica brasileira sobre sistematização da assistência de enfermagem. Ciênc. Cuid. Saúde., Maringá, v. 8, n. 4, p. 707-715, 2009. Disponível em: < http://periodicos.uem.br/ojs/index.php/CiencCuidSaude/article/viewFile/9710/5408 >. Acesso em: 15 Jul 2015. 
10. APÊNDICES 


\title{
10. APÊNDICES
}

\section{APÊNDICE A}

\section{TERMO DE CONSENTIMENTO LIVRE E ESCLARECIDO}

\author{
Caro participante,
}

Gostaríamos de convidá-lo a participar como voluntário da pesquisa intitulada: "DIAGNÓSTICO SITUACIONAL DA SISTEMATIZAÇÃO DA ASSISTÊNCIA DE ENFERMAGEM NO CENTRO DE SAÚDE INTEGRAÇÃO - CAMPINAS- SP", que se refere a um projeto de mestrado da pesquisadora Grasielle Camisão Ribeiro no Programa de Pós- Graduação: Mestrado profissional em enfermagem em atenção primária no SUS, na Universidade de São Paulo- USP.

Esse estudo tem por objetivo principal realizar um diagnóstico situacional sobre a sistematização da assistência de enfermagem no Centro de Saúde Integração, através da percepção da equipe de enfermagem.

Sua participação, voluntária, será respondendo um questionário, sendo que as informações prestadas são de caráter confidencial e sua identidade será mantida em sigilo, não será utilizado seu nome em nenhuma fase da pesquisa.

Você tem a liberdade de se recusar a participar do estudo e, se aceitar, poderá retirar seu consentimento a qualquer momento, sem a necessidade de apresentar justificativas.

Não será cobrado nada e não haverá gastos com relação a sua participação. Como toda pesquisa não é isenta de risco, pode ocorrer algum desconforto; sendo que a pesquisadora compromete-se a sanar ou minimizar esta ocorrência. Não haverá benefícios imediatos na sua participação no estudo, porém o benefício esperado é a contribuição para o conhecimento da ciência e potenciais melhorias nas práticas de enfermagem. O estudo contribuirá com a obtenção de um questionário validado que poderá ser usado por outras unidades para diagnóstico da Sistematização da Assistência de Enfermagem nos serviços e identificação de elementos que apoiem a implantação e a efetivação da SAE na unidade do estudo.

O questionário será respondido em seu horário de trabalho e levará cerca de 30 minutos para sua aplicação.

O estudo foi aprovado pelo Comitê de ética e pesquisa da Escola de Enfermagem da USP.

Você ficará com uma via desse termo e em caso de dúvidas, a pesquisadora está disponível para prestar quaisquer informações a respeito do trabalho, no momento que se fizer necessário.

Eu, li o texto acima e compreendi a natureza e o objetivo do estudo para o qual fui convidado (a).

Compreendi que a minha participação - voluntária, confidencial e que posso desistir em qualquer tempo, sem que isso signifique qualquer tipo de prejuízo para minha pessoa e /ou minha instituição. Também fui informado (a) que posso solicitar à pesquisadora, informações e esclarecimentos sobre eventuais duvidas sobre a pesquisa. 
Considero-me satisfeito(a) com as explicações prestadas pela pesquisadora e concordo em participar como voluntário(a) desta pesquisa, assinando este termo em duas vias.

Campinas / 2015.

\author{
Participante \\ Grasielle Camisao Ribeiro - Pesquisadora
}

Telefones e endereços:

Pesquisadora: (19) 981460084. R. Ézio Wagner da Silva, 89, Residencial Pq Fazenda- Campinas- SP

Comitê de ética e pesquisa- CEP: Av. Dr. Enéas de Carvalho Aguiar, 419 - 05403000 - São Paulo - SP

Fone: 3061-7548 e-mail: edipesq@usp.br 


\section{APÊNDICE B}

\section{CARTA DE APRESENTAÇÃO AOS PERITOS}

Prezado Dr.

Estamos desenvolvendo um estudo em nível de mestrado, no Programa de Pós- Graduação: Mestrado profissional em enfermagem em atenção primária no SUS, na Universidade de São Paulo, que tem como título: "DIAGNÓSTICO SITUACIONAL DA SISTEMATIZAÇÃO DA ASSISTÊNCIA DE ENFERMAGEM NO CENTRO DE SAÚDE INTEGRAÇÃO - CAMPINAS- SP".

Esse estudo tem por objetivo principal realizar um diagnóstico situacional sobre a sistematização da assistência de enfermagem no Centro de Saúde Integração, através da percepção da equipe de enfermagem. Além disso, o produto esperado será a obtenção de um questionário validado que poderá ser usado por outras unidades para diagnóstico da Sistematização da Assistência de Enfermagem nos serviços e identificação de elementos que apoiem a implantação e a efetivação da SAE na unidade do estudo.

O instrumento que estamos propondo validar foi desenvolvido com base na revisão de literatura e na experiência da autora.

Para tanto, solicitamos sua preciosa colaboração no sentido de analisar os itens do instrumento quanto:

\&pertinêcia: a questão é apropriada para o que se deseja avaliar ?

* clareza dos itens: é de fácil compreensão apesar das possíveis pegadinhas ?

*abrangência: Os eixos compreendem todos aspectos de sua temática?

Por favor, leia atentamente cada item do instrumento e emita seu parecer e possíveis sugestões, conforme orientações. Solicitamos um prazo de 30 dias, a partir da data de hoje, para retorno dos pareceres.

Sua colaboração é de extrema importância para a continuidade do estudo.

Agradecemos sua atenção, 


\section{APÊNDICE C \\ PARTE INTEGRANTE DO PROJETO: DIAGNÓSTICO SITUACIONAL DA SISTEMATIZAÇÃO DA ASSISTÊNCIA DE ENFERMAGEM NO CENTRO DE SAÚDE INTEGRAÇÃO - CAMPINAS- SP.. PESQUISADOR: GRASIELLE CAMISÃO RIBEIRO ORIENTADOR: MARIA CLARA PADOVEZE}

\section{QUESTIONÁRIO (entregue aos peritos)}

Parte 1 - Dados de caracterização do participante

1. Dados pessoais

1.1. Sexo
A. ( ) Feminino
B. ( ) Masculino

1.2. Idade: ( anos)

2. Formação Profissional

2.1- Escolaridade :
A. ( )Nível médio
B. ( )Nível superior
C. ( )Pós-graduação

2.2- Ano que concluiu o curso de enfermagem:

2.1- Função que exerce no vínculo empregatício junto a Prefeitura Municipal de Campinas (PMC):
A. ( )Técnico de enfermagem
B. ( )Auxiliar de enfermagem
C. ( )Enfermeiro

3. Ano de admissão na PMC:

Parte 2- Percepção individual sobre Sistematização da Assistência de Enfermagem(SAE) e Processo de enfermagem (PE), nos aspectos : conhecimento, dificultadores, benefícios e facilitadores

- Instruções para o preenchimento: avalie as afirmativas a seguir e de acordo com a sua perspectiva faça a opção pelo número correspondente de um a cinco conforme a escala a seguir:

$1=$ discordo totalmente

2 = discordo

3 = estou em dúvida

$4=$ concordo

$5=$ concordo totalmente

Siglas:

SAE: Sistematização da assistência de enfermagem

PE: Processo de enfermagem 


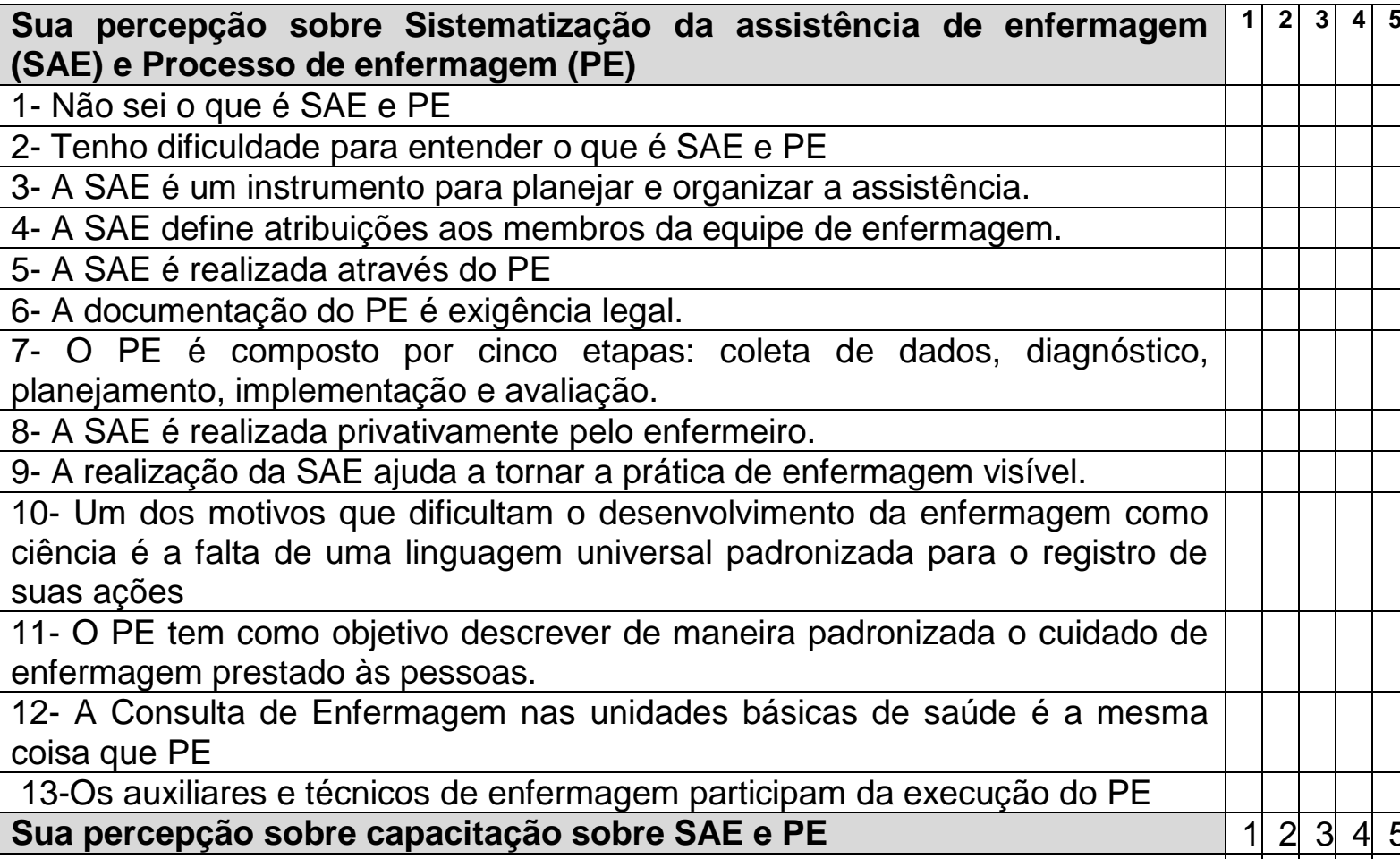

14- A formação acadêmica ensina de modo satisfatório sobre SAE e PE.

15- A formação acadêmica prepara o profissional para a realização da SAE no contexto da atenção primária.

16- A educação permanente facilita a aplicação da SAE.

17- Os cursos de técnicos e auxiliares contemplam a SAE e PE durante a formação profissional.

18- Tenho conhecimento para realizar a parte que me cabe como profissional na efetivação da SAE e PE.

19- Preciso de capacitação para realizar a SAE na prática

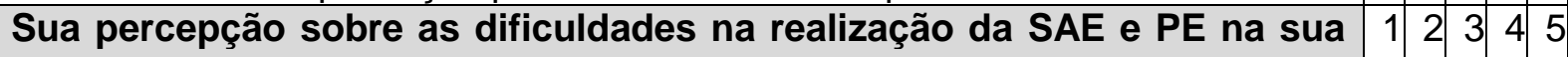
unidade:

20- Não acho que existam dificuldades para realização da SAE

21- A pressão da demanda, com excesso de pacientes é um dificultador para a realização da SAE

22- Não há oferta suficiente de capacitação sobre SAE por parte da instituição.

23- As interrupções por parte da equipe no momento da consulta de enfermagem prejudicam o desenvolvimento do $\mathrm{PE}$

24- Não há consultórios disponíveis para os enfermeiros

25- Os enfermeiros não sabem fazer o PE e não buscam se aprimorar

26- A alta complexidade dos pacientes dificulta a realização da SAE

27- Os profissionais não valorizam a consulta de enfermagem, pois a assistência é focada no médico

28- A população não valoriza a consulta de enfermagem, exige apenas atendimento do médico

29- A instituição não oferece estrutura adequada para a realização da SAE

30- A indefinição do papel do enfermeiro e da extensão de sua autonomia e responsabilidades é um dificultador para a realização da SAE.

31- Os enfermeiros têm pouca familiaridade com as nomenclaturas existentes 


\begin{tabular}{|c|c|c|}
\hline \multicolumn{3}{|l|}{$\begin{array}{l}\text { 32- A inexistência de um guia, em papel, dos diagnósticos e intervenções é } \\
\text { um dificultador para a realizacão da SAE. }\end{array}$} \\
\hline $\begin{array}{l}\text { 33- O uso de nomenclatura padronizada induz o profissional enfermeiro a } \\
\text { "decorar" alguns diagnósticos e aplicá-los sem um profundo raciocínio clínico }\end{array}$ & & \\
\hline Sua percepção sobre os benefícios que o uso da SAE e PE pode trazer: & 123 & \\
\hline 34- Não acredito que a SAE traga benefícios para o paciente & & \\
\hline 35- A utilização do PE melhora a qualidade da consulta de enfermagem & & \\
\hline $\begin{array}{l}\text { 36- A implantação da nomenclatura na consulta de enfermagem favorece a } \\
\text { documentacão do trabalho do enfermeiro }\end{array}$ & & \\
\hline $\begin{array}{l}\text { 37-A execução do PE favorece o desenvolvimento do raciocínio clínico dos } \\
\text { enfermeiros }\end{array}$ & & \\
\hline $\begin{array}{l}\text { 38- A realização da SAE aumenta a autonomia do enfermeiro em seu } \\
\text { processo de trabalho }\end{array}$ & & \\
\hline 39- Elevação da qualidade da assistência de enfermagem & & \\
\hline $\begin{array}{l}\text { 40- Pode trazer benefícios para equipe e para o paciente, através da } \\
\text { individualização do cuidado }\end{array}$ & & \\
\hline $\begin{array}{l}\text { Sua percepção sobre o que poderia facilitar a aplicação da SAE na } \\
\text { unidade }\end{array}$ & & 45 \\
\hline $\begin{array}{l}\text { 41- A elaboração de um impresso com diagnósticos e prescrições de } \\
\text { enfermagem facilita a aplicação da SAE }\end{array}$ & & \\
\hline 42- Oferecer capacitações sobre SAE para equipe facilita sua efetivação & & \\
\hline $\begin{array}{l}\text { 43- A instituição oferecer espaço para educação permanente para os } \\
\text { enfermeiros, com foco em SAE e discussão de casos clínicos, facilita a } \\
\text { aplicação da SAE e PE }\end{array}$ & & \\
\hline $\begin{array}{l}\text { 44- Garantia de estrutura como: número adequado de recursos humanos e a } \\
\text { organização da agenda do enfermeiro com no mínimo } 20 \text { minutos por } \\
\text { paciente, facilita a aplicação da SAE e PE }\end{array}$ & & \\
\hline $\begin{array}{l}\text { 45- Quando o enfermeiro é envolvido com o trabalho, facilita a implementação } \\
\text { da SAE }\end{array}$ & & \\
\hline 46- A adoção de uma linguagem padronizada facilita a aplicação da SAE e PE & & \\
\hline 47- Adoção de protocolos facilita a implementação da SAE & & \\
\hline $\begin{array}{l}\text { 48- Quando o enfermeiro tem conhecimento sobre SAE e PE facilita sua } \\
\text { implementação }\end{array}$ & & \\
\hline
\end{tabular}

\section{Parte 3- Percepção individual sobre a situação da SAE e PE na sua unidade de trabalho}

- Instruções para o preenchimento: avalie as afirmativas a seguir e de acordo com a sua perspectiva faça a opção pelo número correspondente de um a cinco conforme a escala a seguir:

$$
\begin{aligned}
& 1=\text { Nunca } \\
& 2=\text { Raramente } \\
& 3=\text { Algumas vezes } \\
& 4=\text { Muitas vezes }
\end{aligned}
$$

$$
5 \text { = Sempre }
$$




\begin{tabular}{|c|c|c|c|c|}
\hline Sua percepção sobre o que ocorre na sua unidade & \begin{tabular}{l|l}
1 & 2 \\
1 &
\end{tabular} & & & 5 \\
\hline 49- É realizada a consulta de enfermagem, utilizando o PE & & & & \\
\hline 50- A SAE é utilizada para todas as ações de enfermagem & & & & \\
\hline $\begin{array}{l}\text { 51- Os enfermeiros registram o PE no prontuário do paciente de forma } \\
\text { completa. }\end{array}$ & & & & \\
\hline $\begin{array}{l}\text { 52- A equipe de enfermagem valoriza a SAE e checa as prescrições do } \\
\text { enfermeiro }\end{array}$ & & & & \\
\hline 53- A equipe de enfermagem da unidade participa da realização do PE & & & & \\
\hline 54- A SAE é realizada de acordo com as normas do COFEN & & & & \\
\hline 57- O enfermeiro tem apoio institucional para realizar a SAE na unidade. & & & & \\
\hline $\begin{array}{l}\text { 58- A unidade possui número de enfermeiros suficientes para realização } \\
\text { da SAE }\end{array}$ & & & & \\
\hline $\begin{array}{l}\text { 59- Na situações de fiscalização do órgão de classe (COREN) são } \\
\text { encontradas irregularidades na execução da SAE e PE na unidade }\end{array}$ & & & & \\
\hline $\begin{array}{l}\text { Sua percepção quanto a sua atuação profissional individual em } \\
\text { relação ao PE }\end{array}$ & 1 & 2 & 3 & \\
\hline 60- Você realiza exame físico do paciente & & & & \\
\hline 61- Você faz anamnese do paciente & & & & \\
\hline 62- Você faz levantamentos de problemas do paciente & & & & \\
\hline 63- Você faz o diagnóstico de enfermagem & & & & \\
\hline 64- Você prescreve os cuidados para todos os pacientes & & & & \\
\hline $\begin{array}{l}\text { 65- Você segue as prescrições do enfermeiro e checa as ações } \\
\text { realizadas }\end{array}$ & & & & \\
\hline 66- Você avalia o cuidado prestado & & & & \\
\hline 67- Você registra no prontuário do paciente todas etapas que executa & & & & \\
\hline $\begin{array}{l}\text { 68- Os diagnósticos que você utiliza são baseados na nomenclatura } \\
\text { NANDA }\end{array}$ & & & & \\
\hline 69- Os diagnósticos são baseados na nomenclatura CIPE & & & & \\
\hline 70- Os diagnósticos são baseados na nomenclatura CIPESC & & & & \\
\hline $\begin{array}{l}\text { 71-Você utiliza uma nomenclatura não padronizada para elaboraçã } \\
\text { diagnósticos de enfermagem }\end{array}$ & & & & \\
\hline
\end{tabular}




\section{APÊNDICE D \\ UNIVERSIDADE DE SÃO PAULO \\ ESCOLA DE ENFERMAGEM}

Av. Dr. Enéas de Carvalho Aguiar, 419 - CEP 05403-000

Tel.: (011) 3061.7601 - Fax: (011) 3061.7615

São Paulo - SP - Brasil

\section{DIAGNÓSTICO SITUACIONAL DA SISTEMATIZAÇÃO DA ASSISTÊNCIA DE ENFERMAGEM NO CENTRO DE SAÚDE INTEGRAÇÃO - CAMPINAS- SP}

\section{Pesquisador : Grasielle Camisão Ribeiro}

\section{Orientações para os avaliadores}

Prezado especialista, para a sua apreciação como avaliador utilizaremos uma escala do tipo Likert que consiste em uma graduação de 5 pontos para níveis de concordância:

1. Concordo Plenamente

2. Concordo

3. Estou indeciso (a)

4. Discordo

4. Discordo Plenamente

A sua análise deve ser iniciada avaliando o questionário como um todo no que tange aos 7 domínios, em relação ao critério de abrangência. (Parte I)

Em seguida, a análise deve ser feita para cada questão do questionário elaborado, em relação aos critérios de pertinência e clareza (Parte II). Assinale com "x" na coluna correspondente ao seu nível de concordância, para cada uma das questões. As questões estão numeradas de 1 a 69, exatamente como aparece no 
questionário elaborado. Acrescente seus comentários pessoais na coluna destinada, quando julgar necessário.

Por final, faça comentários gerais sobre o questionário, em texto livre (Parte III).

\section{Caracterização do avaliador}

Idade:

Formação acadêmica / titulação:

Atuação profissional:

Instituição:

Cidade atual: 


\section{PARTE I}

Primeiramente, solicitamos que avalie o questionário como um todo de acordo com o seguinte critério:

A - Abrangência: Os domínios compreendem todos os aspectos de sua temática?

TEMÁTICA: SISTEMATIZAÇÃO DA ASSISTÊNCIA DE ENFERMAGEM EM UMA UNIDADE BÁSICA DE SAÚDE

\begin{tabular}{|c|c|c|c|c|c|c|}
\hline Domínio & $\begin{array}{l}\text { Concordo } \\
\text { plenamente }\end{array}$ & Concordo & $\begin{array}{l}\text { Estou } \\
\text { Indeciso } \\
\text { (a) }\end{array}$ & Discordo & $\begin{array}{l}\text { Discordo } \\
\text { plenamente }\end{array}$ & $\begin{array}{l}\text { Comentários / } \\
\text { Sugestões }\end{array}$ \\
\hline $\begin{array}{l}\text { 1- Percepção sobre } \\
\text { Conceitos referentes } \\
\text { a Sistematização da } \\
\text { Assistência de } \\
\text { Enfermagem (SAE) e } \\
\text { Processo de } \\
\text { enfermagem (PE) }\end{array}$ & ( ) & ( ) & ( ) & ( ) & ( ) & \\
\hline $\begin{array}{l}\text { 2- Percepção sobre } \\
\text { capacitação para } \\
\text { realização da SAE e } \\
\text { PE }\end{array}$ & ( ) & ( ) & ( ) & ( ) & ( ) & \\
\hline $\begin{array}{l}3 \text {-Percepção sobre } \\
\text { as dificuldades na } \\
\text { realização da SAE e } \\
\text { PE na sua unidade }\end{array}$ & ( ) & ( ) & () & () & () & \\
\hline $\begin{array}{l}\text { 4-- Percepção sobre } \\
\text { os benefícios que o } \\
\text { uso da SAE e PE } \\
\text { pode trazer }\end{array}$ & ( ) & ( ) & ( ) & ( ) & ( ) & \\
\hline $\begin{array}{l}\text { 5- Percepção sobre o } \\
\text { que poderia facilitar a } \\
\text { aplicação da SAE na } \\
\text { unidade }\end{array}$ & ( ) & () & ( ) & ( ) & ( ) & \\
\hline $\begin{array}{l}\text { 6- Percepção sobre o } \\
\text { a realização da SAE } \\
\text { na sua unidade }\end{array}$ & ( ) & ( ) & ( ) & ( ) & ( ) & \\
\hline $\begin{array}{l}\text { 7- Percepção quanto } \\
\text { a sua atuação } \\
\text { profissional } \\
\text { individual em relação } \\
\text { ao PE }\end{array}$ & ( ) & ( ) & () & ( ) & ( ) & \\
\hline
\end{tabular}


PARTE II

B - A questão está adequada ao que se deseja avaliar?

DESEJAMOS REALIZAR UM DIAGNÓSTICO DA SISTEMATIZAÇÃO DA ASSISTÊNCIA DE ENFERMAGEM EM UMA UNIDADE BÁSICA DE SAÚDE POR MEIO DA PERCEPÇÃO DA EQUIPE DE ENFERMAGEM

\begin{tabular}{|c|c|c|c|c|c|c|}
\hline Questões & $\begin{array}{l}\text { Concordo } \\
\text { plenamente } \\
\text { (Questão } \\
\text { adequada) }\end{array}$ & $\begin{array}{c}\text { Concordo } \\
\text { (Questão } \\
\text { adequada, } \\
\text { mas } \\
\text { precisa de } \\
\text { alguns } \\
\text { ajustes) }\end{array}$ & $\begin{array}{l}\text { Estou } \\
\text { Indeciso } \\
\text { (a) }\end{array}$ & $\begin{array}{c}\text { Discordo } \\
\text { (Questão } \\
\text { pouco } \\
\text { adequada, } \\
\text { necessita } \\
\text { de muitos } \\
\text { ajustes) }\end{array}$ & $\begin{array}{c}\text { Discordo } \\
\text { plenamente } \\
\text { (Questão } \\
\text { não } \\
\text { adequada) }\end{array}$ & $\begin{array}{l}\text { Comentários / } \\
\text { Sugestões }\end{array}$ \\
\hline 1 & ( ) & ( ) & ( ) & ( ) & ( ) & \\
\hline 2 & ( ) & ( ) & ( ) & ( ) & ( ) & \\
\hline 3 & ( ) & ( ) & ( ) & ( ) & ( ) & \\
\hline 4 & ( ) & ( ) & ( ) & ( ) & ( ) & \\
\hline 5 & ( ) & ( ) & ( ) & ( ) & ( ) & \\
\hline 6 & ( ) & ( ) & ( ) & ( ) & ( ) & \\
\hline 7 & ( ) & ( ) & ( ) & ( ) & ( ) & \\
\hline 8 & ( ) & ( ) & ( ) & ( ) & ( ) & \\
\hline 9 & ( ) & ( ) & ( ) & ( ) & ( ) & \\
\hline 10 & ( ) & ( ) & ( ) & ( ) & ( ) & \\
\hline 11 & ( ) & ( ) & ( ) & ( ) & ( ) & \\
\hline 12 & ( ) & ( ) & ( ) & ( ) & ( ) & \\
\hline 13 & ( ) & ( ) & ( ) & ( ) & ( ) & \\
\hline 14 & ( ) & ( ) & ( ) & ( ) & ( ) & \\
\hline 15 & ( ) & ( ) & ( ) & ( ) & ( ) & \\
\hline 16 & ( ) & ( ) & ( ) & ( ) & ( ) & \\
\hline 17 & ( ) & ( ) & ( ) & ( ) & ( ) & \\
\hline 18 & ( ) & ( ) & ( ) & ( ) & ( ) & \\
\hline 19 & ( ) & ( ) & ( ) & ( ) & ( ) & \\
\hline 20 & ( ) & ( ) & ( ) & ( ) & ( ) & \\
\hline
\end{tabular}




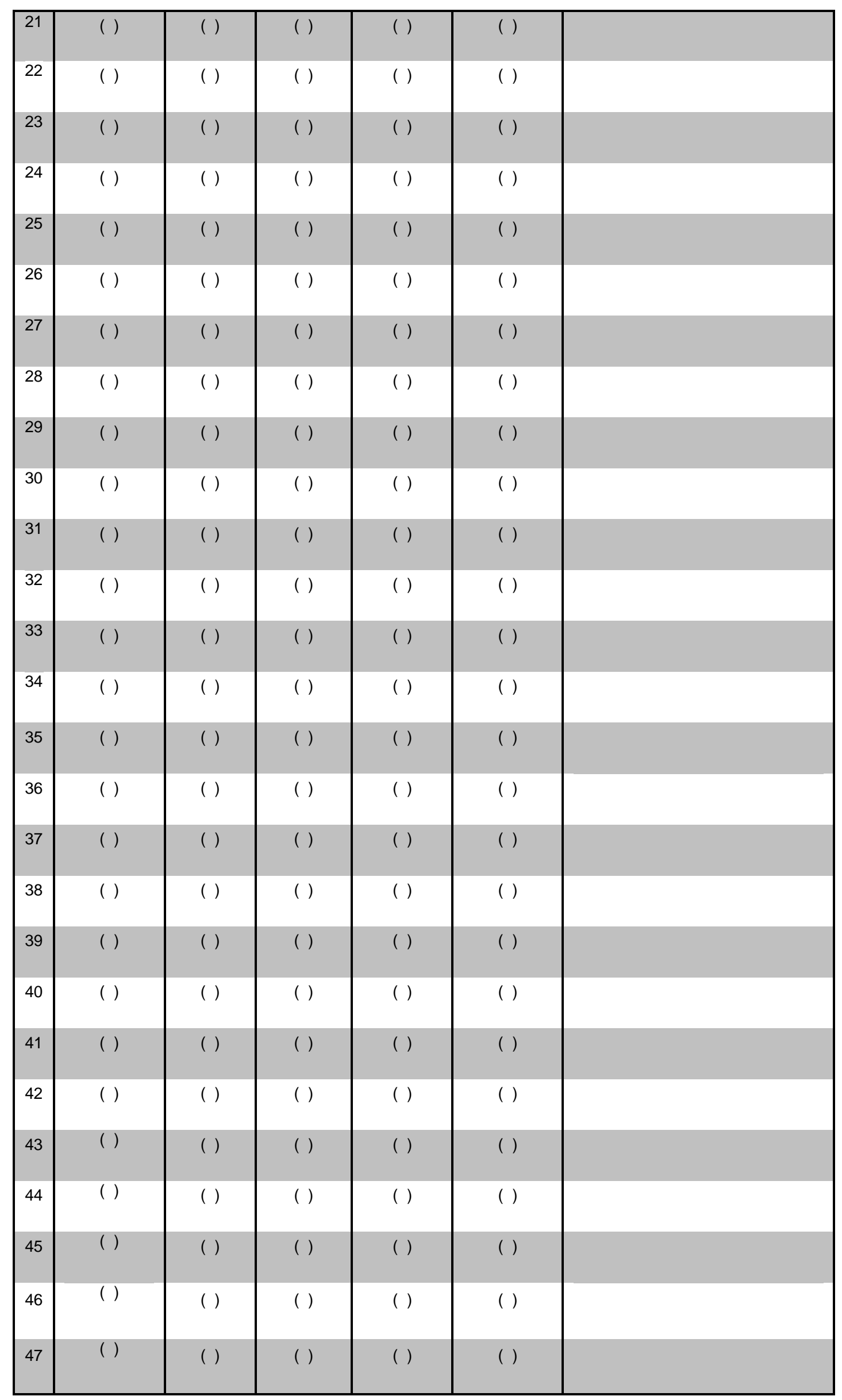


B - A questão apresenta linguagem clara e objetiva?

\begin{tabular}{|c|c|c|c|c|c|c|}
\hline Questões & $\begin{array}{c}\text { Concordo } \\
\text { plenamente } \\
\text { (Questão } \\
\text { com } \\
\text { linguagem } \\
\text { clara e } \\
\text { objetiva) }\end{array}$ & $\begin{array}{l}\text { Concordo } \\
\text { (Precisa } \\
\text { de alguns } \\
\text { ajustes) }\end{array}$ & $\begin{array}{l}\text { Estou } \\
\text { Indeciso } \\
\text { (a) }\end{array}$ & $\begin{array}{c}\text { Discordo } \\
\text { (Precisa } \\
\text { de } \\
\text { muitos } \\
\text { ajustes) }\end{array}$ & $\begin{array}{c}\text { Discordo } \\
\text { plenamente } \\
\text { (A questão } \\
\text { não } \\
\text { apresenta } \\
\text { linguagem } \\
\text { clara e } \\
\text { objetiva) } \\
\end{array}$ & Comentários \\
\hline 1 & ( ) & ( ) & ( ) & ( ) & () & \\
\hline 2 & ( ) & ( ) & ( ) & ( ) & ( ) & \\
\hline 3 & ( ) & ( ) & ( ) & ( ) & ( ) & \\
\hline 4 & ( ) & ( ) & ( ) & ( ) & ( ) & \\
\hline 5 & ( ) & ( ) & ( ) & ( ) & ( ) & \\
\hline 6 & ( ) & ( ) & ( ) & ( ) & ( ) & \\
\hline 7 & ( ) & ( ) & ( ) & ( ) & ( ) & \\
\hline 8 & ( ) & ( ) & ( ) & ( ) & ( ) & \\
\hline 9 & ( ) & ( ) & ( ) & ( ) & ( ) & \\
\hline 10 & ( ) & ( ) & ( ) & ( ) & ( ) & \\
\hline 11 & ( ) & ( ) & ( ) & ( ) & ( ) & \\
\hline 12 & ( ) & ( ) & ( ) & ( ) & ( ) & \\
\hline 13 & ( ) & ( ) & ( ) & ( ) & ( ) & \\
\hline 14 & ( ) & ( ) & ( ) & ( ) & ( ) & \\
\hline 15 & ( ) & ( ) & ( ) & ( ) & () & \\
\hline 16 & ( ) & ( ) & ( ) & ( ) & ( ) & \\
\hline 17 & ( ) & ( ) & ( ) & ( ) & ( ) & \\
\hline 18 & ( ) & ( ) & ( ) & ( ) & ( ) & \\
\hline 19 & ( ) & ( ) & ( ) & ( ) & ( ) & \\
\hline 20 & ( ) & ( ) & ( ) & ( ) & ( ) & \\
\hline 21 & () & () & () & () & () & \\
\hline 22 & ( ) & ( ) & ( ) & ( ) & ( ) & \\
\hline 23 & () & () & ( ) & ( ) & ( ) & \\
\hline
\end{tabular}




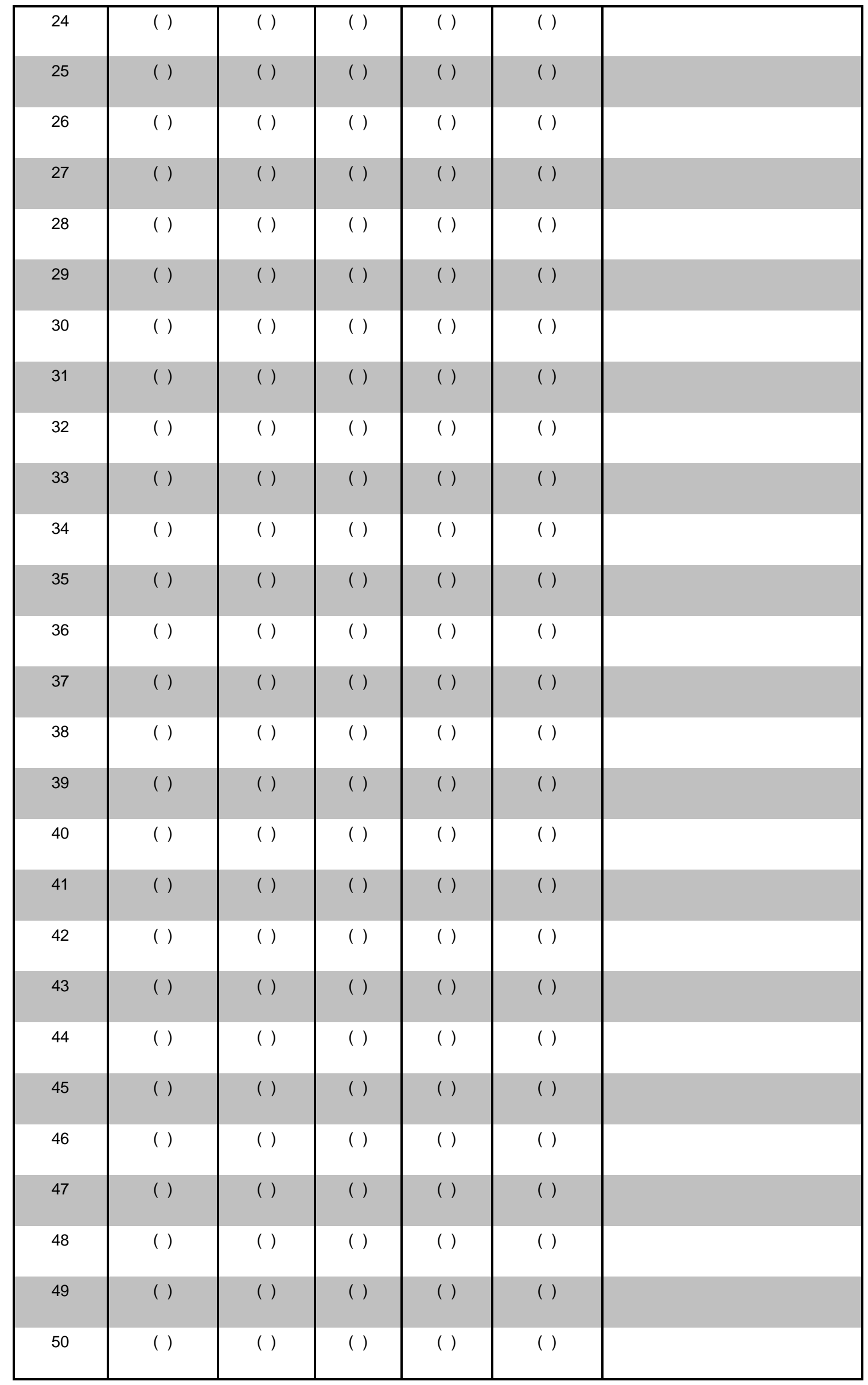




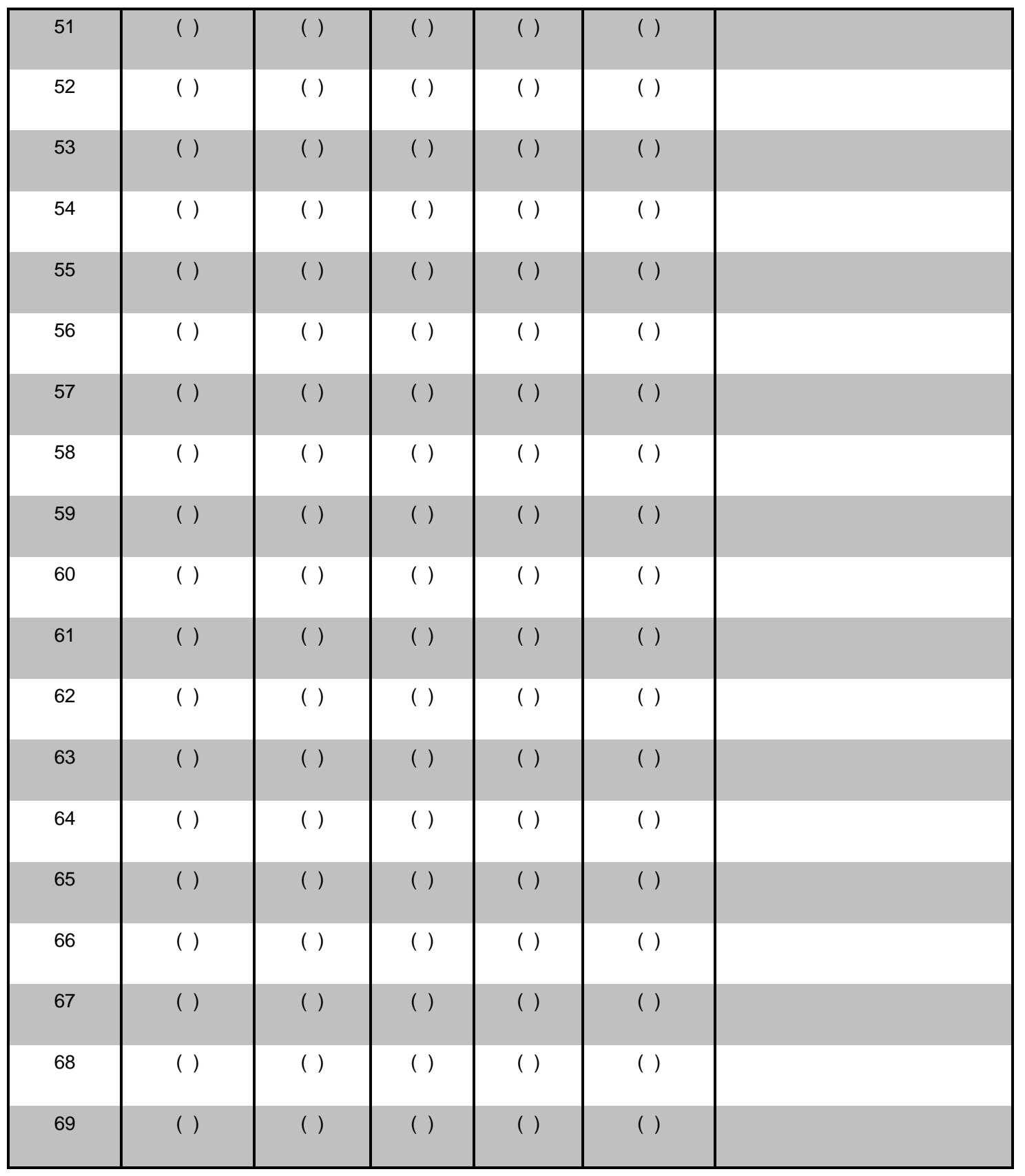


PARTE III

Por favor, faça as suas considerações gerais sobre o questionário, com as recomendações que julgar pertinentes:

Obrigada pela colaboração!

Grasielle 


\section{UNIVERSIDADE DE SÃO PAULO \\ ESCOLA DE ENFERMAGEM}

Av. Dr. Enéas de Carvalho Aguiar, 419 - CEP 05403-000

Tel: (011) 3061.7601 - Fax: (011) 3061.7615

São Paulo - SP - Brasil

APÊNDICE E

Questionário validado: Diagnóstico situacional da Sistematização da

Assistência de Enfermagem

PARTE INTEGRANTE DO PROJETO: DIAGNÓSTICO SITUACIONA DA SISTEMATIZAÇ̃̃O DA ASSISTÊNCIA DE ENFERMAGEM NO CENTRO DE SAÚDE INTEGRAÇÃO - CAMPINA̧S- SP.

PESQUISADOR: GRASIELLE CAMISÃO RIBEIRO

ORIENTADOR: MARIA CLARA PADOVEZE

Parte 1 - Dada de caracterização do participante

1. Dados pessoais

1.1. Sexo
A. ( ) Feminino
B. ( ) Masculino

1.2. Idade: (anos)

2. Formação Profissional

2.1- Escolaridade:
A. ( ) Nível médio
B. ( ) Nível superior
C. ( ) Pós-graduação

2.2- Ano que concluiu o curso de enfermagem:

2.1- Função que exerce no vínculo empregatício junto a Prefeitura Municipal de Campinas (PMC):

A. ( ) Técnico de enfermagem

B. ( ) Auxiliar de enfermagem

C. ( ) Enfermeiro

3. Ano de admissão na PMC:

Parte 2- Percepção individual sobre Sistematização da Assistência de Enfermagem (SAE) e Processo de enfermagem (PE), nos aspectos: conhecimento, benefícios e elementos dificultadores ou facilitadores

- Instruções para o preenchimento: avalie as afirmativas a seguir e de acordo com a sua perspectiva faça a opção pelo número correspondente de um a cinco conforme a escala a seguir:

1 = discordo totalmente 2 = discordo 3 = estou em dúvida

$4=$ concordo $5=$ concordo totalmente

Siglas:

SAE: Sistematização da assistência de enfermagem PE: Processo de enfermage 


\begin{tabular}{|c|c|c|c|}
\hline $\begin{array}{l}\text { D1- Sua percepção sobre Sistematização da Assistência de } \\
\text { Enfermagem (SAE) e Processo de Enfermagem (PE) }\end{array}$ & & 3 & \begin{tabular}{l|l}
4 & 5
\end{tabular} \\
\hline 1- Não sei o que é SAE e PE. & & & \\
\hline 2- Tenho dificuldade para entender o que é SAE e PE. & & & \\
\hline 3- A SAE auxilia o planejamento e organização da assistência. & & & \\
\hline 4- A SAE é um instrumento mais amplo que o PE & & & \\
\hline 5- O registro das fases do PE é exigência legal. & & & \\
\hline $\begin{array}{l}\text { 6- O PE é composto por cinco etapas: coleta de dados de enfermagem, } \\
\text { diagnóstico de enfermagem, planejamento de enfermagem, } \\
\text { implementação e avaliação de enfermagem. }\end{array}$ & & & \\
\hline $\begin{array}{l}\text { 7- Cabem privativamente ao enfermeiro o Diagnóstico e a Prescrição de } \\
\text { Enfermagem }\end{array}$ & & & \\
\hline 8- A SAE ajuda a tornar a prática de enfermagem visível. & & & \\
\hline $\begin{array}{l}\text { 9- Um dos motivos que dificultam o desenvolvimento da enfermagem } \\
\text { como ciência é a falta de uma linguagem universal padronizada para o } \\
\text { registro de suas ações. }\end{array}$ & & & \\
\hline $\begin{array}{l}\text { 10- O PE tem como objetivo descrever de maneira padronizada a } \\
\text { assistência de enfermagem prestada. }\end{array}$ & & & \\
\hline $\begin{array}{l}\text { 11- A Consulta de Enfermagem realizada nas unidades básicas de saúde } \\
\text { e ambulatórios é considerada a mesma coisa que PE. }\end{array}$ & & & \\
\hline $\begin{array}{l}\text { 12- Os auxiliares e técnicos de enfermagem participam da execução do } \\
\text { PE. }\end{array}$ & & & \\
\hline D2- Sua percepção sobre capacitação sobre SAE e PE & & & 45 \\
\hline
\end{tabular}

13- Só responda se for enfermeiro: A formação acadêmica ensina de modo satisfatório sobre SAE e PE.

14- Só responda se for enfermeiro: A formação acadêmica prepara o profissional para a realização da SAE no contexto da atenção primária.

16- Só responda se for auxiliar ou técnico de enfermagem: Os cursos técnicos e auxiliares contemplam a SAE e PE durante a formação profissional.

15- A educação permanente facilita a implantação da SAE.

17- Tenho conhecimento para realizar a parte que me cabe como profissional na efetivação da SAE e PE.

18- Preciso de capacitação para implantar a SAE e realizar PE na prática.

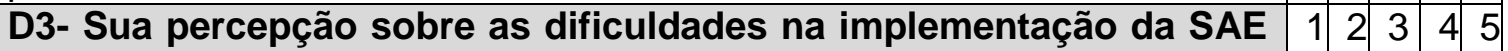
e realização do PE na sua unidade:

19- Não acho que existam dificuldades para implementação da SAE/PE.

20- A pressão da demanda, com excesso de pacientes, é um dificultador para a realização do $\mathrm{PE}$.

21- Não há oferta suficiente de capacitação sobre SAE/PE por parte da instituição.

22- As interrupções por parte da equipe no momento da consulta de enfermagem prejudicam o desenvolvimento do PE.

23- Uma das dificuldades de implementar a SAE/PE decorre da ausência de consultórios disponíveis para os enfermeiros.

24- Os enfermeiros não sabem fazer o PE e/ou não buscam se aprimorar. 
25- A baixa complexidade dos pacientes torna a SAE/PE dispensável na atenção básica.

26- Os profissionais de saúde não valorizam a consulta de enfermagem, pois a assistência é focada no médico.

27- A população não valoriza a consulta de enfermagem, exige apenas atendimento do médico.

28- A instituição não oferece estrutura adequada para a realização da $\mathrm{SAE} / \mathrm{PE}$.

D4- Sua percepção sobre os benefícios que o uso da SAE e PE $1 \begin{array}{lllll}1 & 2 & 3 & 4 & 5\end{array}$ podem trazer:

32- Não acredito que a SAE/PE tragam benefícios para o paciente.

33- A utilização do PE melhora a qualidade da consulta de enfermagem.

34- A implantação da nomenclatura padronizada na consulta de enfermagem favorece a documentação do trabalho do enfermeiro.

35-A execução do PE favorece o desenvolvimento do raciocínio clínico dos enfermeiros.

36- A realização da SAE/PE aumenta a autonomia do enfermeiro em seu processo de trabalho.

37- A SAE e o PE de enfermagem pode trazer benefício para o paciente através da individualização do cuidado.

38- A SAE pode trazer benefícios para equipe através da organização do processo de trabalho.

D5- Sua percepção sobre o que poderia facilitar a implementação da $1 \begin{array}{llllll}1 & 2 & 3 & 4 & 5\end{array}$ SAE e realização do PE na sua unidade

39- A existência de prontuário eletrônico facilita a implantação do PE.

40- A elaboração de um impresso com diagnósticos e prescrições de enfermagem facilita a aplicação do PE.

41- Oferecer capacitações sobre SAE/PE para equipe facilita sua efetivação.

42- A instituição oferecer espaço para educação permanente para os enfermeiros, com foco em SAE, facilita a aplicação da SAE e PE.

43- A garantia de recursos humanos em número adequado ao preconizado pelo Ministério da Saúde facilita a implementação da SAE e realização do PE na atenção básica.

44- Quando o enfermeiro é envolvido com o trabalho, facilita a implementação da SAE/PE.

45- A adoção de uma linguagem padronizada facilita a aplicação do PE.

46- Adoção de protocolos facilita a implementação da SAE/PE.

47- Quando o enfermeiro tem conhecimento sobre SAE e PE facilita sua implementação. 


\section{Parte 3- Percepção individual sobre a situação da SAE e PE na sua unidade de trabalho}

- Instruções para o preenchimento: avalie as afirmativas a seguir e de acordo com a sua perspectiva faça a opção pelo número correspondente de um a cinco conforme a

$1=$ Nunca escala a seguir:

$2=$ Raramente

$3=$ Algumas vezes

4 = Muitas vezes

5 = Sempre

\begin{tabular}{|c|c|c|c|c|}
\hline D6- Sua percepção sobre o que ocorre na sua unidade & & & & \\
\hline 48- É realizada a consulta de enfermagem, utilizando o PE. & & & & \\
\hline 49- A SAE é utilizada para todas as ações de enfermagem. & & & & \\
\hline $\begin{array}{l}\text { 50- Os enfermeiros registram o PE no prontuário do paciente de forma } \\
\text { completa. }\end{array}$ & & & & \\
\hline $\begin{array}{l}\text { 51- A equipe de enfermagem valoriza a SAE e checa as prescrições do } \\
\text { enfermeiro. }\end{array}$ & & & & \\
\hline 52- A equipe de enfermagem da unidade participa da realização do PE. & & & & \\
\hline 53- O PE é realizado de acordo com as normas do COFEN. & & & & \\
\hline 54- O enfermeiro tem apoio institucional para realizar a SAE/PE na unidade. & & & & \\
\hline $\begin{array}{l}\text { 55- A unidade possui número de enfermeiros suficientes para realização da } \\
\text { SAE/PE }\end{array}$ & & & & \\
\hline $\begin{array}{l}\text { 56- Nas situações de fiscalização do órgão de classe (COREN) tem sido } \\
\text { encontradas irregularidades na execução da SAE e PE na unidade que } \\
\text { trabalho. }\end{array}$ & & & & \\
\hline $\begin{array}{l}\text { D7- Sua percepção quanto a sua atuação profissional individual em } \\
\text { relação ao PE }\end{array}$ & 1 & 2 & 3 & \\
\hline 57- Realizo coleta de dados de enfermagem ou histórico de enfermagem. & & & & \\
\hline 58- Sigo as prescrições de enfermagem e checo as ações realizadas. & & & & \\
\hline 59- Avalio o cuidado prestado. & & & & \\
\hline 60- Registro no prontuário do paciente todas as etapas que executo. & & & & \\
\hline $\begin{array}{l}\text { 61- Só responda se for enfermeiro: Prescrevo os cuidados para todos os } \\
\text { pacientes. }\end{array}$ & & & & \\
\hline 62- Só responda se for enfermeiro: Faço diagnóstico de enfermagem. & & & & \\
\hline $\begin{array}{l}\text { 63- Só responda se for enfermeiro: Utilizo diagnósticos de enfermagem } \\
\text { baseados na nomenclatura NANDA. }\end{array}$ & & & & \\
\hline $\begin{array}{l}\text { 64- Só responda se for enfermeiro: Utilizo diagnósticos baseados na } \\
\text { nomenclatura CIPE. }\end{array}$ & & & & \\
\hline $\begin{array}{l}\text { 65- Só responda se for enfermeiro: Utilizo diagnóstico baseados na } \\
\text { nomenclatura CIPESC. }\end{array}$ & & & & \\
\hline $\begin{array}{l}\text { 6- Só responda se for enfermeiro: Utilizo uma nomenclatura não } \\
\text { adronizada para elaboração de diagnósticos de enfermagem. }\end{array}$ & & & & \\
\hline
\end{tabular}




\title{
ANEXO 1- AUTORIZAÇÃO DA INSTITUIÇÃO
}

\author{
PREFEITURA MUNICIPAL DE CAMPINAS
}

Secretaria Municipal de Saúde

SUS

\section{AUTORIZAÇÃO}

$006 / 2015$

Autorizo a realização da Pesquisa intitulada "DIAGNÓSTICO SITUACIONAL DA SISTEMATIZAÇÃO DA ASSISTÊNCIA DE ENFERMAGEM NO CENTRO DE SAÚDE INTEGRAÇÃO - CAMPINAS-SP", que tem por objetivo geral realizar um diagnóstico situacional da SAE no Centro de Saúde Integração a partir das percepções dos trabalhadores da equipe de enfermagem e por objetivos específicos: i) descrever como é realizada a SAE no Centro de Saúde Integração; ii) reconhecer a percepção dos profissionais de enfermagem sobre a SAE; iii) identificar, na percepção da equipe de enfermagem, as potencialidades e limitações para uso da SAE no Centro de Saúde Integração e iv) construir e validar um instrumento diagnóstico situacional para avaliação da SAE na perspectiva do profissional de enfermagem.

Declaro estar ciente que a pesquisa será desenvolvida por estudante do Programa de Mestrado Profissional em Enfermagem em Atenção Primária no Sistema Único de Saúde, Escola de enfermagem da Universidade de São Paulo, junto aos profissionais de enfermagem que atuam no Centro de Saúde Integração (Distrito Noroeste), sob a orientação da Professora Doutora Maria Clara Padoveze.

Campinas, 02 de fevereiro de 2015

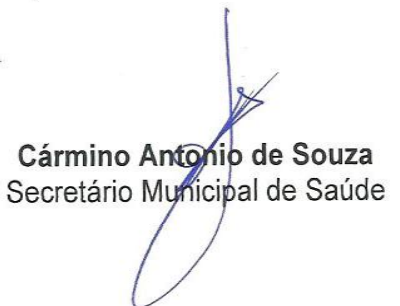

Av. Aquidabă, 505- $4^{\circ}$ Andar - Centro - Campinas/SP - CEP 13015-900 Fone / Fax: (19) 3232-8415 E-mail: cets-sms@ig.com.br 


\section{ANEXO 2- PARECER CEP}

\section{EE DSPP ESCOLA DE ENFERMAGEM DA
UNIVERSIDADE DE SÃO
PAULO - EEUSP}

\section{PARECER CONSUBSTANCIADO DO CEP}

\section{DADOS DO PROJETO DE PESQUISA}

Título da Pesquisa: DIAGNÓSTICO SITUACIONAL DA SISTTEMATIZAÇÃO DA ASSISTÊNCIA DE ENFERMAGEM NO CENTRO DE SAÚDE INTEGRAÇÃO - CAMPINAS- SP

Pesquisador: GRASIELLE CAMISAO RIBEIRO

Área Temática:

Versão: 3

CAAE: 41491815.4 .0000 .5392

Instituição Proponente: Escola de Enfermagem da Universidade de São Paulo - EEUSP

Patrocinador Principal: Financiamento Próprio

\section{DADOS DO PARECER}

Número do Parecer: 1.075 .023

Data da Relatoria: 19/05/2015

Apresentação do Projeto:

Trata-se de estudo descritivo - exploratório de abordagem quantitativa, que será realizado em uma Unidade Básica de Saúde de Campinas e que tem por objetivo realizar um diagnóstico situacional da Sistematização da Assistência de Enfermagem no Centro de Saúde Integração, a partir das percepções dos trabalhadores da equipe de enfermagem (aproximadamente 25 profissionais). Para a coleta dos dados será aplicado um questionário estruturado, que será validado por especialistas. Os dados serão avaliados por meio de análise descritiva, utilizando tabelas e gráficos, quando pertinente.

Objetivo da Pesquisa:

Objetivo Primário:

- Realizar um diagnóstico situacional da SAE no Centro de Saúde Integração a partir das percepções dos trabalhadores da equipe de enfermagem.

Objetivo Secundário:

- Descrever como é realizada a SAE no Centro de Saúde Integração;

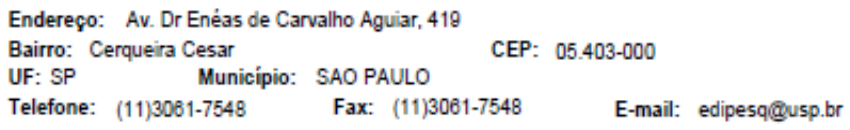




\section{EE UNIVERSIDADE DE SÃO Platoformo
PAULO - EEUSP}

Continuaçåo do Parecer. 1.075.023

- Reconhecer a percepção dos profissionais de enfermagem sobre a SAE;

- Identificar, na percepção da equipe de enfermagem, as potencialidades e limitações para o uso da SAE no Centro de Saúde Integração;

- Construir e validar um instrumento de diagnóstico situacional para avaliação da Sistematização da Assistência de enfermagem na perspectiva do profissional de enfermagem.

Avaliação dos Riscos e Benefícios:

Riscos:

O pesquisador refere que o estudo não apresenta riscos, no entanto, a entrevista pode gerar constrangimento ou desconforto, pois busca conhecimentos de atividades e processos que são próprios da profissão da enfermagem e que podem ser desconhecidos, realizados de maneira inadequada ou até mesmo não realizados por esses profissionais.

Benefícios:

O estudo justifica-se, pois para um planejamento eficiente de intervenção é necessário o diagnóstico situacional, visando identificar a realidade atual, servindo de ponto de partida para a adequação da SAE na unidade

Comentários e Considerações sobre a Pesquisa:

Pesquisa relevante para a produção de conhecimento da Enfermagem na Atenção Básica, pois visa contribuir para uma futura implementação da SAE no Centro de Saúde Integração e subsidiar um instrumento de avaliação para outras unidades.

Considerações sobre os Termos de apresentação obrigatória:

O termo de consentimento livre e esclarecido (TCLE) dirigido aos profissionais de enfermagem está redigido em formato de convite. Informa o objetivo do estudo; o tempo estimado para responder ao questionário, o momento da coleta de dados, assegura o anonimato e a liberdade de participação; os riscos e benefícios da pesquisa; a possibilidade de desistência a qualquer

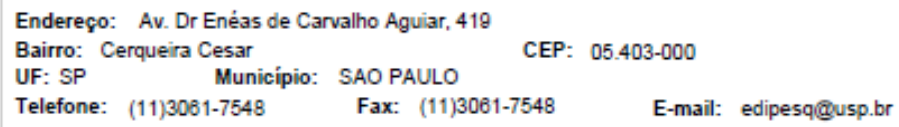




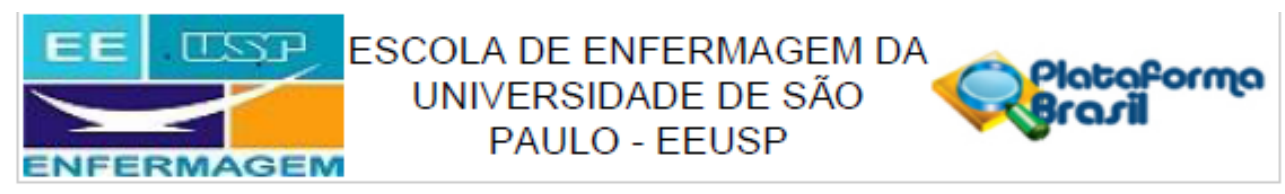

Continuaçăo do Parecer. 1.075.023

momento, sem prejuízos; os contatos da pesquisadora e do CEP da EEUSP; e que o mesmo será assinado em duas vias, sendo uma para a pesquisadora e outra para o participante. Foram anexados ainda, a carta convite aos juízes com as especificações da solicitação, além da autorização da instituição para realização do estudo.

Recomendaçöes:

Não há recomendações para o projeto.

Conclusões ou Pendências e Lista de Inadequações:

Após análise, observa-se que o pesquisador:

1-Acrescentou no TCLE a existência de risco quanto à participação no estudo, pois a pesquisa não está isenta de riscos/desconfortos.

2-Especificou no documento "informações básicas do projeto" início para coleta de dados com data posterior à data de reunião para aprovação do projeto pelo CEP.

O pesquisador atendeu todas as solicitações deste CEP. Não há óbices éticos para a realização deste projeto.

Situaçäo do Parecer:

Aprovado

Necessita Apreciação da CONEP:

Não

Consideraçōes Finais a critério do CEP:

Este CEP informa a necessidade de registro dos resultados parciais e finais na Plataforma Brasil.

Esta aprovação não substitui a autorização da instituição coparticipante, antes do início da coleta de dados.

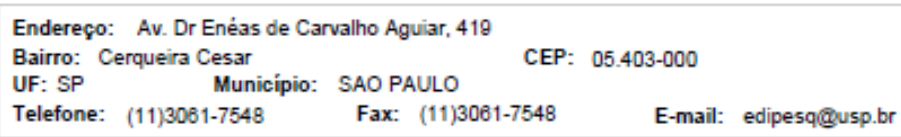




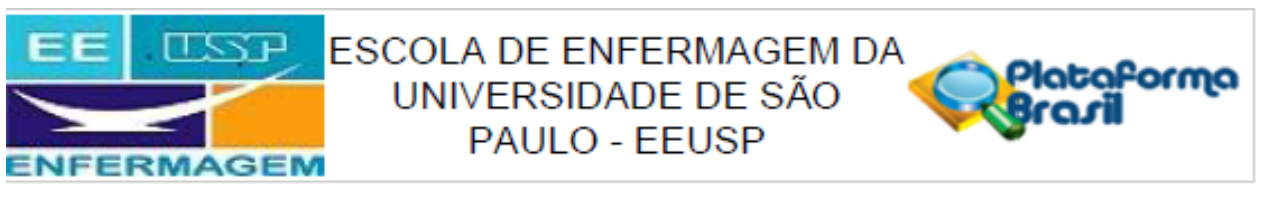

Sontinuaçăo do Parecer. 1.075.023

SAO PAULO, 22 de Maio de 2015

Assinado por:

Marcelo José dos Santos

(Coordenador)

Endereço: Av. Dr Enéas de Carvalho Aguiar, 419

Telefone: (11)3061-7548 Fax: (11)3061-7548 E-mail: edipesq@usp.br 